Prepared in cooperation with the U.S. Environmental Protection AgencyGreat Lakes Restoration Initiative

\title{
Hydrology of and Current Monitoring Issues for the Chicago Area Waterway System, Northeastern Illinois
}

\section{......... minimi}

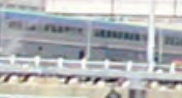$$
\text { is }
$$ 
Front cover: A USGS crew prepares for an acoustic Doppler current meter discharge measurement on the South Branch of the Chicago River, part of the Chicago Area Waterway System. 


\section{Hydrology of and Current Monitoring Issues for the Chicago Area Waterway System, Northeastern Illinois}

By James J. Duncker and Kevin K. Johnson

Prepared in cooperation with the U.S. Environmental Protection Agency-

Great Lakes Restoration Initiative

Scientific Investigations Report 2015-5115 


\title{
U.S. Department of the Interior \\ Sally Jewell, Secretary
}

\section{U.S. Geological Survey \\ Suzette M. Kimball, Acting Director}

\author{
U.S. Geological Survey, Reston, Virginia: 2015
}

For more information on the USGS - the Federal source for science about the Earth, its natural and living resources, natural hazards, and the environment—visit http://www.usgs.gov or call 1-888-ASK-USGS.

For an overview of USGS information products, including maps, imagery, and publications, visit http://www.usgs.gov/pubprod/.

Any use of trade, firm, or product names is for descriptive purposes only and does not imply endorsement by the U.S. Government.

Although this information product, for the most part, is in the public domain, it also may contain copyrighted materials as noted in the text. Permission to reproduce copyrighted items must be secured from the copyright owner.

Suggested citation:

Duncker, J.J. and Johnson, K.K., 2015, Hydrology of and current monitoring issues for the Chicago Area Waterway System, northeastern Illinois: U.S. Geological Survey Scientific Investigations Report 2015-5115, 48 p., http://dx.doi. org/10.3133/sir20155115.

ISSN 2328-0328 (online) 


\section{Contents}

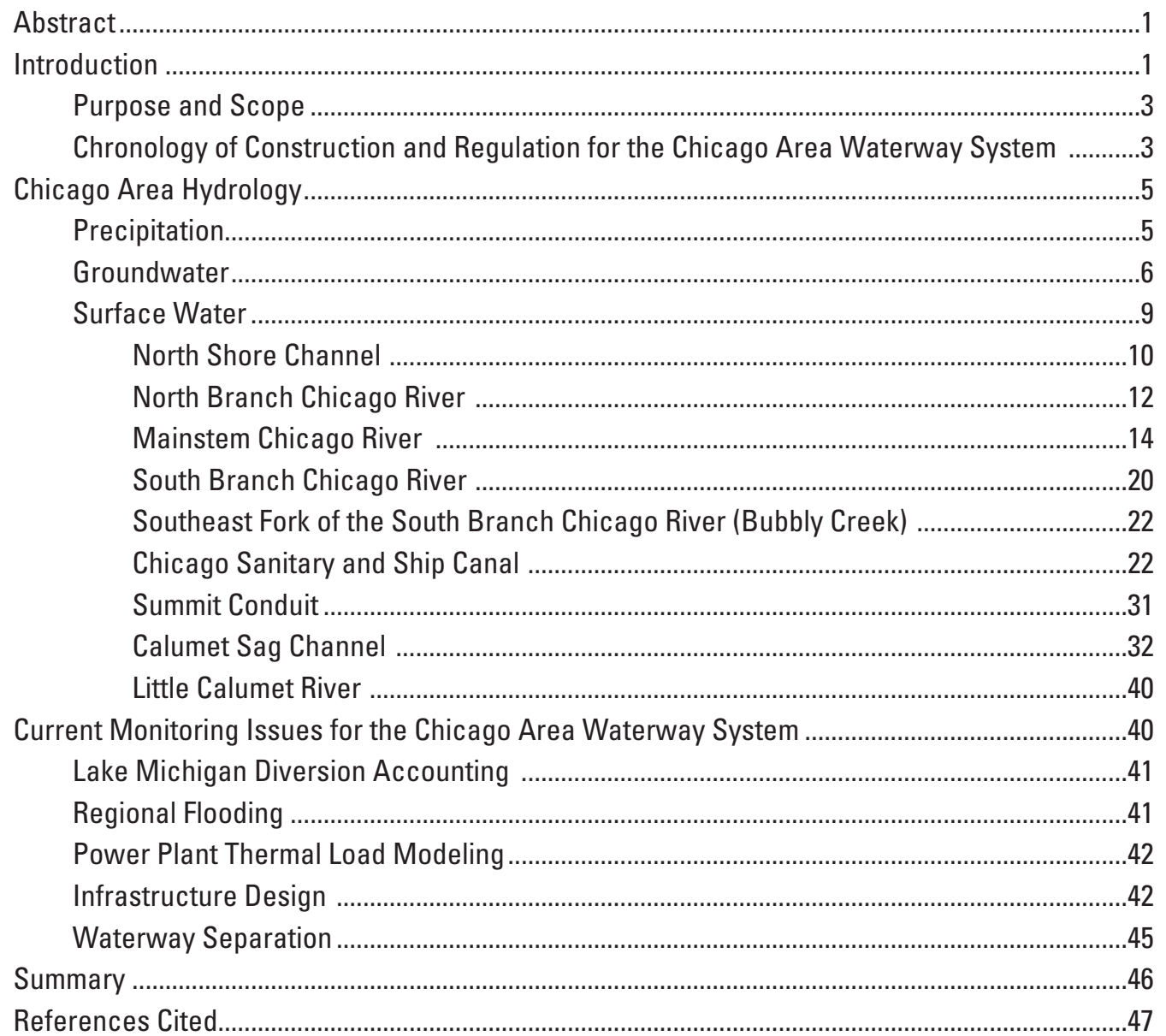

\section{Figures}

1. Map showing the Chicago Area Waterway System study area, northeastern Illinois.....2

2. Historical engineering drawings of the map, profile, and cross-sections of the Main Drainage Channel for the Chicago Sanitary District of Chicago, from Chicago to Joliet, Illinois 3

3. Map showing the Tunnel and Reservoir Plan service area, Chicago, Illinois ...................4

4. Schematic drawing of the hydrologic cycle ...........................................................5

5. Maps showing $A$, pre-diversion, and $B$, post-diversion surface drainage in Chicago, Illinois, and vicinity

6. Map showing lines of equal precipitation pattern for the 2012 water year, Chicago, Illinois, and vicinity

7. Schematic cross-section diagram showing the elevations of the water table, local combined sewer invert, and Chicago Sanitary and Ship Canal water-surface elevation in the Pilsen neighborhood on the south side of Chicago, Illinois. 
8. Map showing the potentiometric surface of the deep sandstone aquifers in the Chicago area, northeastern Illinois, fall 2007.

9. Graph showing water-surface profile data for the Chicago Area Waterway System, Chicago, Illinois, and vicinity during an April 17-18, 2013, storm and the extent of drawdown of the water surface at points along the waterway...

10. Map showing the Chicago Area Waterway System with the North Shore Channel, Chicago, Illinois, and vicinity .

11. Graph showing mean daily discharge for the North Shore Channel at Wilmette, Illinois, for the 2003 water year, which is the last year of record.

12. Map showing the Chicago Area Waterway System, including the North Branch Chicago River and U.S. Geological Survey streamflow-gaging stations, Chicago, Illinois, and vicinity

13. Graph showing mean daily discharge for the streamflow-gaging station (05536105) on the North Branch Chicago River at Albany Avenue, Chicago, Illinois, and vicinity, for the 2012 water year.

14. Photograph showing the concrete control structure at the confluence of the North Branch Chicago River and the North Shore Channel, Chicago, Illinois, and vicinity......15

15. Map showing the Chicago Area Waterway System and the mainstem of the Chicago River, Chicago, Illinois

16. Data from acoustic Doppler current profiler measurements in the mainstem of the Chicago River near Columbus Drive in Chicago, Illinois showing: $A$, typical low-flow water velocity magnitude and $B$, direction; $C$, typical high-flow velocity magnitude and $D$, direction; $E$, reverse flow magnitude and $F$, direction.

17. Graph showing gage heights for the Chicago River at Columbus Drive at Chicago, Illinois, streamflow-gaging station, hourly precipitation measured at the Chicago Lock, and gate settings at the Chicago River Controlling Works during the April 2013 storm

18. Map showing the Chicago Area Waterway System including the South Branch of the Chicago River and the Southeast Fork of the South Branch of the Chicago River, Chicago, Illinois, and vicinity

19. Graphs showing discharge and water-surface profiles for the Chicago Area Waterway, Illinois, during the April 17-23, 2013, storm: $A$, rising storm discharge hydrograph and canal drawdown, $B$, near peak of storm discharge and opening of the Chicago River Controlling Works, and $C$, the effect of flow reversal at the Chicago River Controlling Works on the water-surface elevation profile...

20. Data from horizontal acoustic Doppler current profiler (H-ADCP) measurements May 25-27, 2009, for Bubbly Creek near 36th Street, Chicago, Illinois: $A$, water velocity, and $B$, discharge.....

21. Map showing the Chicago Area Waterway System including the Chicago Sanitary and Ship Canal and Calumet Sag Channel, Chicago, Illinois, and vicinity... .26

22. Graphs showing discharge for the Chicago Sanitary and Ship Canal near Lemont, Illinois, for: $A$, a normal pool elevation with highly unsteady flow conditions, April-May 2013, $B$, a typical dry-weather pattern showing cycle of ponding and increased flows, 0 ctober 12,2013 , and $C$, a wet weather pattern showing the pre-storm drawdown and subsequent flood wave, April-May 2013

23. Graph showing mean daily effluent discharge for the Metropolitan Water Reclamation District of Greater Chicago-Stickney Water Reclamation Plant, Chicago, Illinois, for the 2012 water year.

24. Graph showing mean daily discharge for the Chicago Sanitary and Ship Canal near Lemont, Illinois, for the 2012 water year 
25. Graph showing data from low-, medium-, and high-flow acoustic Doppler current profiler measurements in the Chicago Sanitary and Ship Canal near Lemont, Illinois, showing: $A$, low-flow cross-section water velocity contour; $B$, low-flow plan view of depth-averaged velocity magnitude and direction; $C$, medium-flow cross-section velocity contour; $D$, medium-flow plan view of depth-averaged velocity magnitude and direction; $E$, high-flow cross-section velocity contour; and $F$, high-flow plan view of depth-averaged velocity magnitude and direction.

26. Photograph showing the entrance to the Summit Conduit and the location of the streamflow-gaging station

27. Graph showing mean daily discharge for the Summit Conduit at Summit, Illinois, for the 2012 water year.

28. Map showing the Chicago Area Waterway System including the Calumet-Sag Channel, Chicago, Illinois, and vicinity.....

29. Graph showing mean daily discharge at the U.S. Geological streamflow-gaging station on the Calumet Sag Channel near Route 83 at Sag Bridge, Illinois, for the 2012 water year.

30. Graphs showing data from low- and high-flow acoustic Doppler current profiler measurements in the Calumet Sag Channel near Route 83 at Sag Bridge, Illinois, showing: $A$, low-flow cross-section water velocity contour, $B$, low-flow plan view of depth-averaged velocity magnitude and direction, $C$, high-flow cross-section velocity contour, and $D$, high-flow plan view of depth-averaged velocity magnitude and direction...

31. Graph showing mean daily effluent discharge for the Metropolitan Water Reclamation District of Greater Chicago Calumet Water Reclamation Plant in Illinois for the 2012 water year

32. Screen capture and schematic diagrams showing data from acoustic Doppler current profiler measurements in the Calumet River near the Thomas J. O'Brien Lock and Dam, Chicago, Illinois, showing: $A$, complex water velocity patterns adjacent to the lock and dam, $B$, circulation patterns in the Calumet River below the lock and dam, and $C$, the complex velocity patterns near the Calumet Water Reclamation Plant outfall

33. Graph showing daily mean discharge for Tinley Creek near Palos Park, Illinois, for the 2012 water year. . .41

34. Photograph showing the coal-fired power plant at Romeo Rd along the Chicago Sanitary and Ship Canal near Romeoville, Illinois. . .43

35. Map showing synoptic water temperature data from the upper Chicago Sanitary and Ship Canal collected February 2012 and the sharp increase in water temperature at the power plant discharge locations.

36. Photograph showing construction of the river walk along the mainstem of the Chicago River

37. Map showing one of the waterway separation scenarios proposed by the U.S. Army Corps of Engineers Great Lakes and Mississippi River Interbasin Study.

\section{Tables}

1. Summary of backflow events on the Chicago Area Waterway System, Chicago, Illinois, and vicinity, 2000-14

2. Long-term U.S. Geological Survey streamflow-gaging stations on the North Branch of the Chicago River and its tributary streams, Chicago, Illinois, and vicinity . 


\section{Conversion Factors}

Inch/pound to International System of Units

\begin{tabular}{lll}
\hline \multicolumn{1}{c}{ Multiply } & By & \multicolumn{1}{c}{ To obtain } \\
\hline inch (in.) & Length & \\
inch (in.) & 2.54 & centimeter $(\mathrm{cm})$ \\
foot (ft) & 25.4 & millimeter $(\mathrm{mm})$ \\
mile (mi) & 0.3048 & meter $(\mathrm{m})$ \\
\hline & 1.609 & kilometer $(\mathrm{km})$ \\
\hline foot per second $(\mathrm{ft} / \mathrm{s})$ & Flow rate & \\
cubic foot per second $\left(\mathrm{ft}^{3} / \mathrm{s}\right)$ & 0.3048 & meter per second $(\mathrm{m} / \mathrm{s})$ \\
million gallons per day $(\mathrm{Mgal} / \mathrm{d})$ & 0.02832 & cubic meter per second $\left(\mathrm{m}^{3} / \mathrm{s}\right)$ \\
\hline
\end{tabular}

Temperature in degrees Celsius $\left({ }^{\circ} \mathrm{C}\right)$ may be converted to degrees Fahrenheit $\left({ }^{\circ} \mathrm{F}\right)$ as follows:

${ }^{\circ} \mathrm{F}=\left(1.8 x^{\circ} \mathrm{C}\right)+32$

\section{Datum}

Vertical coordinate information is referenced to the National Geodetic Vertical Datum of 1929 (NGVD 29) and Chicago City Datum (CCD), which is 579.48 feet above NGVD 29.

Elevation, as used in this report, refers to distance above the vertical datum.

\section{Supplemental Information}

Specific conductance is given in microsiemens per centimeter at 25 degrees Celsius ( $\mu \mathrm{S} / \mathrm{cm}$ at $\left.25^{\circ} \mathrm{C}\right)$. 


\title{
Hydrology of and Current Monitoring Issues for the Chicago Area Waterway System, Northeastern Illinois
}

\author{
By James J. Duncker and Kevin K. Johnson
}

\section{Abstract}

The Chicago Area Waterway System (CAWS) consists of a combination of natural and manmade channels that form an interconnected navigable waterway of approximately 90-plus miles in the metropolitan Chicago area of northeastern Illinois. The CAWS serves the area as the primary drainage feature, a waterway transportation corridor, and recreational waterbody. The CAWS was constructed by the Metropolitan Water Reclamation District of Greater Chicago (MWRDGC). Completion of the Chicago Sanitary and Ship Canal (initial portion of the CAWS) in 1900 breached a low drainage divide and resulted in a diversion of water from the Lake Michigan Basin. A U.S. Supreme Court decree (Consent Decree 388 U.S. 426 [1967] Modified 449 U.S. 48 [1980]) limits the annual diversion from Lake Michigan. While the State of Illinois is responsible for the diversion, the MWRDGC regulates and maintains water level and water quality within the CAWS by using several waterway control structures. The operation and control of water levels in the CAWS results in a very complex hydraulic setting characterized by highly unsteady flows. The complexity leads to unique gaging requirements and monitoring issues. This report provides a general discussion of the complex hydraulic setting within the CAWS and quantifies this information with examples of data collected at a range of flow conditions from U.S. Geological Survey streamflow gaging stations and other locations within the CAWS. Monitoring to address longstanding issues of waterway operation, as well as current (2014) emerging issues such as wastewater disinfection and the threat from aquatic invasive species, is included in the discussion.

\section{Introduction}

The Chicago Area Waterway System (CAWS) consists of a combination of natural and manmade channels that form an interconnected navigable waterway of approximately 90-plus miles (mi) in the metropolitan Chicago area (fig. 1) of northeastern Illinois. The CAWS is a principal component of the regional hydrology of the Chicago metropolitan area. The CAWS functions as an important waterway for both commercial and recreational transportation and as a conduit for the discharge of wastewater effluent and stormwater runoff from the region. Water levels and flows within the CAWS are regulated through a series of control structures operated and maintained by the Metropolitan Water Reclamation District of Greater Chicago (MWRDGC). The CAWS was constructed in response to the growing population and the need for improvements to the natural drainage system in the region. The physiography of the Chicago area prior to settlement consisted of a low-lying region with sluggish streams and wetlands.

The primary canals and infrastructure of the CAWS were constructed from 1892 to 1939 (Hill, 2000). Since completion of the CAWS, water levels and flows within the waterway have been maintained on the basis of water levels at various points along the waterway. Theoretical equations were used to estimate flows at the control structures. Following a 1980 U.S. Supreme Court ruling (Consent Decree 388 U.S. 426 [1967] Modified 449 U.S. 48 [1980]), the U.S. Geological Survey (USGS) in 1984 installed an acoustic velocity meter (AVM) streamflow-gaging station on the Chicago Sanitary and Ship Canal at Romeoville, Ill. The AVM streamflow-gaging station provided a means for the direct measurement and near real-time monitoring of streamflow within the CAWS. Analysis of the stage, velocity, and discharge data from the AVM streamflow-gaging station at Romeoville revealed the complex hydraulic setting that is present throughout the CAWS. Since the 1984 installation of the streamflow-gaging 


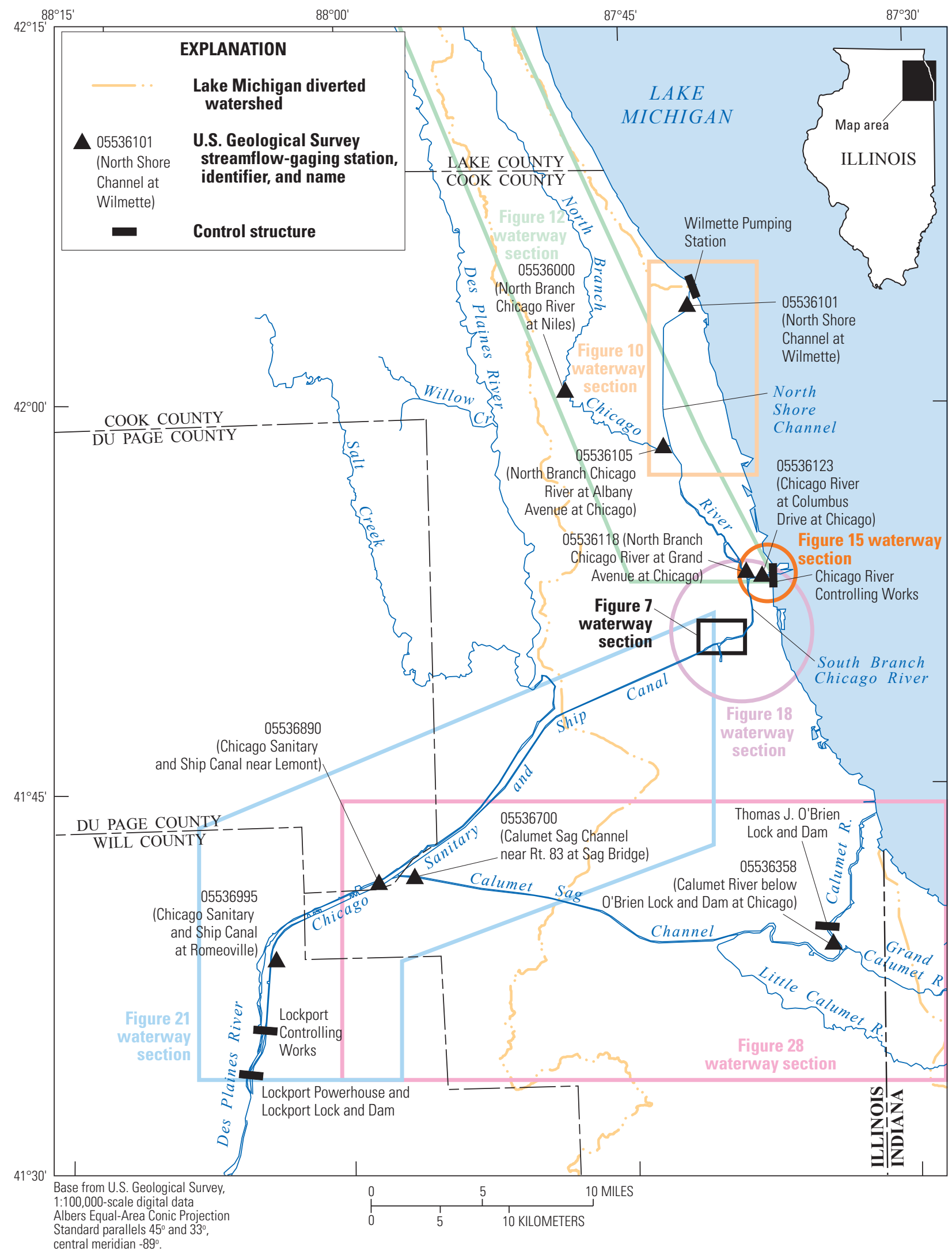

Figure 1. The Chicago Area Waterway System study area, northeastern Illinois. (NB, North Branch) 
station at Romeoville, the USGS has worked closely with local, State, and Federal partners to advance the understanding of the hydrology of the CAWS. The USGS, with support and cooperation from the U.S. Environmental Protection AgencyGreat Lakes Environmental Restoration Initiative, compiled this report to describe the hydrology of the CAWS.

\section{Purpose and Scope}

The purpose of this report is to describe the hydrology of the metropolitan Chicago area and the primary hydrologic components of the CAWS in quantifiable engineering terms. The report was prepared in cooperation with the U.S. Environmental Protection Agency's Great Lakes Environmental Restoration Initiative.

The scope of this report is a description of the primary hydrologic components of the metropolitan Chicago area and specifically the CAWS. Recent focus on the CAWS with respect to a number of issues has highlighted the value of waterway data and an understanding of the complex hydrologic and hydraulic setting. This report discusses issues facing decision makers at a time when, due to regional economic conditions, the level of CAWS monitoring is at a historic low.

\section{Chronology of Construction and Regulation for the Chicago Area Waterway System}

The CAWS was constructed from 1892 to 1939 to serve the Chicago region as an integral part of the region's sanitation system and as an important waterway for the transportation of bulk goods (fig. 2). The purpose of the CAWS monitoring stations in the early days was initially very specific to operation and maintenance of the waterway. Water-level gages along the waterway recorded water-surface elevations, which were used by engineers to maintain a water-surface slope towards Lockport and away from the city of Chicago. Completion of the Chicago Sanitary and Ship Canal (CSSC) in 1900 resulted in the diversion of water from the Lake Michigan Basin to the Illinois River/Mississippi River Basin. A series of legal rulings regarding the diversion resulted in a 1980 U.S. Supreme Court decree that mandates the State of Illinois to monitor the CAWS as a component of Lake Michigan Diversion Accounting. This decree tasks the U.S. Army Corps of Engineers (USACE) to maintain a Lake Michigan Diversion Accounting, which relies on the USGS for accurate streamflow monitoring in the CAWS. In 1984, the USGS installed an AVM streamflow-gaging station on the CSSC at Romeoville, Ill., to monitor flows for Lake Michigan Diversion Accounting.



Figure 2. Historical engineering drawings of the map, profile, and cross-sections of the Main Drainage Channel for the Chicago Sanitary District of Chicago, from Chicago to Joliet, Illinois. (Figs. 2 and 3 from Hill, 1896) 
As environmental regulations developed in the 1960s and 1970s, State and Federal water-quality standards were established for the waterway (Copeland, 2010; Hines, 2012). The MWRDGC, as the operating agency for the waterway, installed a water-quality monitoring network along the waterway. Waterway operation procedures were modified to use the information from the water-quality monitoring network and incorporate flows to help meet the water-quality standards.
In 1972 the MWRDGC, in order to comply with waterquality standards, adopted the Tunnel and Reservoir Plan (TARP), which is composed of a network of large underground tunnels (11-33 feet [ $\mathrm{ft}]$ in diameter and referred to as "Deep Tunnel") and several large storage reservoirs that connect to the CAWS (fig. 3). The TARP system presents a major change for regional hydrology and provides for flood control and the routing of combined sewer runoff in the region. The

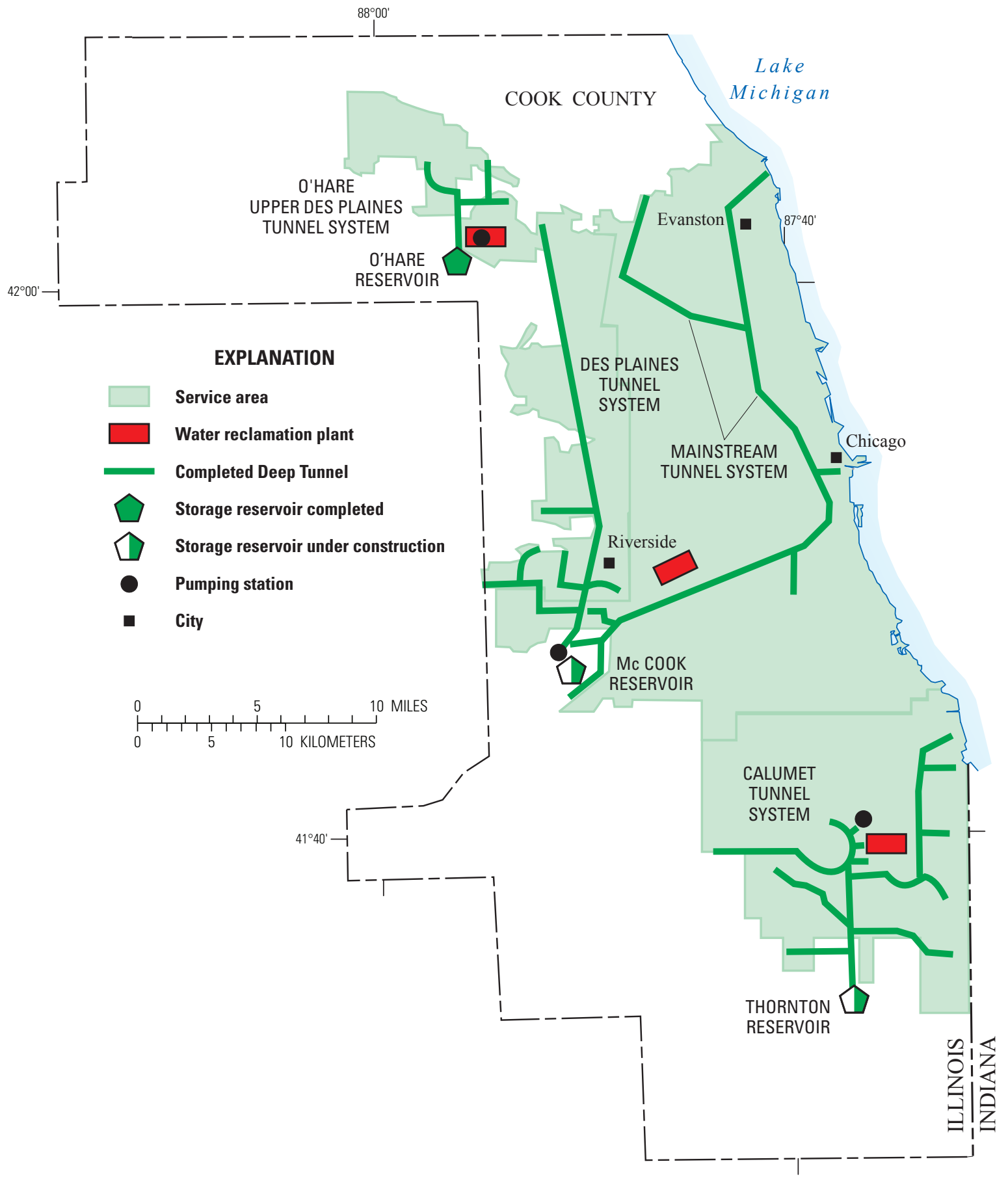

Figure 3. The Tunnel and Reservoir Plan service area, Chicago, Illinois. 
Deep Tunnel system provides an outlet for combined sewer runoff that otherwise would have overflowed to the CAWS. The Deep Tunnel system provides some additional storage but is primarily designed to convey the combined sewer runoff to storage reservoirs that are under construction. When completed, the TARP system of tunnels and reservoirs will help mitigate flooding in the region.

\section{Chicago Area Hydrology}

The hydrologic cycle is depicted schematically (fig. 4) to outline how the components interact with each other. In the relatively flat urban setting of Chicago, the primary features of the hydrologic cycle include engineered structures. The engineered drainage system is designed to facilitate the rapid removal of excess stormwater from the area to prevent overland flooding, combined sewer overflows, and flooded basements.

Prior to the start of construction of the CSSC in 1892, the natural drainage for much of the Chicago area was towards Lake Michigan. The relatively flat, low-lying area that composed much of the city was surrounded by wetlands and was drained by low-slope sluggish streams. The mouths of the Chicago and Calumet Rivers were open to the lake, and shifting sandbars were present that affected the geometry of the river mouths. The diversion of water away from Lake Michigan initially began with the completion of the Illinois and Michigan Canal in 1848 and continued with the completion of the CSSC in 1900 (fig. 5).

\section{Precipitation}

The climate of the Chicago area is classified as a humid continental (Changnon and others, 2004). The Illinois State Water Survey (ISWS) operates a network of 25 rain gages (fig. 6) in the Chicago area for Lake Michigan Diversion Accounting (Westcott, 2013). Average precipitation from the ISWS network (1990-2012) is 36.77 inches (in.). Long-term average annual precipitation for the National Weather Service rain gage at Chicago O'Hare Airport is 36.89 in. (1981-2010). Most of this precipitation falls in the form of rainfall. Average annual snowfall in the Chicago area is approximately $40 \mathrm{in}$. per year (Changnon and others, 2004).

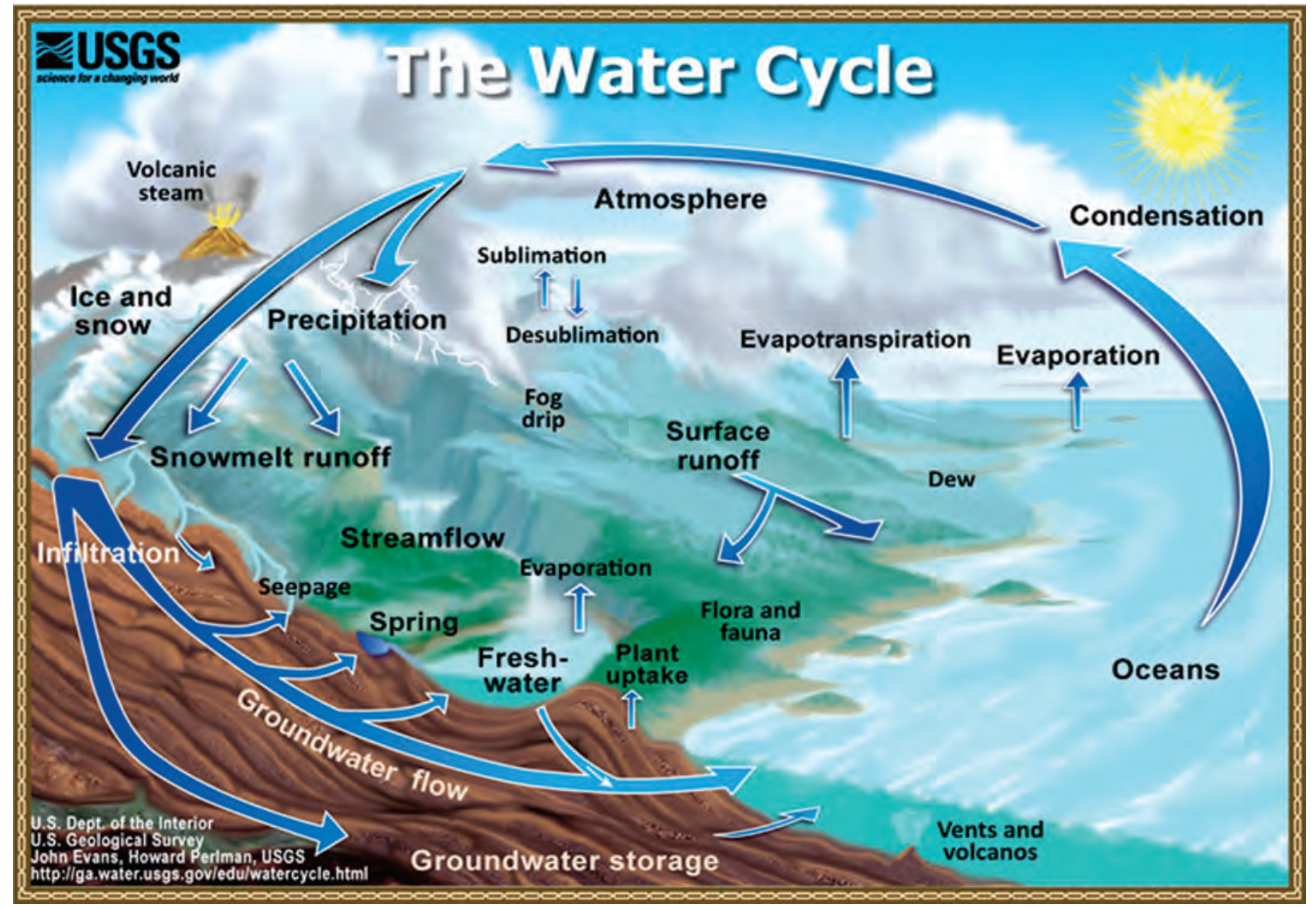

Figure 4. The hydrologic cycle (U.S. Geological Survey, 2014). 
A



B

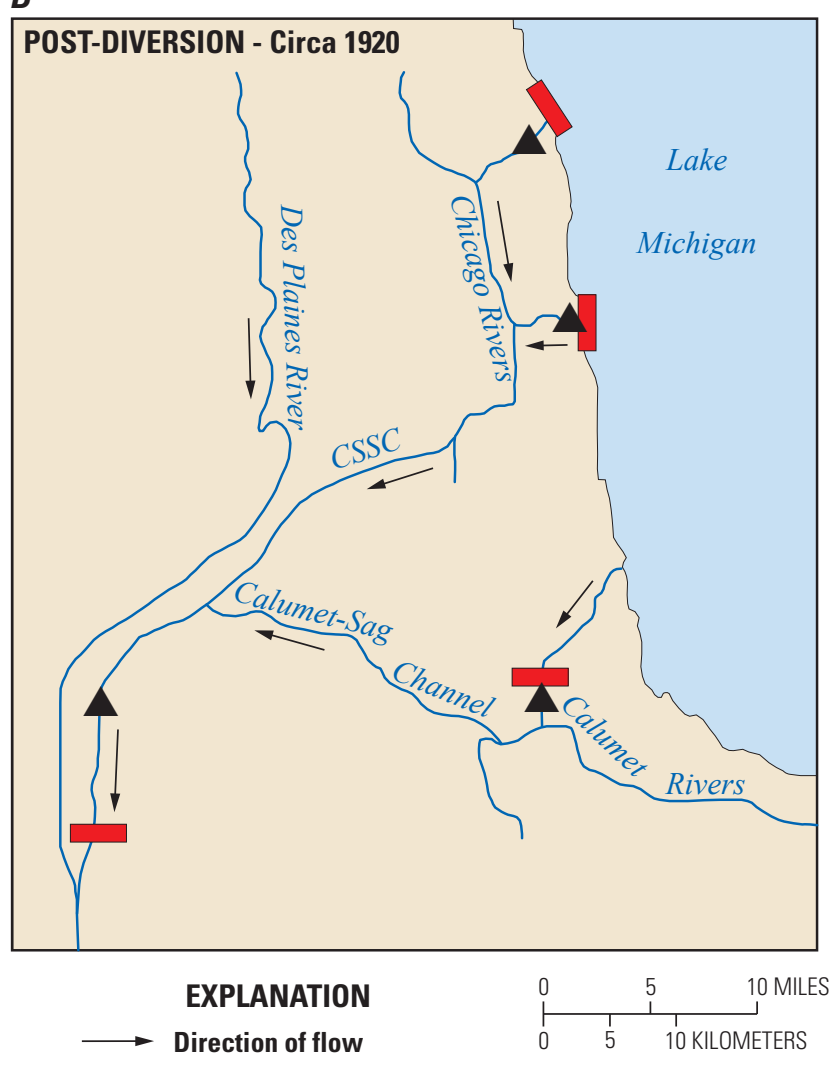

Control structure

- Streamflow-gaging station

Figure 5. $\quad A$, pre-diversion, and $B$, post-diversion surface drainage in Chicago, Illinois, and vicinity.

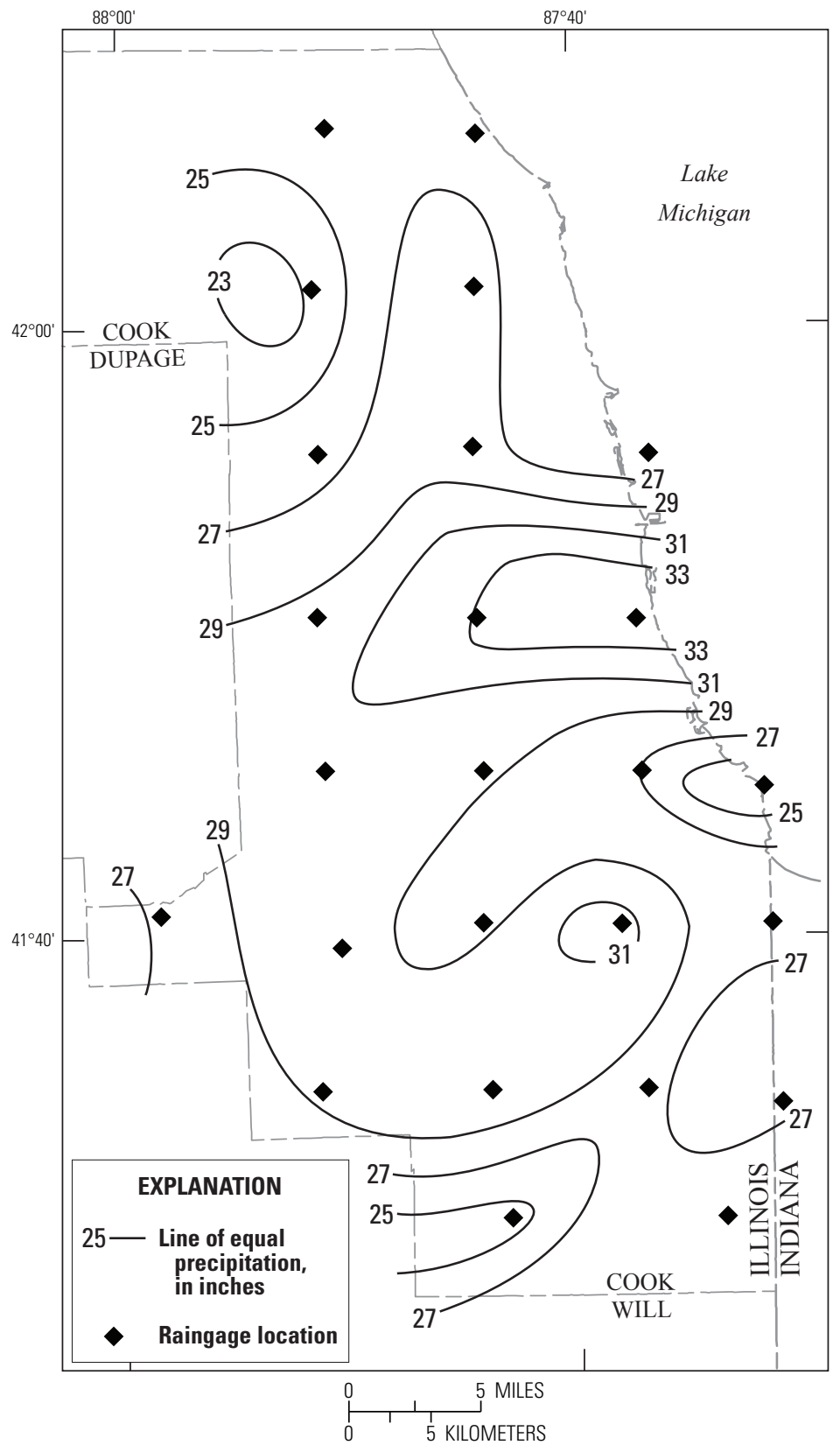

Figure 6. Lines of equal precipitation pattern for the 2012 water year, Chicago, Illinois, and vicinity. (Data are from the Illinois State Water Survey dense rain gage network [Westcott, 2013])

\section{Groundwater}

The groundwater component of the hydrologic cycle in the Chicago area is composed of an interconnected pathway of natural subsurface drainage consisting of groundwater flow through the soils and bedrock, but it also includes the subsurface sewer system to some extent. Precipitation infiltrates into soils and fill material to become shallow groundwater. Shallow 
groundwater moves through soils and fill material at varying rates controlled by the physical properties of the material (porosity and permeability) and hydraulic gradients (pressure head). The soils and fill material may be connected to local sewer systems to varying degrees. Many of the local sewers in the Chicago area are very old, brick-lined sewers that are susceptible to inflow and infiltration. Shallow groundwater monitoring wells in Chicago record a varying water-table surface (piezometric surface) that for much of the year is above the elevation of the local sewer system (fig. 7).

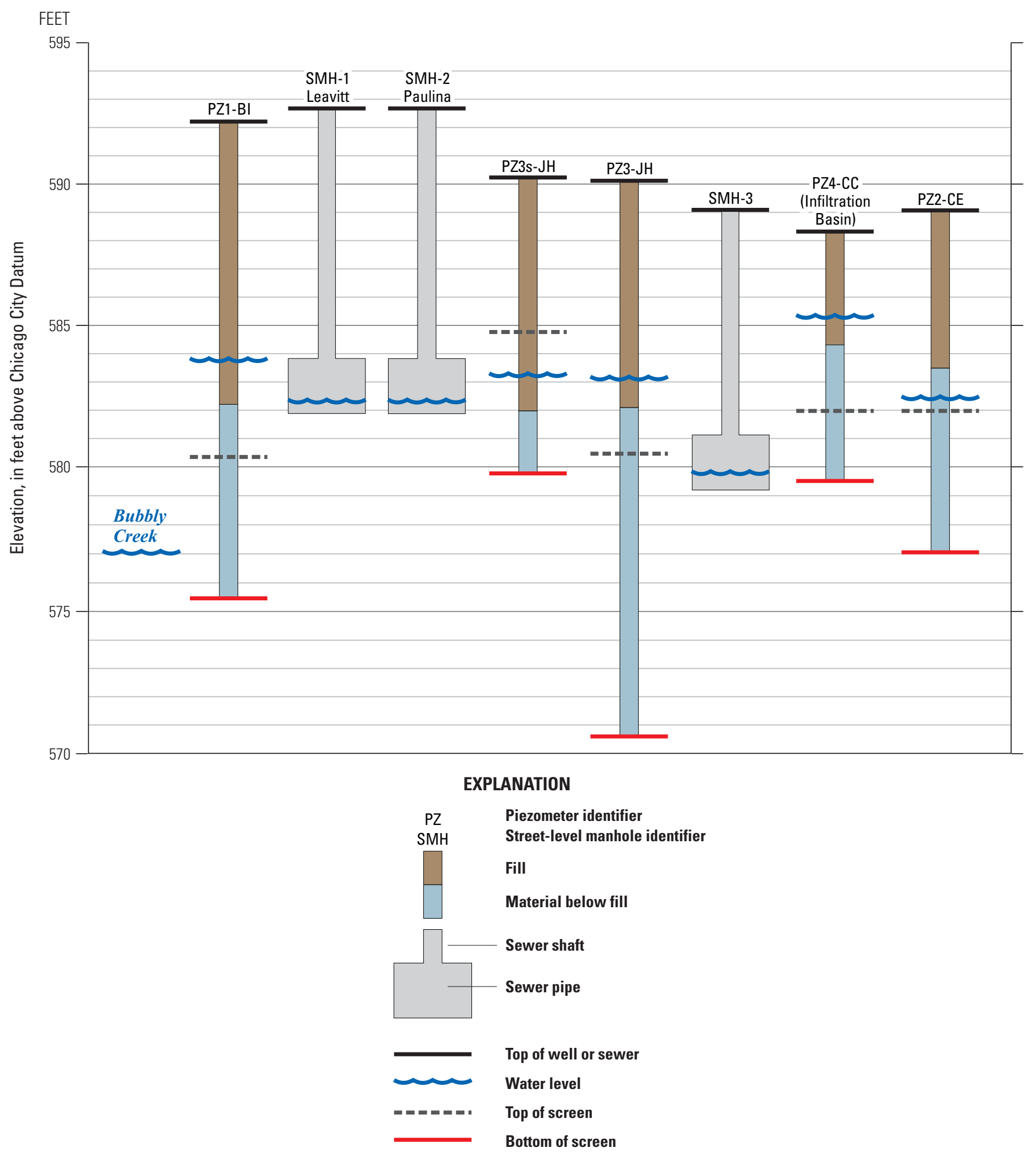

Figure 7. Schematic cross-section diagram showing the elevations of the water table, local combined sewer invert, and Chicago Sanitary and Ship Canal water-surface elevation in the Pilsen neighborhood on the south side of Chicago, Illinois. 
The thickness of the glacial till varies across the Chicago area (Piskin and Bergstrom, 1975). Silurian-age carbonate bedrock underlies the glacial till throughout the Chicago area (Kolata and Nimz, 2010). The Silurian dolomite forms a shallow bedrock groundwater aquifer. Sandstone and dolomite bedrock of Cambrian and Ordovician age form a deep bedrock aquifer (Burch, 2008; fig. 8).

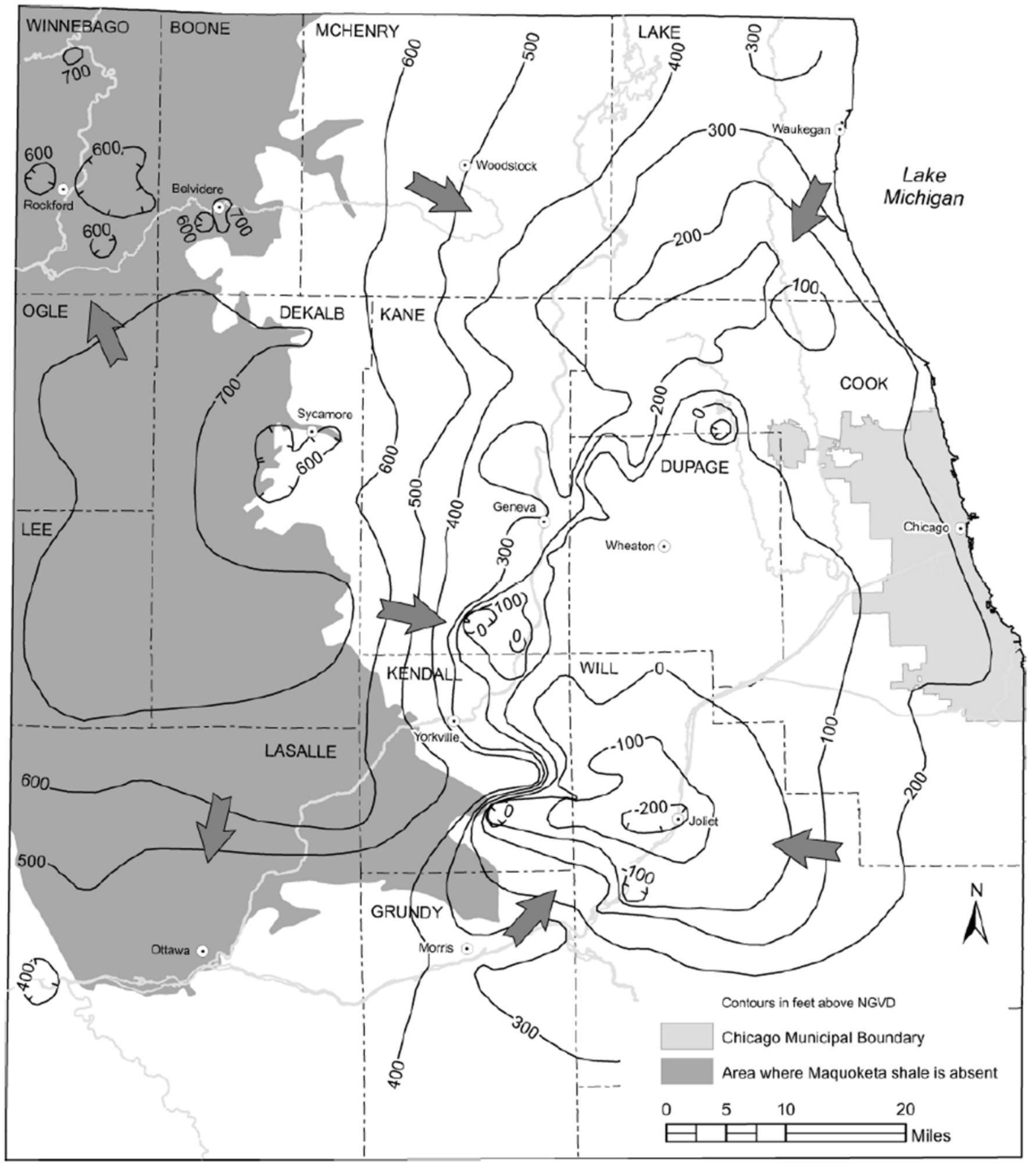

Figure 8. The potentiometric surface of the deep sandstone aquifers in the Chicago area, northeastern Illinois, fall 2007. (From Burch, 2008) 
Beneath the city streets of Chicago lies a vast network of sewers that facilitates the drainage of the metropolitan area. This network of sewers consists of local and interceptor sewers that convey sanitary and stormwater runoff in addition to industrial discharges. Underlying the Chicago metropolitan area at a much greater depth (110-330 ft below the land surface) is the MWRDGC Deep Tunnel (fig. 3). The Deep Tunnel is the tunnel portion of MWRDGC's TARP. The 100-plus mi network of four tunnel systems was completed in 2006 and lies between 70 and $300 \mathrm{ft}$ below the land surface. The tunnels were excavated in bedrock and, when the TARP project is completed, will drain combined sewer overflows and stormwater to three large storage reservoirs. The water in the reservoirs will then be pumped to wastewater-treatment plants before being treated and discharged to area waterways.

\section{Surface Water}

The dominant features of the hydrology for the Chicago area are the surface-water components that make up the CAWS. These consist of a combination of natural channels and manmade canals that form the primary surface-drainage features. During dry weather, the hydraulic conditions found within the CAWS are typically a low-velocity setting with water levels maintained by control structures to facilitate navigation. During dry weather much of the waterway is affected by diurnal wastewater-effluent discharges. The navigable reaches of canal and river channels exhibit very unsteady flow characteristics. Many of the flow characteristics described by Jackson and others (2011) are found throughout the CAWS. Lockages, variable-flow control structures at the lakefront and downstream, wastewater-effluent discharges, power-plant and industrial withdrawals, and commercial and recreational boat traffic all contribute to the unsteady flow characteristics found throughout the CAWS. Water-quality conditions during dry weather are affected by the large volume of treated wastewater effluent in the channel, which can exceed 70 percent of the total volume of flow at times.

During wet weather, when storms are forecast for the Chicago area, the MWRDGC uses control structures (Lockport Powerhouse and Lockport Controlling Works) near the downstream end of the waterway near Lockport, Ill., to proactively draw down the water-surface elevation and create storage space within the CAWS channel for the influx of stormwater. Navigation depth requirements and the hydraulic properties of the CAWS channels limit the amount of drawdown that is possible from the downstream control structures. Although the drawdown near the Lockport control structures (River mile 291) may reach 10-11 ft below the normal pool elevation when all of the control structures are open, the drawdown near Sag Junction (River mile 302) may only be $3 \mathrm{ft}$, and the effect near the lakefront may not be noticeable (fig. 9).

At times during extreme wet weather, the stormwater inflow to the CAWS channel may exceed the channel's capacity. When this occurs, water levels within the CAWS may increase rapidly and approach flood levels. In order to prevent flooding, the MWRDGC then opens the lakefront control structures and backflows the river water into Lake Michigan. The MWRDGC has backflow capability at each of the three lakefront control structures. The MWRDGC maintains records of backflow events, backflow duration, and estimated backflow volumes. Table 1 shows the MWRDGC record of backflow events at the lakefront control structures since 2000 .

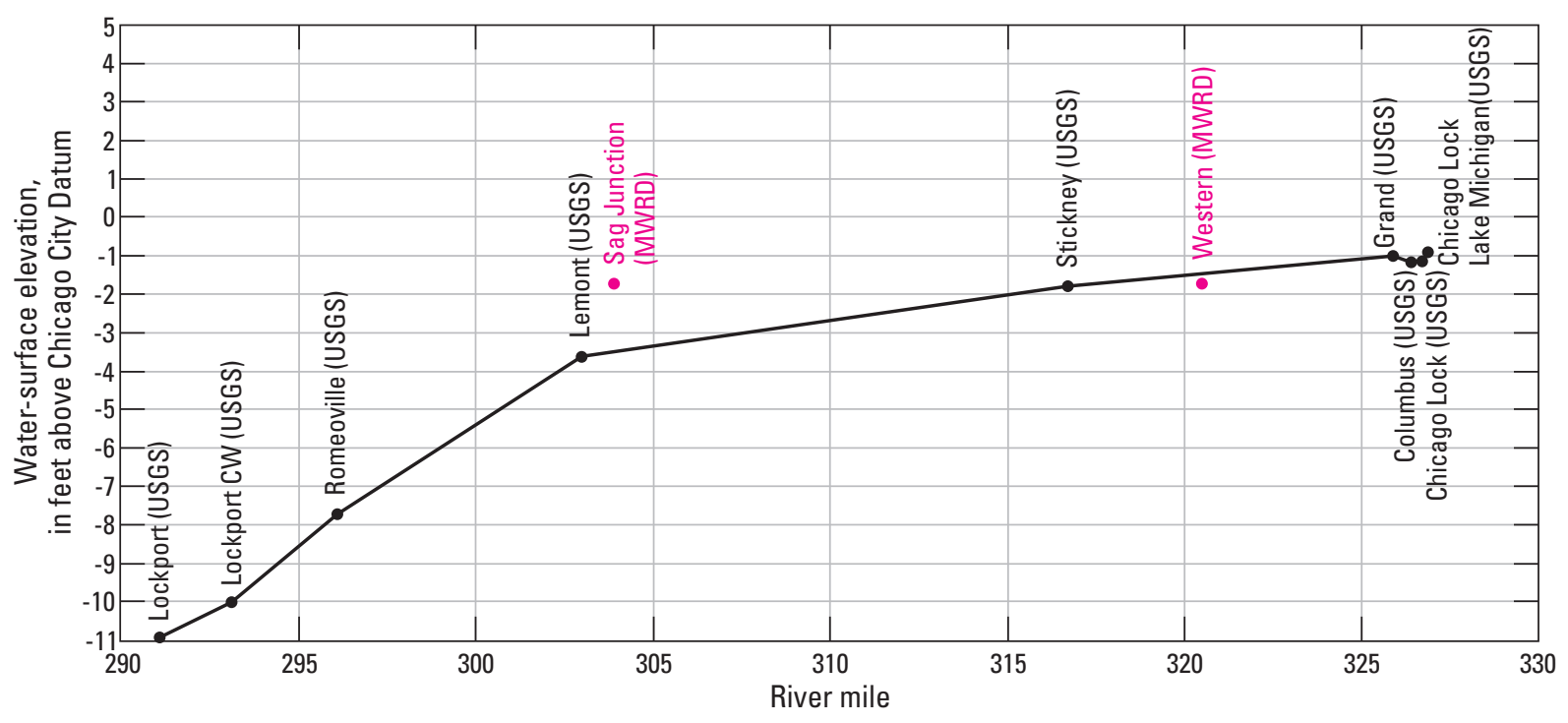

Figure 9. Water-surface profile data for the Chicago Area Waterway System, Chicago, Illinois, and vicinity during an April 17-18, 2013, storm and the extent of drawdown of the water surface at points along the waterway. (MWRDGC, Metropolitan Water Reclamation District of Greater Chicago; USGS, U.S. Geological Survey) 
Table 1. Summary of backflow events on the Chicago Area Waterway System, Chicago, Illinois, and vicinity, 2000-14.

[From Metropolitan Water Reclamation District of Greater Chicago (2014)]

\begin{tabular}{|c|c|c|}
\hline Year & $\begin{array}{l}\text { Number of } \\
\text { backflows }\end{array}$ & $\begin{array}{c}\text { Total volume } \\
\text { (in millions of } \\
\text { gallons) }\end{array}$ \\
\hline 2000 & 0 & 0.0 \\
\hline 2001 & 3 & $1,189.0$ \\
\hline 2002 & 1 & $1,751.8$ \\
\hline 2003 & 0 & 0.0 \\
\hline 2004 & 0 & 0.0 \\
\hline 2005 & 0 & 0.0 \\
\hline 2006 & 0 & 0.0 \\
\hline 2007 & 1 & 224.0 \\
\hline 2008 & 2 & $11,509.9$ \\
\hline 2009 & 3 & 413.6 \\
\hline 2010 & 1 & $6,534.9$ \\
\hline 2011 & 2 & $2,327.5$ \\
\hline 2012 & 0 & 0.0 \\
\hline 2013 & 1 & $10,719.5$ \\
\hline 2014 & 1 & 525.0 \\
\hline
\end{tabular}

Several factors influence the frequency and magnitude of backflow events. The timing and distribution of precipitation, the hydraulic properties of the channels, and the regulation and operation of control structures may impact backflows.

The general discussion of CAWS hydrology and flow regulation gives an overall view of the complex hydraulic setting and flow characteristics found in the CAWS. The following sections of this report will focus on individual reaches of the CAWS and describe in detail some of the hydraulic characteristics of those sections. These descriptions are supported by data whenever possible to validate the setting.

\section{North Shore Channel}

The North Shore Channel (NSC; fig. 10) is a tributary to the North Branch of the Chicago River and receives flow from the MWRDGC Wilmette Pumping Station (WPS; a lakefront control structure at Wilmette, Ill.) and effluent discharge from the MWRDGC Thomas J. O'Brien Water Reclamation Plant (OWRP; formerly known as the North Side Water Reclamation Plant). During summer months, in dry weather, the WPS diverts lake water into the NSC to dilute the effluent discharge from the OWRP. During large storms, the NSC receives combined sewer overflows (CSOs) at numerous CSO outfall locations along the NSC. Also during large storms, the WPS may be used to backflow excess water to the lake to mitigate flooding. During winter months, the channel in the vicinity of the OWRP outfall is often free of ice cover owing to the effluent discharge.

The USGS operated and maintained a streamflow-gaging station (05536101) on the NSC (approximately $1 / 4 \mathrm{mi}$ from the WPS) from 2000 to 2003 as part of the Lake Michigan Diversion Accounting Program. The streamflow data from this gage (fig. 11) provided accurate monitoring of the water that was diverted through the WPS; the data also were used to calculate flow volume during storm-related backflows to Lake Michigan. The data collected during the time that the streamflow-gaging station was in operation show unsteady flow conditions and periods of reverse flows, which likely were the result of the variable input from the NSWRP. The range in stage measured at the streamflow-gaging station during the period of data collection was -2.84 to $6.91 \mathrm{ft}$ Chicago City Datum (CCD). The range in daily mean discharge during this same period was estimated to be from -58 to 245 cubic feet per second $\left(\mathrm{ft}^{3} / \mathrm{s}\right)$.

Data collection at the USGS streamflow-gaging station 05536101 was discontinued in 2003. The USACE had completed a study (USACE, n.d; referred to as "Lakefront Accounting") of monitoring the diversion near the three lakefront control structures. The Lakefront Accounting study resulted from the U.S. Department of Justice mediation efforts to reconcile mid-1990s disputes among Great Lakes states resulting from the State of Illinois' noncompliance with the 1980 U.S. Supreme Court mandate. In May 2013, streamflowgaging station 05536101 was reestablished with funding support from the MWRDGC. The streamflow-gaging station provides flow data useful to the MWRDGC for allocation of diversion water, maintenance of water-quality standards for the NSC, and measurement of backflow volumes. Recent studies on waterway separation by the Great Lakes Commission and the Great Lakes and St. Lawrence Cities Initiative (Great Lakes Commission, 2012) and the USACE (USACE, 2014) have proposed barrier locations that would reroute the OWRP effluent discharge directly to Lake Michigan. The complex, unsteady flow that would result from the proposed waterway separation scheme would warrant monitoring to determine flow direction and contaminant loading to the lake that would occur if the waterway separation plan were implemented. 


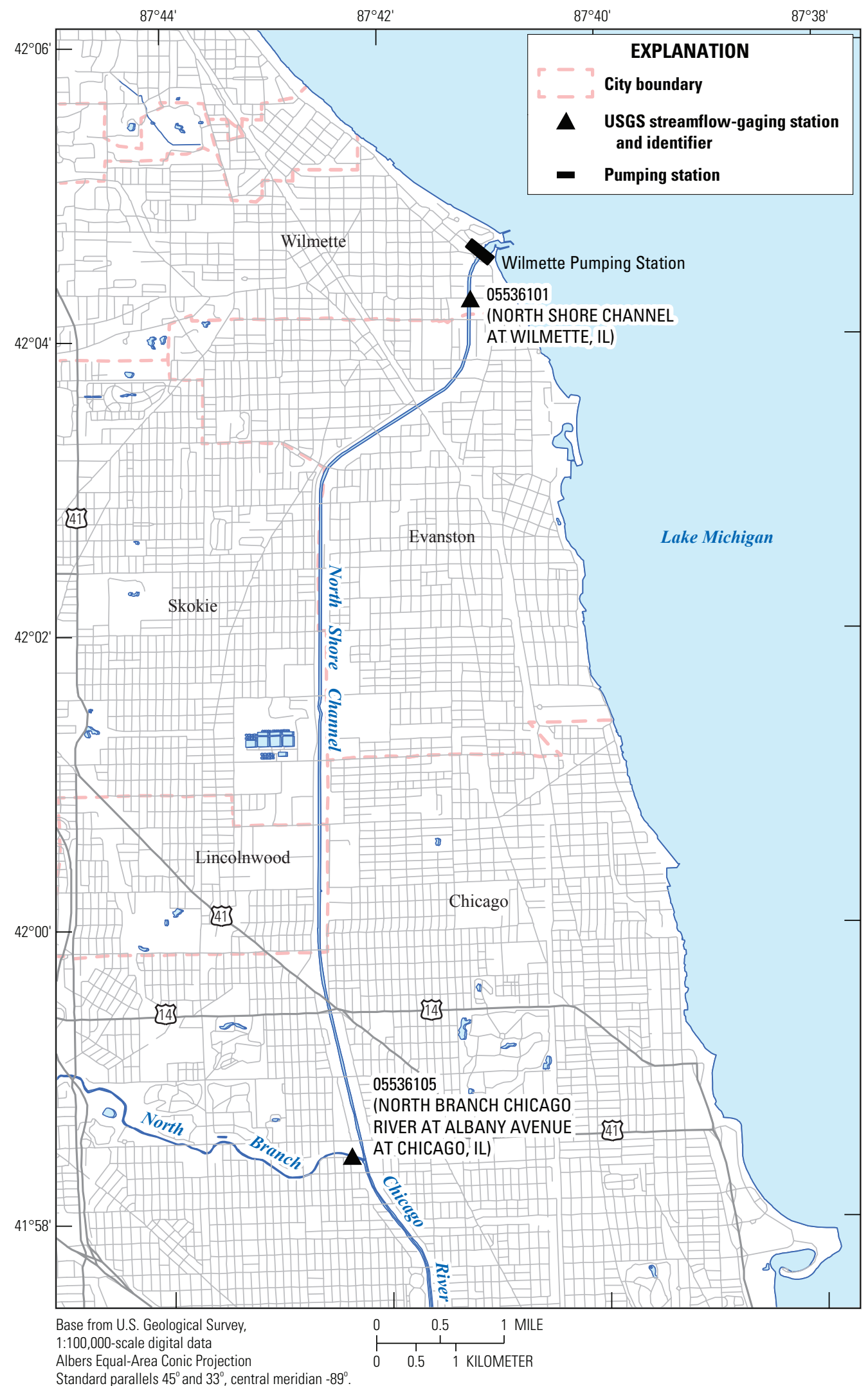

Figure 10. The Chicago Area Waterway System with the North Shore Channel, Chicago, Illinois, and vicinity. (USGS, U.S. Geological Survey) 


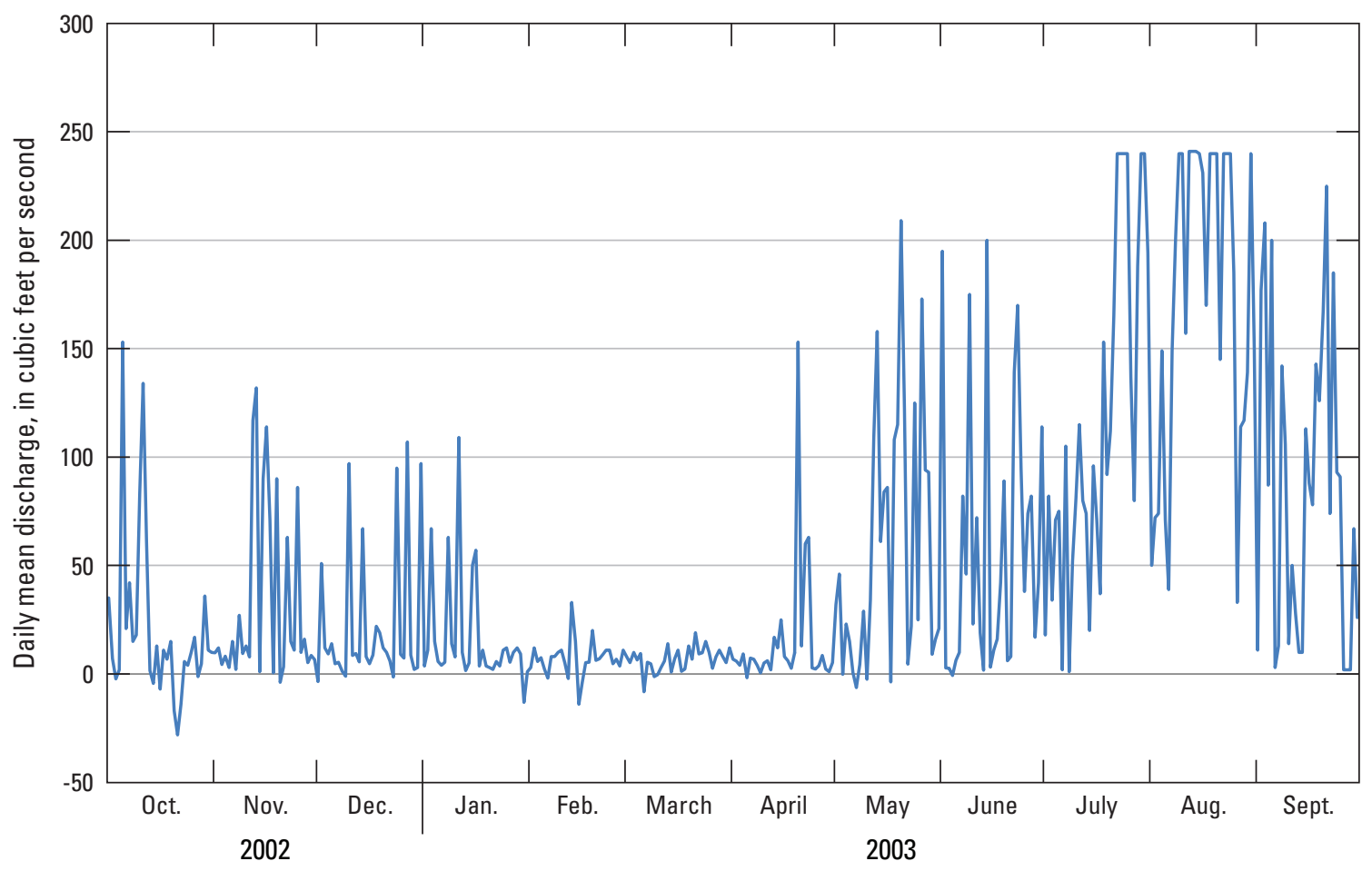

Figure 11. Daily mean discharge for the North Shore Channel at Wilmette, Illinois, for the 2003 water year, which is the last year of record.

Table 2. Long-term U.S. Geological Survey streamflow-gaging stations on the North Branch of the Chicago River and its tributary streams, Chicago, Illinois, and vicinity.

[USGS, U.S. Geological Survey]

\begin{tabular}{cll}
\hline $\begin{array}{c}\text { USGS station } \\
\text { number }\end{array}$ & \multicolumn{1}{c}{ Station name } & Period of record \\
\hline 05535000 & Skokie R. at Lake Forest, IL & 1951-present \\
05535070 & Skokie R. near Highland Park, IL & 1966 -present \\
05534500 & N. Br. Chicago R. at Deerfield, IL & 1952 -present \\
05535500 & WF N. Br Chicago R. at Northbrook, IL & 1951 -present \\
05536000 & N.Br. Chicago R. at Niles, IL & 1950 -present \\
05536105 & N. Br. Chicago R. at Albany Avenue at Chicago, IL & 1989 -present \\
05536118 & N. Br. Chicago R. at Grand Avenue at Chicago, IL & 2002-present \\
\hline
\end{tabular}

\section{North Branch Chicago River}

The North Branch of the Chicago River (NBrCR) is tributary to the CAWS and joins the NSC (fig. 12); the combined streamflow represents most of the flow from the north side of Chicago and the northern metropolitan area. The NBrCR is composed of a mostly natural channel that is relatively shallow and nonnavigable for motor vessels. During large storms, the $\mathrm{NBrCR}$ receives CSOs at numerous CSO outfall locations along the NBrCR. Dry weather flows consist primarily of wastewater effluent from treatment plants and base flow from shallow groundwater.

The NBrCR and its tributaries are currently (2014) gaged at several locations. Streamflow-gaging station 05536105 near the confluence of the NBrCR and the NSC quantifies the flows entering the CAWS from the $\mathrm{NBrCR}$ (table 2). 


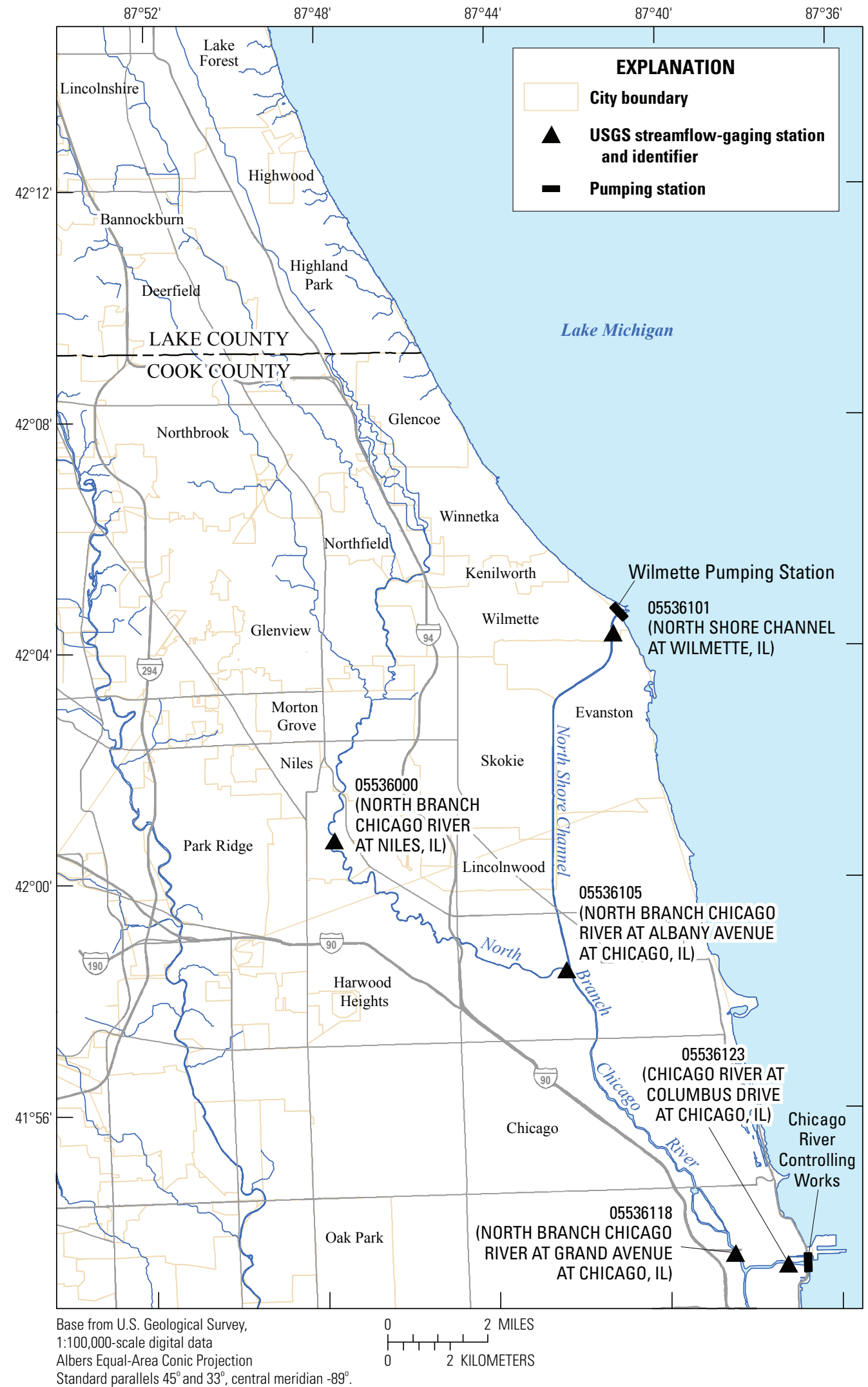

Figure 12. The Chicago Area Waterway System, including the North Branch Chicago River and U.S. Geological Survey streamflow-gaging stations, Chicago, Illinois, and vicinity. 
The USGS streamflow-gaging station (05536105) on the $\mathrm{NBrCR}$ is approximately $400 \mathrm{ft}$ upstream from a concrete control structure that regulates the flow of the $\mathrm{NBrCR}$ as the flow combines with the NSC. Mean daily discharge at this streamflow-gaging station is shown in figure 13. The control structure consists of a multilevel concrete weir structure, wing walls, and abutment that constrain the flow at low, medium, and high stages (fig. 14). The range in stage measured at the streamflow-gaging station during the period of data collection was 1.00-7.86 ft. Discharge during this same period ranged from 3.6 to $3,580 \mathrm{ft}^{3} / \mathrm{s}$.

The USGS streamflow-gaging station (05536118) on the $\mathrm{NBrCR}$ at Grand Avenue is approximately $1 / 4$ mi upstream from the confluence of the $\mathrm{NBrCR}$ and the mainstem of the Chicago River at Wolf Point (fig. 15). The flow in this reach is a combination from the NBrCR and the NSC. The channel through this reach is approximately $150 \mathrm{ft}$ wide and $15-20 \mathrm{ft}$ deep with vertical sheet piling walls. The range in stage measured at streamflow-gaging station (05536118) during the period of data collection was -4.32 to $5.00 \mathrm{ft} \mathrm{CCD}$. The range in daily mean discharge during this same period was from -20 to $14,100 \mathrm{ft}^{3} / \mathrm{s}$. Negative daily mean discharges occur as a result of regulation or the effects of upstream and downstream (bidirectional) flow from density currents. A vertical string of six probes that measured water temperature and specific conductance was installed in 2002 to document the density currents in this reach. The range in water temperature during the period of data collection was 0.0-27.0 degrees Celsius $\left({ }^{\circ} \mathrm{C}\right)$. The range in specific conductance during the period of data collection was $264-5,420$ microsiemens per centimeter at $25^{\circ} \mathrm{C}$.

\section{Mainstem Chicago River}

The mainstem of the Chicago River is a relatively short reach of channel (1.6 mi) that connects Lake Michigan to the confluence of the North and South Branches of the Chicago River (fig. 15). The channel is characterized by vertical sheet-pile or concrete walls through the high-rise corridor of downtown Chicago. The channel is primarily rectangular in cross section with depths in the 15 - to 23 - $\mathrm{ft}$ range when the water level is at $-2.0 \mathrm{ft} \mathrm{CCD}$. The flow through this reach has been monitored since 1996 for the Lake Michigan Diversion Accounting Program and lakefront accounting of direct diversions. The AVM data combined with data from a vertical string of probes that measured water temperature and specific conductance at the Columbus Drive streamflow-gaging station (05536123) were used to define the complexity of flows in this reach. Leakage of Lake Michigan water into the Chicago River was first quantified using discharge data from

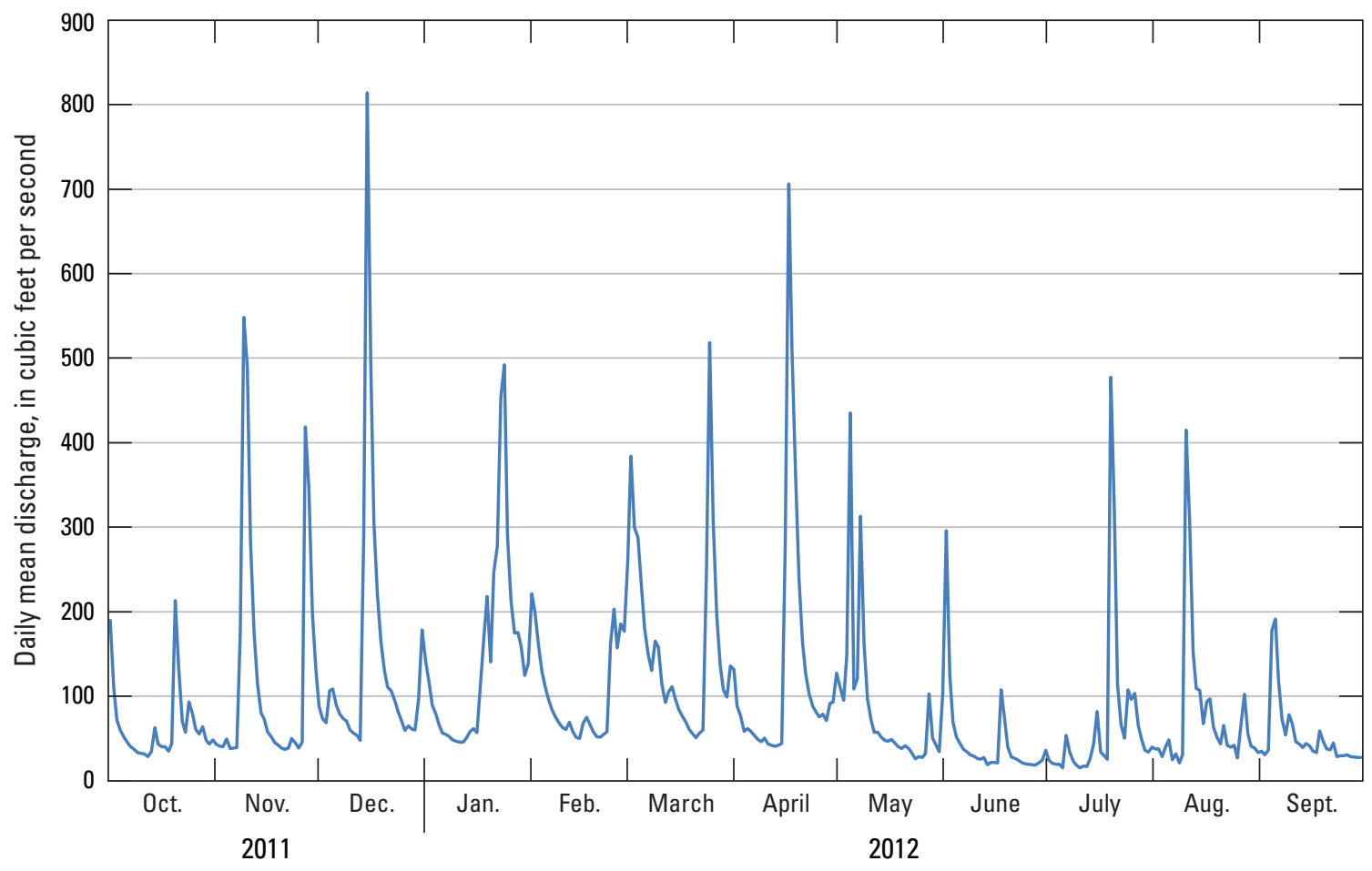

Figure 13. Daily mean discharge for the streamflow-gaging station (05536105) on the North Branch Chicago River at Albany Avenue, Chicago, Illinois, and vicinity, for the 2012 water year. 


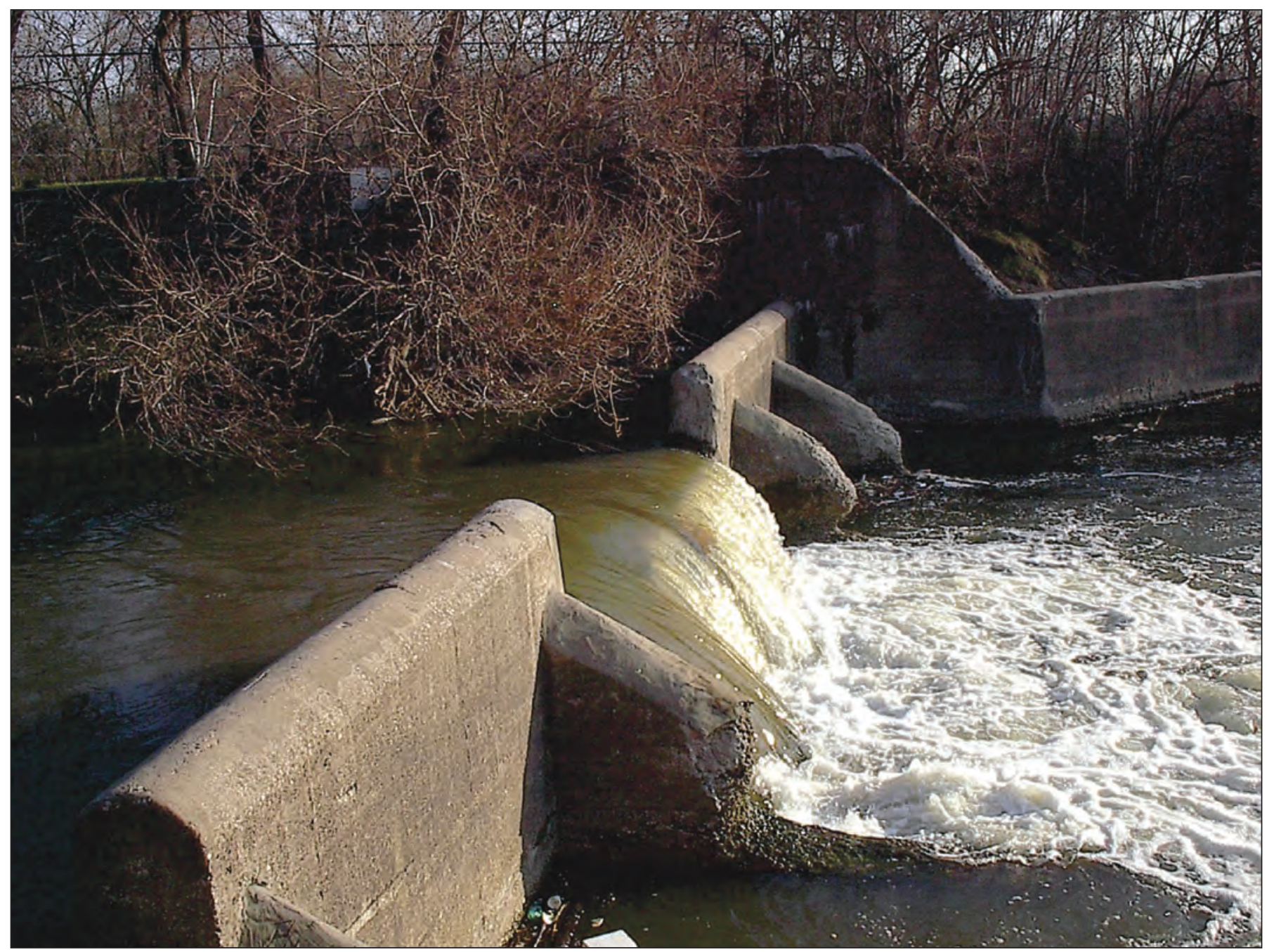

Figure 14. The concrete control structure at the confluence of the North Branch Chicago River and the North Shore Channel, Chicago, Illinois, and vicinity. (Photograph by Shawn Cutshaw, U.S. Geological Survey)

this station, which resulted in the use of several infrastructure projects to reduce the leakage. Bidirectional flows, driven by density contrasts between the Lake Michigan water and the Chicago River water, were also first identified from monitoring at this location (Jackson and others, 2008). Density differences driving the flow primarily arise from salinity differences between the NBrCR and the mainstem of the Chicago River; water temperature is secondary in the creation of these currents. Deicing salts appear to be the primary source of salinity in the NBrCR. These salts enter the waterway in direct runoff and in runoff entering the combined sewer system that becomes effluent from water-treatment plants. Knowledge of the complex flows in this reach helped to account for problematic variability in long-term monitoring of water quality in this reach. Water-quality assessments of the Chicago River may underestimate (or overestimate) the impairment of the river because standard water-quality monitoring practices do not account for density-driven underflows (or overflows) (Jackson and others, 2008). The range in stage measured at the Chicago River at Columbus Drive streamflow-gaging station (05536123) during the period of data collection was from $-4.52 \mathrm{ft}$ to $4.72 \mathrm{ft} \mathrm{CCD}$ owing to regulation. The range in daily mean discharge during this same period was from $-2,450$ to $1,370 \mathrm{ft}^{3} / \mathrm{s}$. Typical low- and high-flow velocity direction and magnitude data from discharge measurements at the streamflow-gaging station are shown in figure $16 A-D$. Velocity magnitude and direction data for a reverse flow event are shown in figure $16 E-F$. 


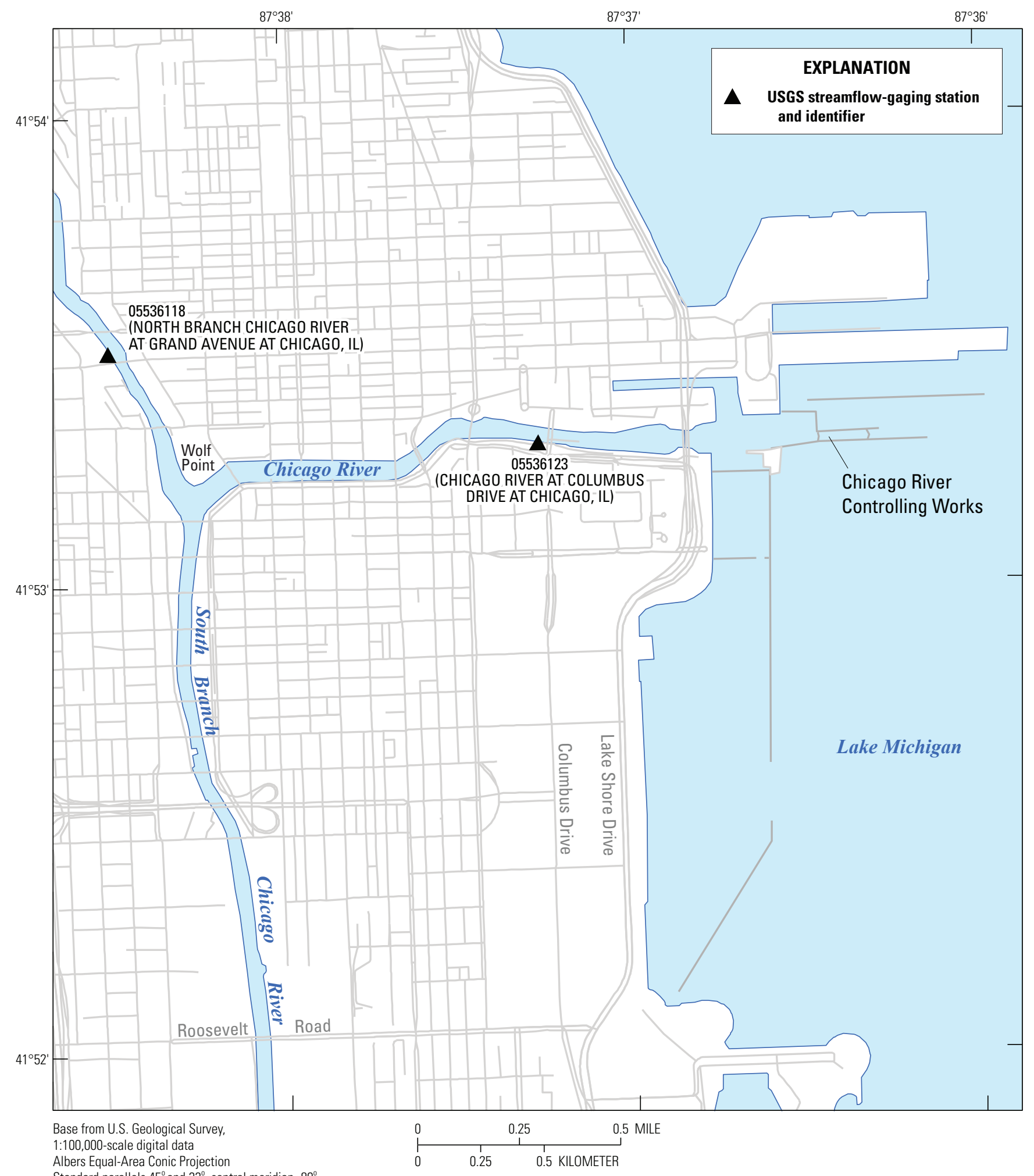

Figure 15. The Chicago Area Waterway System and the mainstem of the Chicago River, Chicago, Illinois. (USGS, U.S. Geological Survey) 

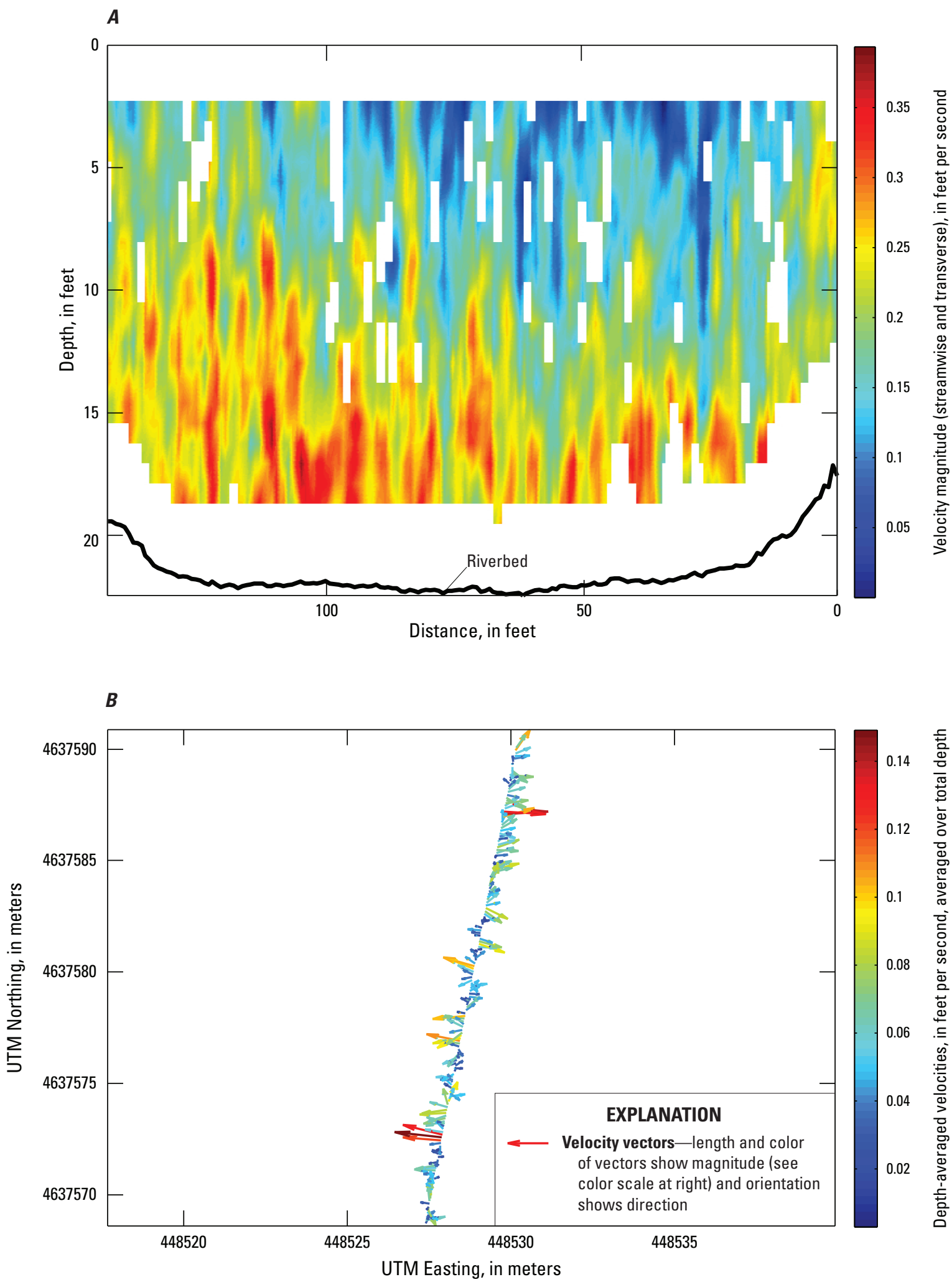

Figure 16. Data from acoustic Doppler current profiler measurements in the mainstem of the Chicago River near Columbus Drive in Chicago, Illinois showing: $A$, typical low-flow water velocity magnitude and $B$, direction; $C$, typical high-flow velocity magnitude and $D$, direction; $E$, reverse flow magnitude and $F$, direction.

(UTM, Universal Transverse Mercator) 

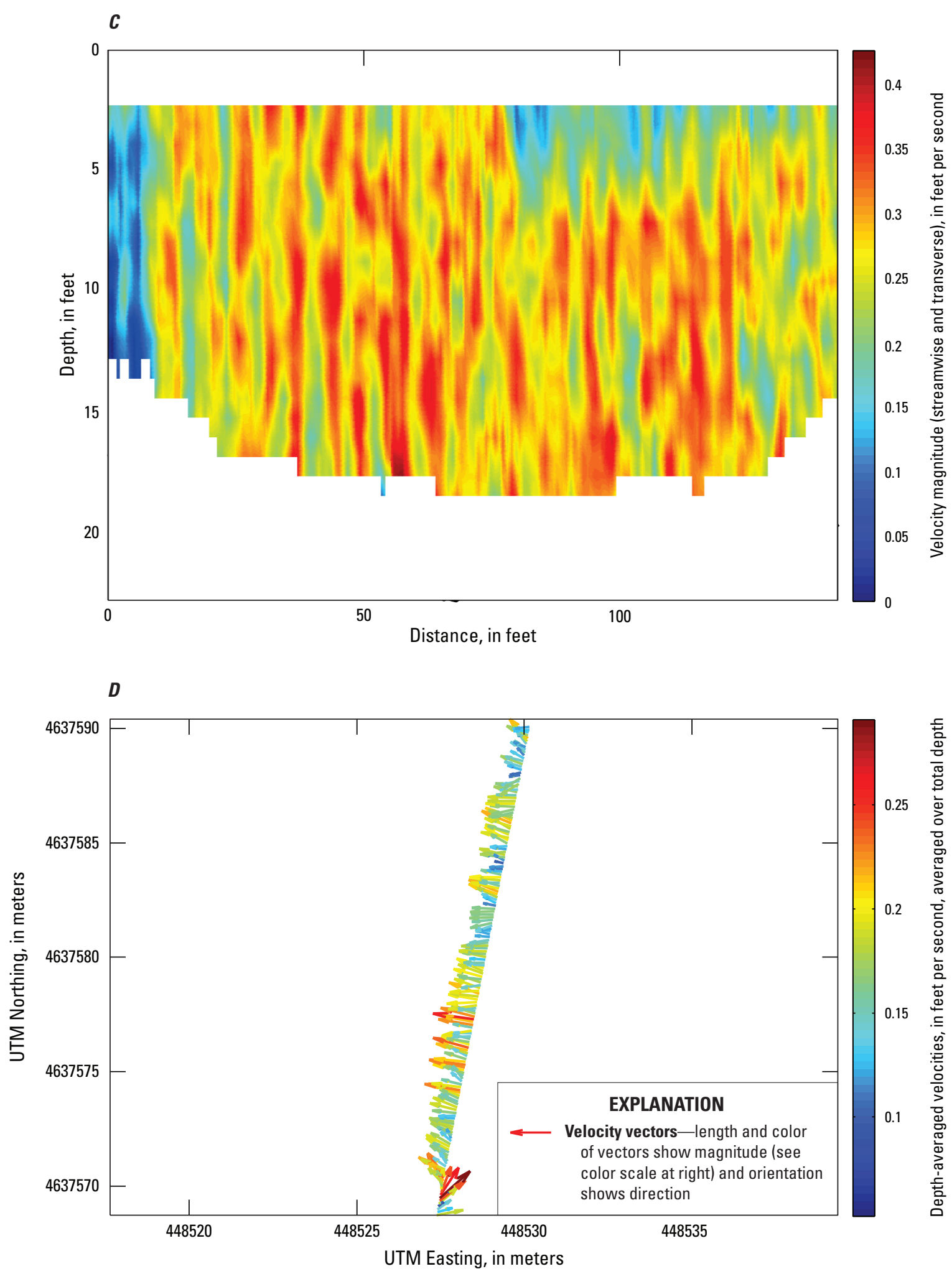

Figure 16. Data from acoustic Doppler current profiler measurements in the mainstem of the Chicago River near Columbus Drive in Chicago, Illinois showing: $A$, typical low-flow water velocity magnitude and $B$, direction; $C$, typical high-flow velocity magnitude and $D$, direction; $E$, reverse flow magnitude and $F$, direction.-Continued (UTM, Universal Transverse Mercator) 

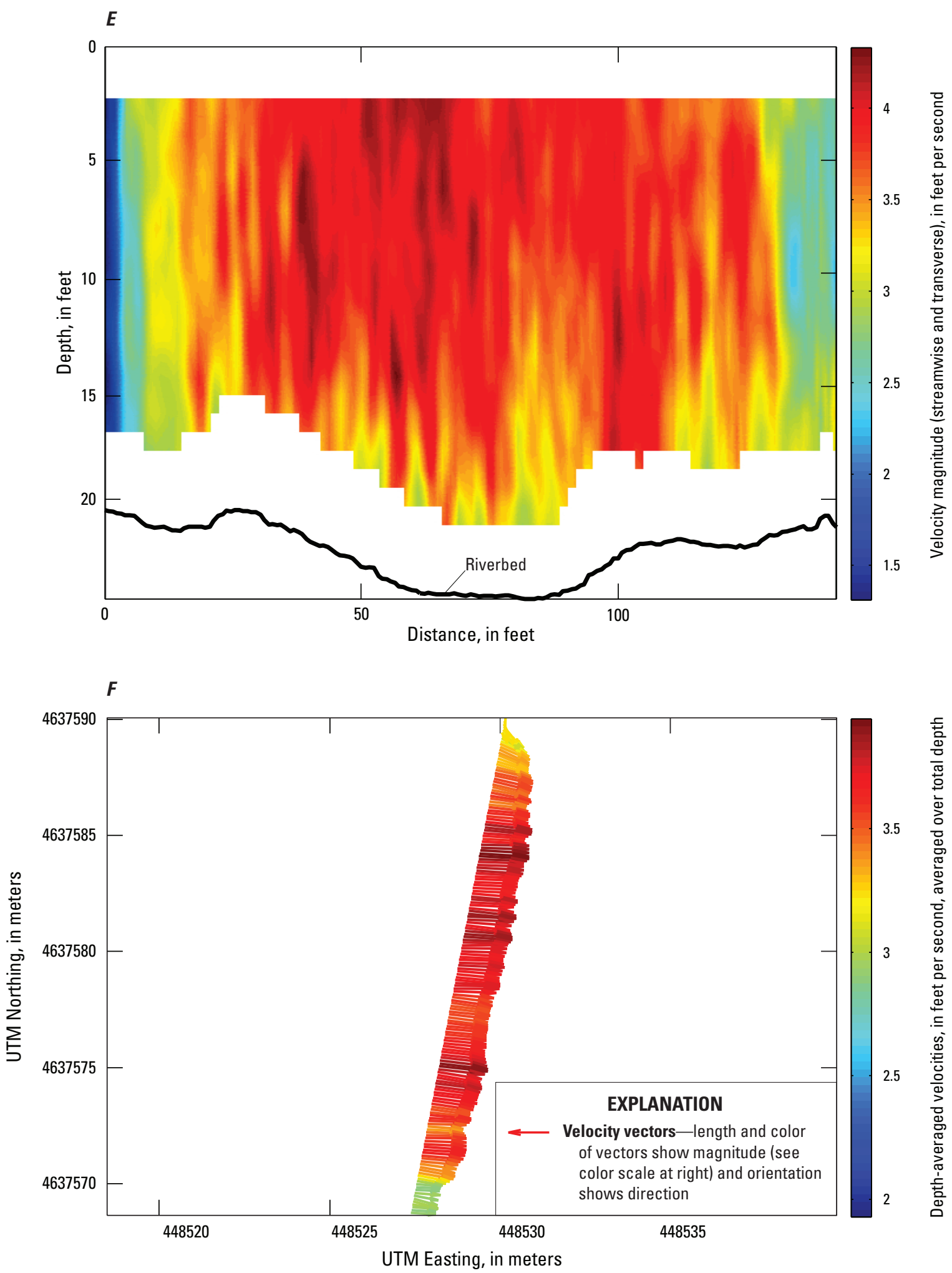

Figure 16. Data from acoustic Doppler current profiler measurements in the mainstem of the Chicago River near Columbus Drive in Chicago, Illinois showing: $A$, typical low-flow water velocity magnitude and $B$, direction; $C$, typical high-flow velocity magnitude and $D$, direction; $E$, reverse flow magnitude and $F$, direction.-Continued (UTM, Universal Transverse Mercator) 
Even prior to the potential changes associated with waterway separation, recent declines in the water level of Lake Michigan have been changing the hydraulic setting of this reach. At times, record low lake levels can affect the direct diversion (by gravity through existing sluice gates) of lake water into the river at the Chicago River Controlling Works (CRCW; fig. 1). The USGS established river- and lake-level gages at the CRCW in August 1997 to evaluate sluice gate flow ratings and leakage through the structure. The USACE also uses the streamflow data for operations during storms. At times, during extreme precipitation events, the water level of the mainstem of the Chicago River approaches a threshold flood elevation $(+3.5 \mathrm{ft} \mathrm{CCD})$. This elevation triggers a response from the MWRDGC and USACE to mitigate imminent flooding by opening the CRCW to backflow the river water to Lake Michigan. The backflow occurs as sluice gates in the control structure are opened and the river water (at an elevation near $+3.5 \mathrm{ft} \mathrm{CCD}$ ) flows by gravity into the lake. If opening the sluice gates does not immediately lower the river water-surface elevation, the gates to the lock chamber may be opened for increased backflow capacity. A large backflow event in April 2013 required the use of sluice gates and lock chamber gates to mitigate potential flooding (fig. 17). USGS field crews made discharge measurements to verify backflow capacity and volumes.

Flow in the mainstem of the Chicago River is heavily affected by the regulated flows coming through the CRCW. These flows include the flow through sluice gates and the lockages. The regulated flows are part of the MWRDGC's allocation of Lake Michigan water and are classified as a direct diversion. In most years, the MWRDGC uses its allocation between April 1 and October 31 to dilute treated wastewater effluent and maintain the waterway "in a reasonably satisfactory sanitary condition" (U.S. Supreme Court, 1980). The direct diversion of Lake Michigan water during the warmer months of the year helps to maintain dissolved oxygen levels in the waterway. In most years, there is no direct diversion during November 1-March 31. During winter months, flow in the mainstem of the Chicago River is very low, consisting mainly of leakage through the control structures and occasionally through lockage. The mainstem of the Chicago River can have variable ice cover during winter months; ice thickness generally is greatest close to the lake.

\section{South Branch Chicago River}

The South Branch of the Chicago River (SBrCR) is the section of channel from the confluence with the NBrCR and mainstem Chicago River at Wolf Point south and southwest to the start of the CSSC near South Damen Avenue (fig. 18). Flow through this reach is generally to the south, then southwest into the CSSC; however, at the mouth of southeast fork of the SBrCR, locally known as Bubbly Creek, the flow may become complex during storms. The high flows discharging from Bubbly Creek are the result of combined sewer

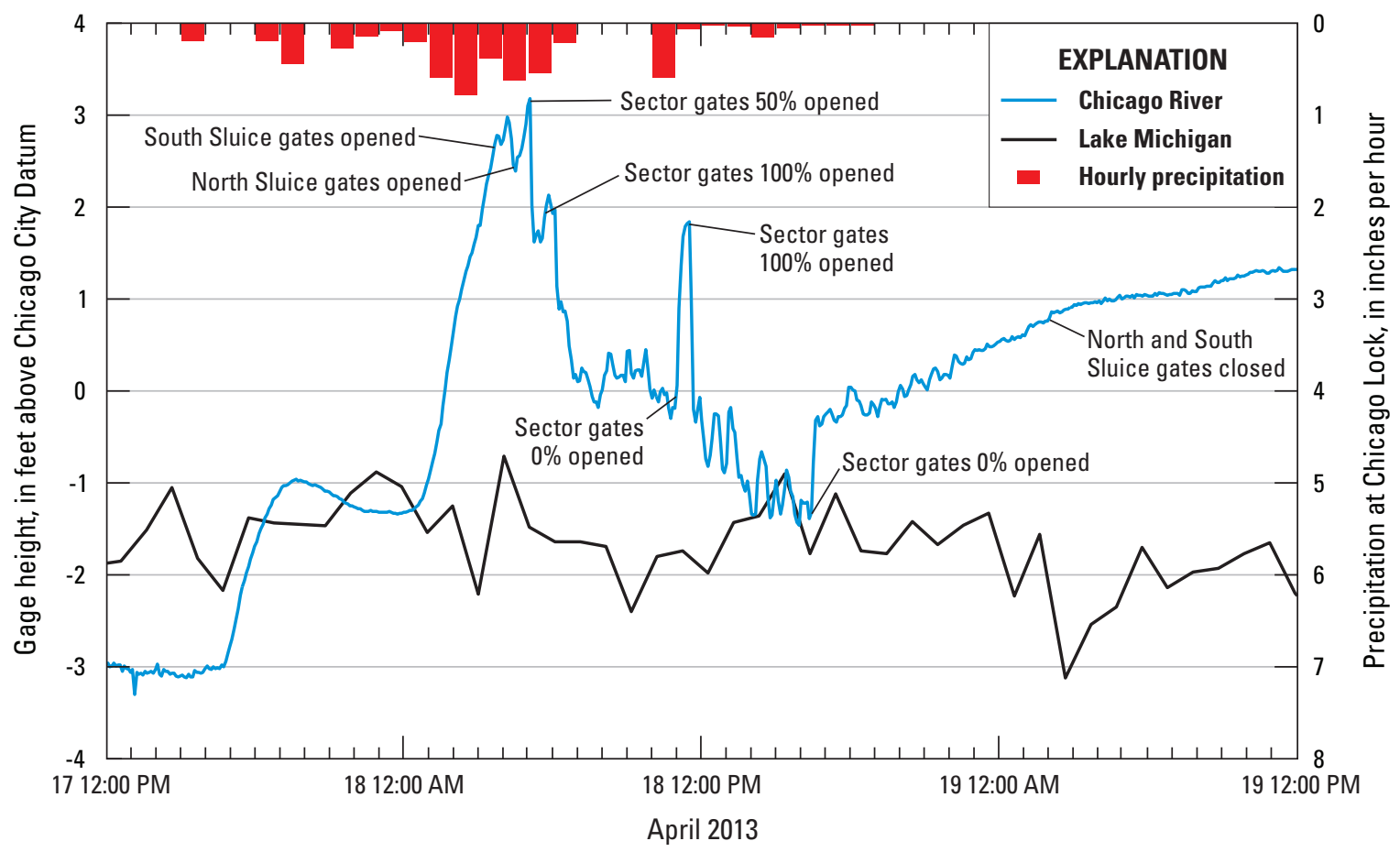

Figure 17. Gage heights for the Chicago River at Columbus Drive at Chicago, Illinois, streamflow-gaging station, hourly precipitation measured at the Chicago Lock, and gate settings at the Chicago River Controlling Works during the April 2013 storm. 


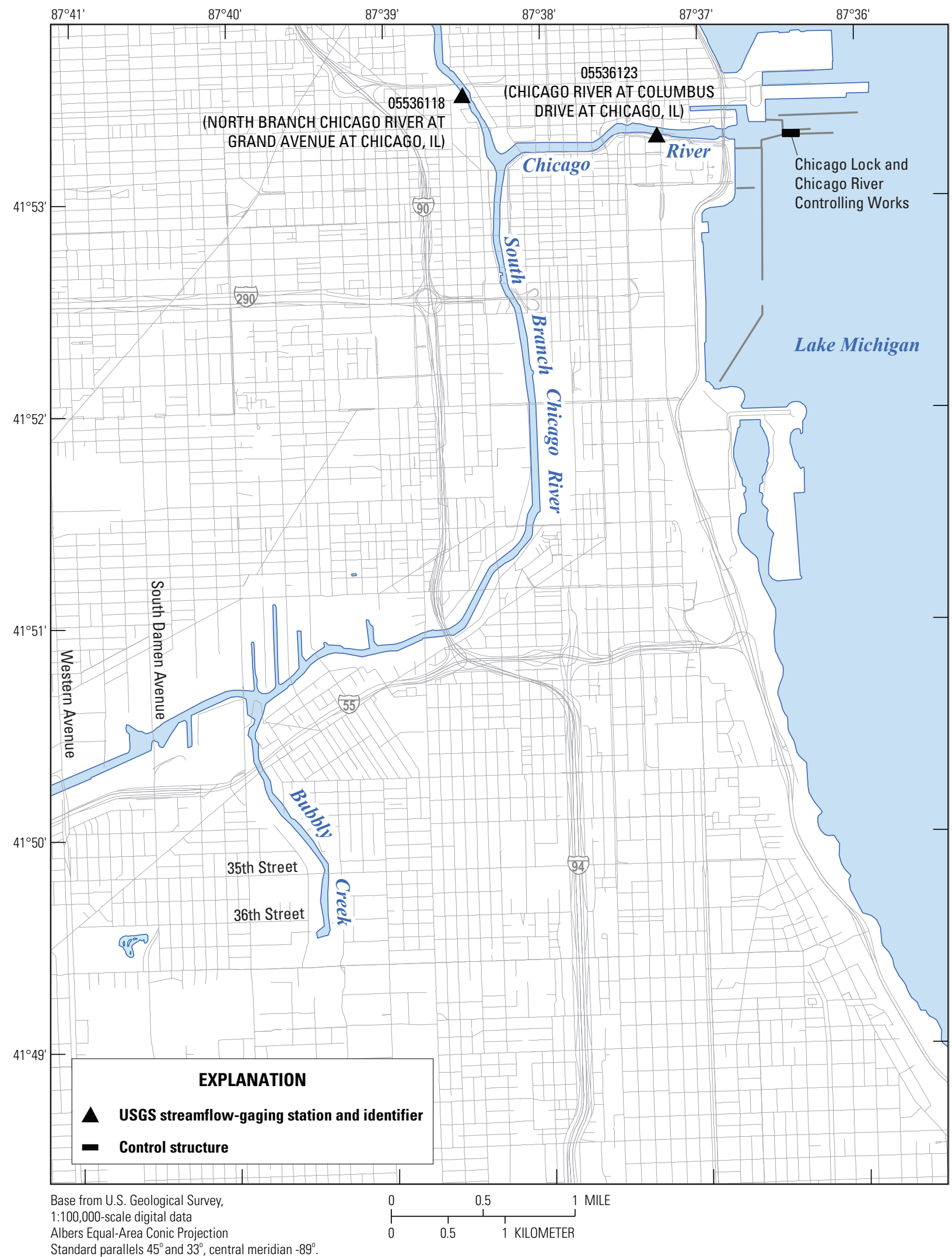

Figure 18. The Chicago Area Waterway System including the South Branch of the Chicago River and the Southeast Fork of the South Branch of the Chicago River (Bubbly Creek), Chicago, Illinois, and vicinity. (USGS, U.S. Geological Survey) 


\section{Hydrology of and Current Monitoring Issues for the Chicago Area Waterway System, Northeastern Illinois}

overflows from the MWRDGC's Racine Avenue Pumping Station (RAPS). These flows enter the SBrCR perpendicular to the flow in the SBrCR. Results of hydraulic modeling studies indicate that during high flows from the RAPS, hydraulic mounding may be likely at the confluence and that it is possible for a portion of the Bubbly Creek discharge to flow upstream to the northeast. A profile of the water-surface elevation for an April 2013 flood (fig. 19A-B) from the MWRDGC Lockport Powerhouse to the CRCW (Chicago Lock) reveals interesting aspects of the CAWS hydraulic setting. This storm produced approximately 4-5 in. of rainfall across much of the Chicago area on April 17-18, 2013 (N.E. Westcott, ISWS, written commun., 2013). A water-surface profile was produced for this storm event based on USGS and MWRDGC streamflow-gaging station data. Animating this profile over time shows definite reversal of the water-surface slope as the MWRDGC opened the gates (backflow) at the CRCW. With the outlet to the lake open and with backflow conditions, the water-surface profile shows a hydraulic mound or divide near Stickney. This condition persisted for several hours, routing the flows from a portion of the upper CSSC, Bubbly Creek, and the South Branch and Branches of the Chicago River to Lake Michigan. Field discharge measurements document the backflows on the mainstem of the Chicago River at Columbus Drive, but no discharge measurements have been made to verify the mounding or upstream flows in the upper reaches of the CSSC or SBrCR. These observations and measurements may factor into discussions about locating proposed barriers for waterway separation in this reach of the CAWS.

During winter months, the SBrCR is usually free of ice cover. The large amount of effluent in the NBrCR and minimal flows from the mainstem would keep ice from forming. Until its closing in 2012, the thermal discharge from the Fisk Generating Plant also contributed to keeping this reach free of ice.

\section{Southeast Fork of the South Branch Chicago River (Bubbly Creek)}

The Southeast Fork of the South Branch of the Chicago River is more commonly referred to by its local name Bubbly Creek (fig. 18). Bubbly Creek received its local name when it drained the Chicago Stockyards and areas of the meat packing industry. Today (2014), Bubbly Creek is a relatively short reach of channel $(1.4 \mathrm{mi})$ that is primarily stagnant during dry weather but receives discharge from the MWRDGC RAPS, stormwater runoff, and a few smaller combined sewer overflows during storms. Pumps within RAPS are capable of a combined discharge of almost $6,000 \mathrm{ft}^{3} / \mathrm{s}$. During dry weather, there is essentially no flow entering Bubbly Creek channel. Water within Bubbly Creek rises and falls as levels in the CSSC fluctuate. A short-term streamflow-gaging station was operated near 36th Street from 2009 to 2010, which deployed a side-looking acoustic Doppler velocity profiler (ADCP) to record stage and velocity for verification of a hydraulic model (fig. 20). During winter months, the Bubbly Creek channel can be completely covered by ice.
The USACE is currently (2014) studying the feasibility of stream restoration for Bubbly Creek. The stream restoration plans would benefit from additional flow data for Bubbly Creek. Waterway separation scenarios include designs to locate a waterway barrier in the vicinity of the mouth of Bubbly Creek; the exact location depends on whether or not the discharge from RAPS is to go to Lake Michigan or to the CSSC. Monitoring of Bubbly Creek would provide measured flows for evaluation of waterway separation barriers and mitigation strategies for the effects of these flows on the receiving water bodies ( $\mathrm{SBrCR}$, mainstem Chicago River, and Lake Michigan).

\section{Chicago Sanitary and Ship Canal}

The CSSC consists of approximately $30 \mathrm{mi}$ of manmade canal excavated into the bedrock and glacial material from Lockport Powerhouse to Damen Avenue in Chicago (fig. 21). The CSSC was constructed from 1892 to 1900 and effectively reversed the flow of the Chicago River by capturing the flow and draining it away from Lake Michigan. The CSSC varies in width from approximately 160 to $200 \mathrm{ft}$ and in depth from approximately 18 to $22 \mathrm{ft}$ (at normal pool elevation) for most of its reach.

Flow within the CSSC is highly regulated by downstream control structures (Lockport Controlling Works, Lockport Powerhouse, and the Lockport Lock and Dam) (fig. 22A). During dry weather, water levels are maintained for navigation, and discharge through the control structures is regulated to balance the inflow to the waterway. At times, power generation at the MWRDGC Lockport Powerhouse is timed to maximize power generation when utility rates are favorable. This results in a cycle of "ponding" of water for a period of time and subsequent increased flows as water is released through turbines (fig. 22B).

During wet weather, prior to a storm, and in anticipation of potential regional flooding, water levels within the CSSC are drawn down to increase storage capacity within the channel (fig. 22C). The drawdown is accomplished by opening gates at the downstream control structures. These gates continue to be operated during a storm to manage water levels and mitigate flood effects. Measured flows recorded at the USGS streamflow-gaging stations since 1986 show a maximum discharge for the CSSC of approximately $20,000 \mathrm{ft}^{3} / \mathrm{s}$.

The MWRDGC Stickney Water Reclamation Plant discharges treated effluent directly to the CSSC near Stickney, Ill. (fig. 21). This treatment plant is one of the largest wastewatertreatment plants in the world with a design capacity of 1,200 million gallons per day (https://www.mwrd.org/irj/portal/ anonymous/stickney).

During most years, the CSSC is ice free due to the thermal loads of the large wastewater-treatment plants, power plants, and industrial discharges. During extended periods of extreme cold weather, portions of the CSSC above Sag Junction have become ice covered. Below Sag Junction, the authors have never seen ice cover on the CSSC, even during extended periods of subzero air temperatures. 

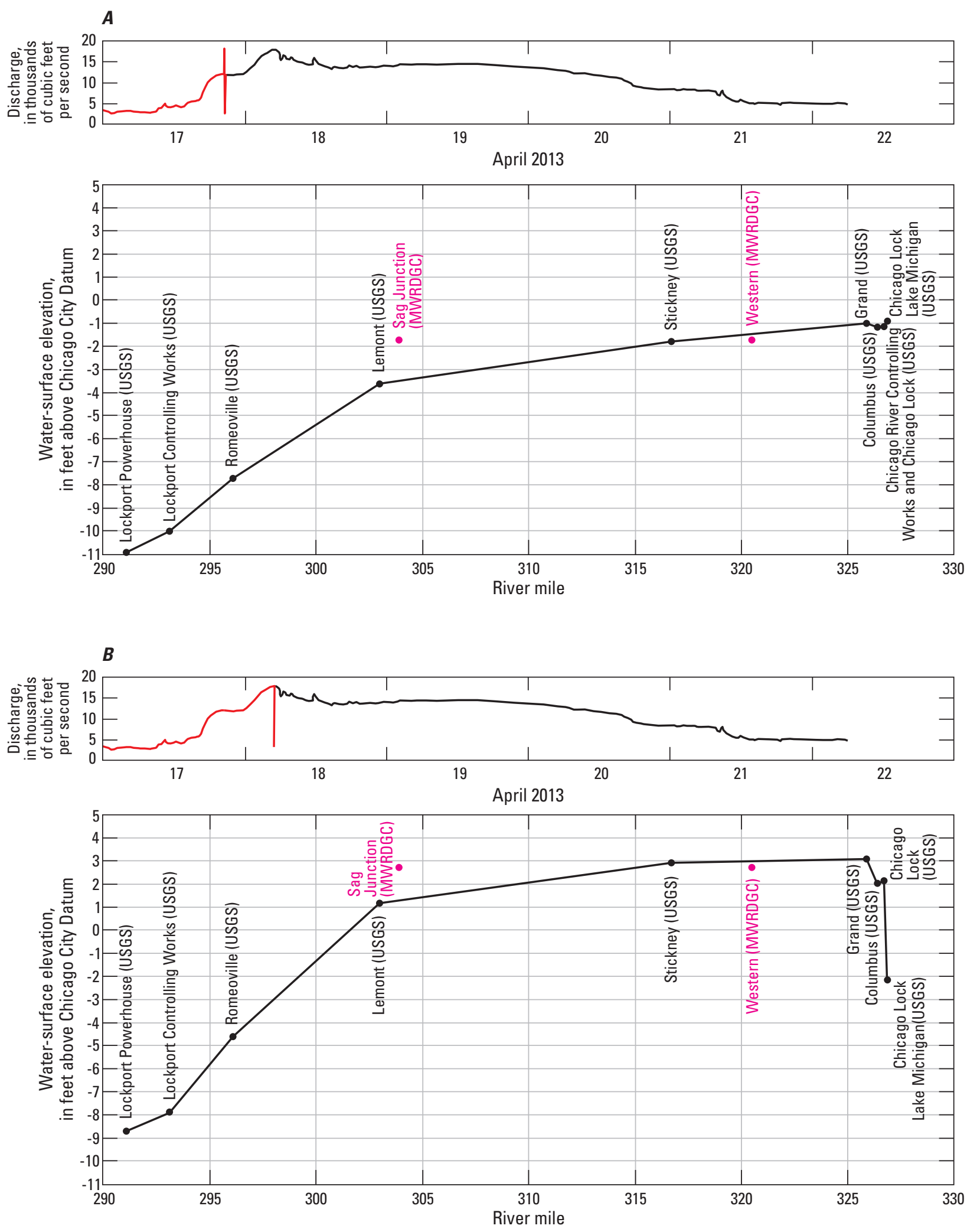

Figure 19. Discharge and water-surface profiles for the Chicago Area Waterway, Illinois, during the April 17-23, 2013, storm: $A$, rising storm discharge hydrograph and canal drawdown, $B$, near peak of storm discharge and opening of the Chicago River Controlling Works, and $C$, the effect of flow reversal at the Chicago River Controlling Works on the water-surface elevation profile. (USGS, U.S. Geological Survey; CRCW, Chicago River Controlling Works; MWRDGC, Metropolitan Water Reclamation District of Greater Chicago) 

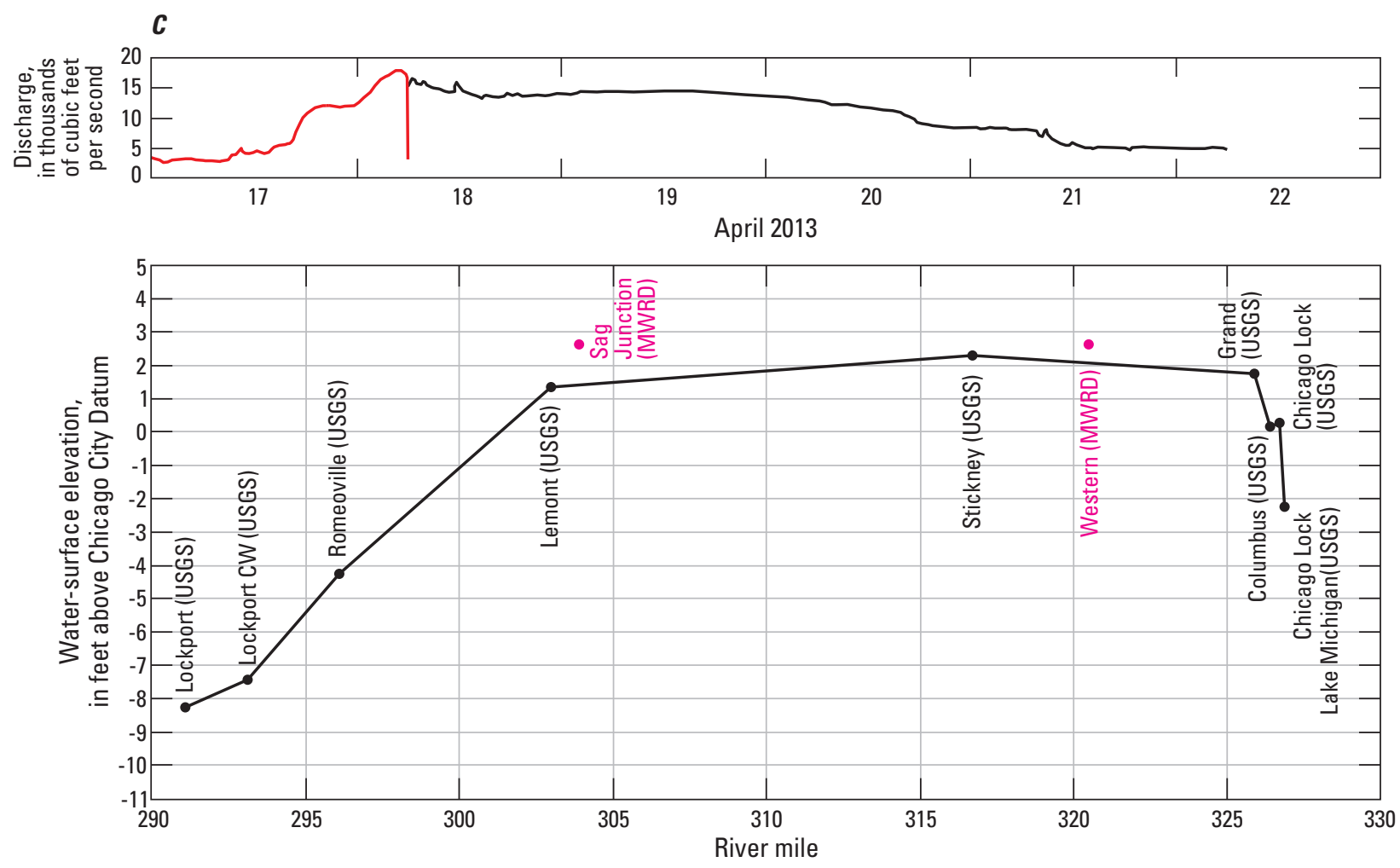

Figure 19. Discharge and water-surface profiles for the Chicago Area Waterway, Illinois, during the April 17-23, 2013, storm: $A$, rising storm discharge hydrograph and canal drawdown, $B$, near peak of storm discharge and opening of the Chicago River Controlling Works, and $C$, the effect of flow reversal at the Chicago River Controlling Works on the water-surface elevation profile. (USGS, U.S. Geological Survey; CRCW, Chicago River Controlling Works; MWRDGC, Metropolitan Water Reclamation District of Greater Chicago)—Continued 

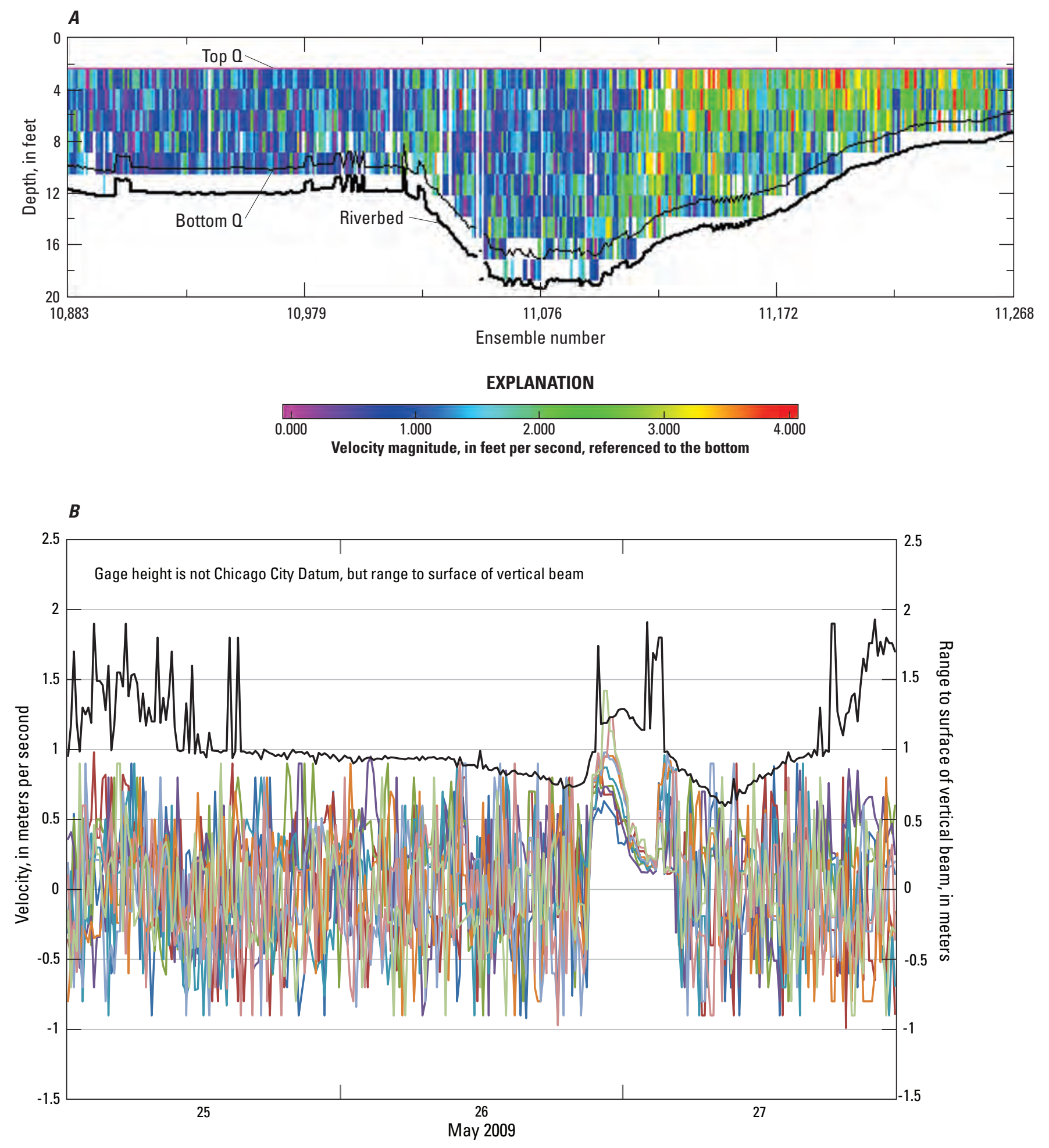

EXPLANATION

Horizontal acoustic Doppler current meter (H-ADVM)

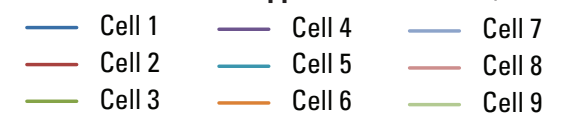

Figure 20. Data from horizontal acoustic Doppler velocity profiler measurements May 25-27, 2009, for Bubbly Creek near 36th Street, Chicago, Illinois: $A$, water velocity, and $B$, discharge. 


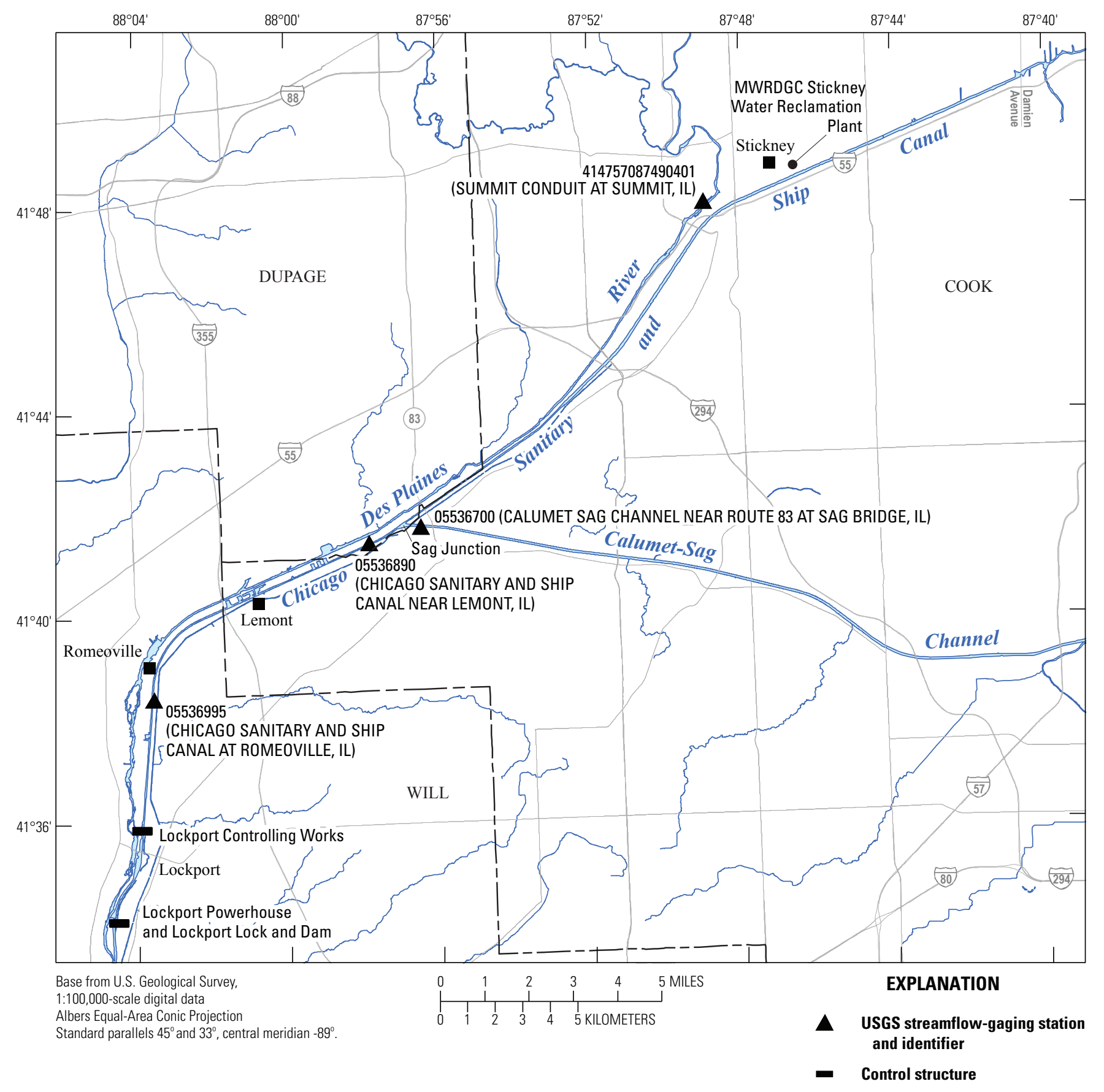

Figure 21. The Chicago Area Waterway System including the Chicago Sanitary and Ship Canal and Calumet Sag Channel, Chicago, Illinois, and vicinity. (USGS, U.S. Geological Survey; MWRDGC, Metropolitan Water Reclamation District of Greater Chicago) 

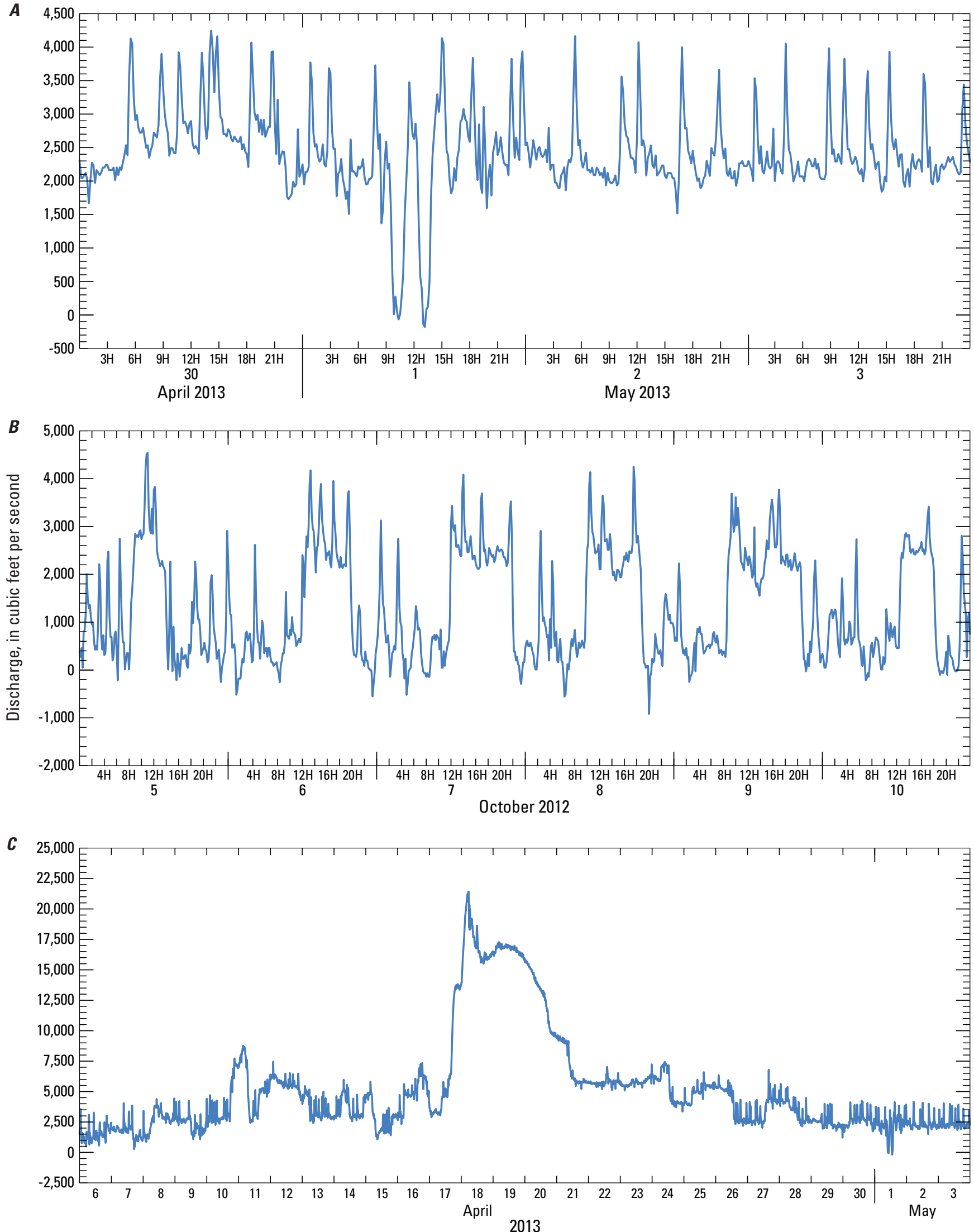

Figure 22. Discharge for the Chicago Sanitary and Ship Canal near Lemont, Illinois, for: $A$, a normal pool elevation with highly unsteady flow conditions, April-May 2013, B, a typical dry-weather pattern showing cycle of ponding and increased flows, October 12, 2013, and C, a wet weather pattern showing the pre-storm drawdown and subsequent flood wave, April-May 2013. 
The daily mean discharge of effluent for the 2012 water year is shown in figure 23. The treatment-plant effluent discharge greatly increases the flow within the CSSC at the MWRDGC Stickney Water Reclamation Plant. Dry-weather flows within the CSSC are highly unsteady.

The USGS operated an AVM streamflow-gaging station at Romeoville, Ill., from 1984 to 2005. The information from this gage was used for the State of Illinois' compliance with a U.S. Supreme Court decree (Consent Decree 388 U.S. 426 [1967] Modified 449 U.S 48 [1980] on Lake Michigan diversion. In 2006, construction at the USACE electric fish barrier necessitated that the USGS remove the streamflowgaging station and establish a new streamflow-gaging station approximately $5 \mathrm{mi}$ upstream near Lemont, Ill.

The USGS streamflow-gaging station on the CSSC near Lemont, Ill., is the primary measurement point for determining the State of Illinois' Lake Michigan diversion. The mean annual flow computed from the data collected at this streamflow-gaging station (fig. 24) is used by the USACE Lake Michigan Diversion Accounting Program.

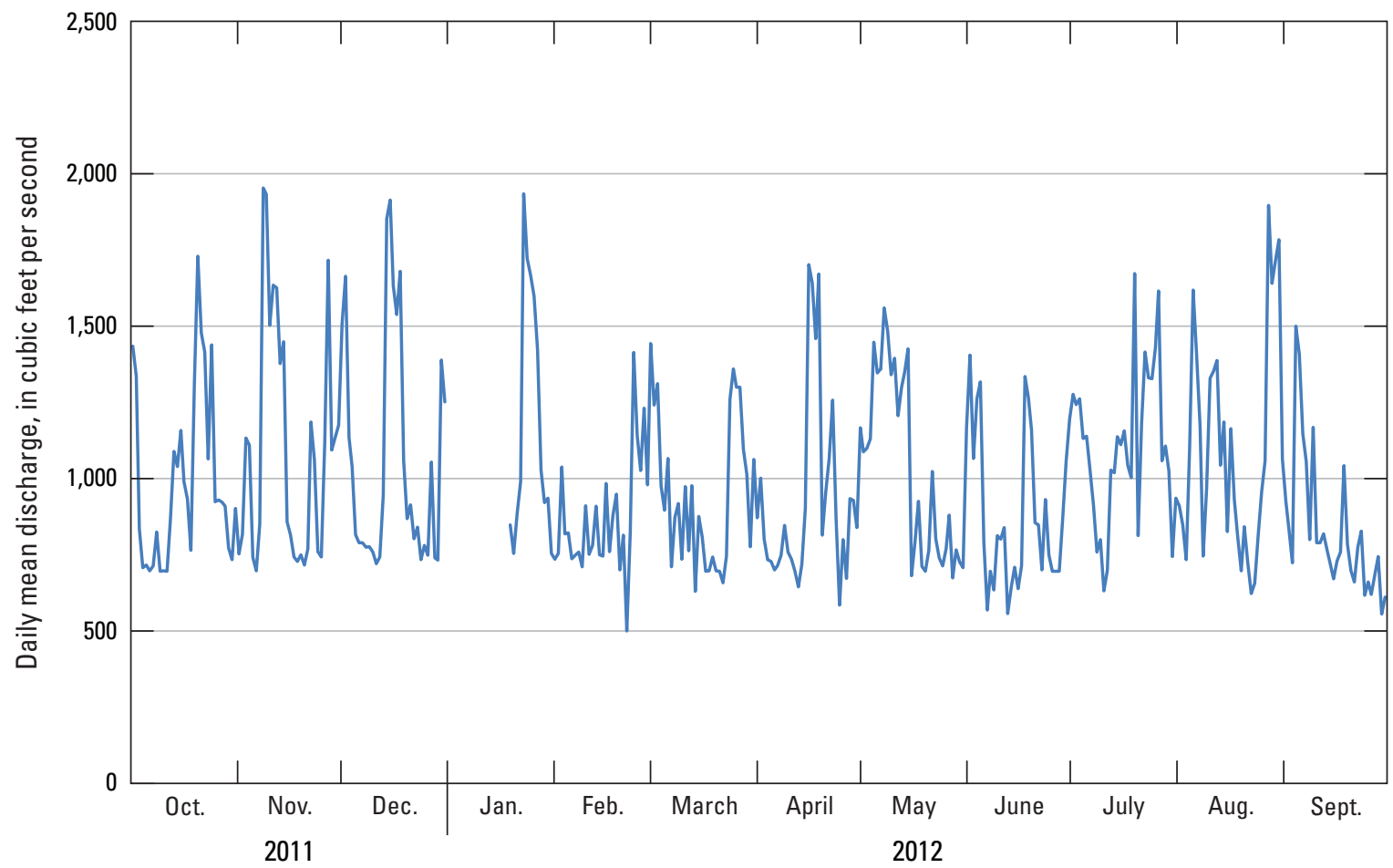

Figure 23. Daily mean effluent discharge for the Metropolitan Water Reclamation District of Greater Chicago-Stickney Water Reclamation Plant, Chicago, Illinois, for the 2012 water year.

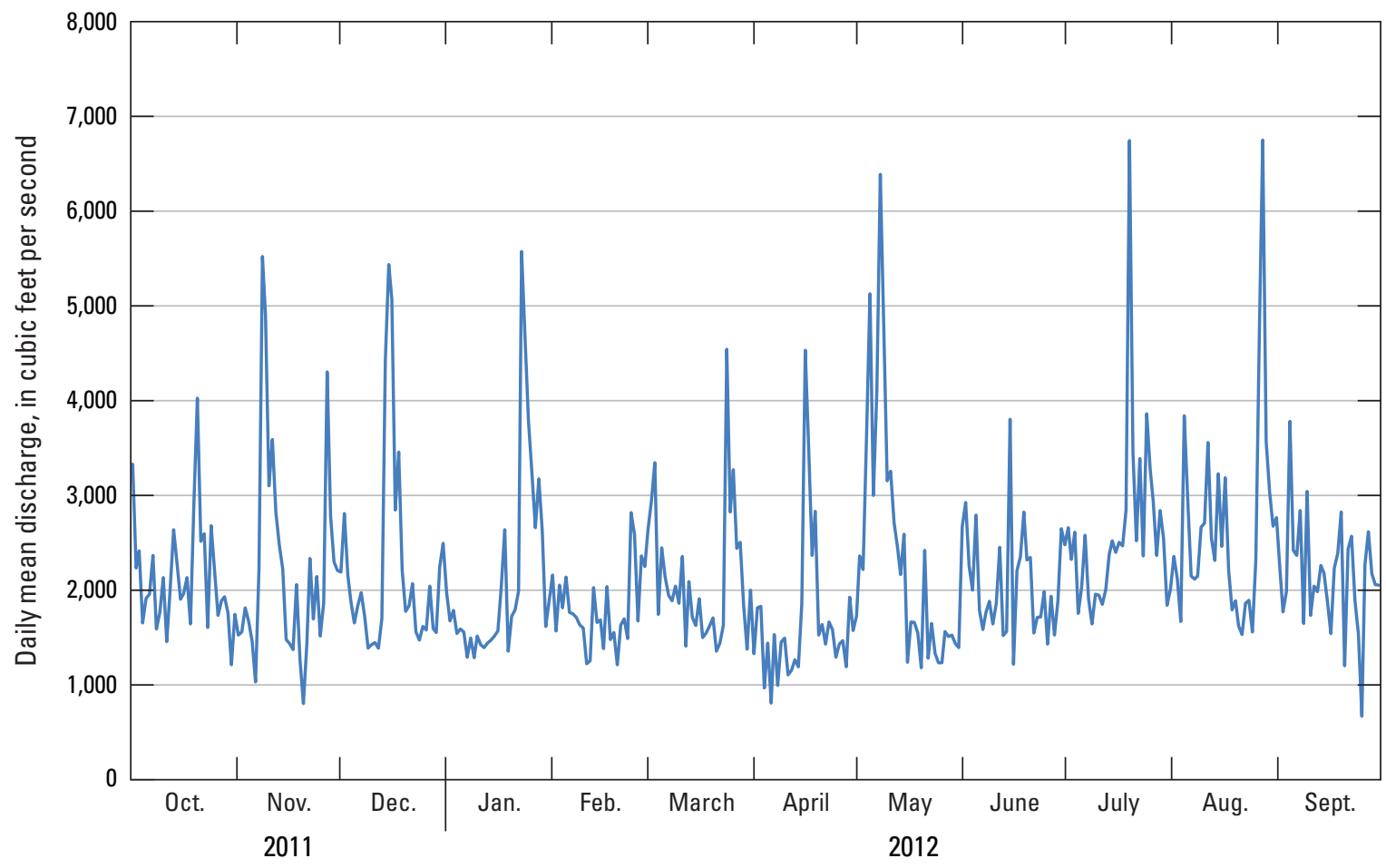

Figure 24. Daily mean discharge for the Chicago Sanitary and Ship Canal near Lemont, Illinois, for the 2012 water year. 
Water velocity throughout the CAWS, especially in the lower reach of the CAWS, is susceptible to the surface layer being affected by wind-driven flow. Winds from the south or southwest can effectively push the surface layer of water against the predominant downstream flow direction; in contrast, winds from the north or northeast can provide an added push to the surface layer in the downstream direction. Discharge measurements and velocity profiles document the effects of wind on the water velocities (fig. 25).

$\boldsymbol{A}$
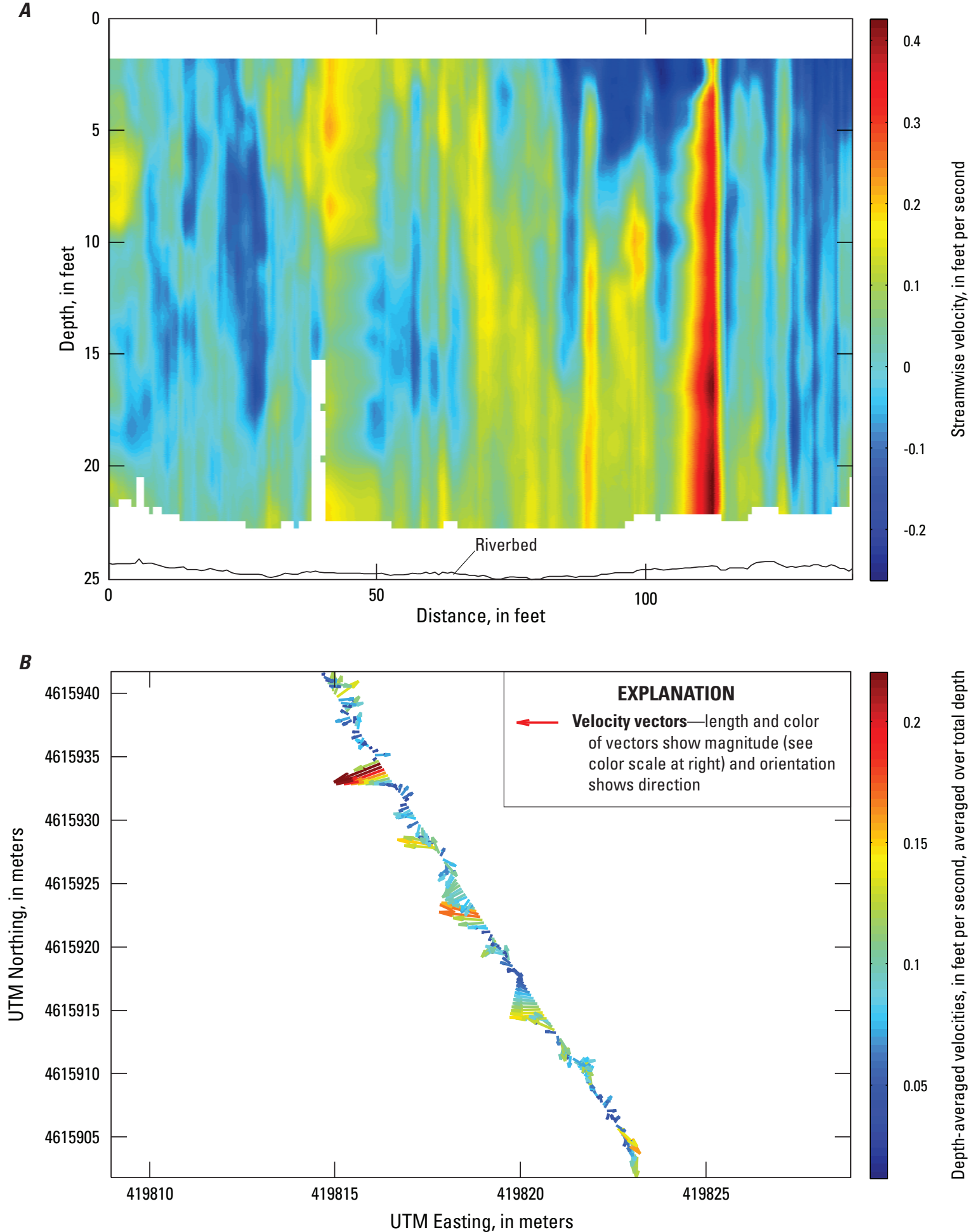

Figure 25. Data from low-, medium-, and high-flow acoustic Doppler current profiler measurements in the Chicago Sanitary and Ship Canal near Lemont, Illinois, showing: $A$, low-flow cross-section water velocity contour; $B$, low-flow plan view of depth-averaged velocity magnitude and direction; $C$, medium-flow cross-section velocity contour; $D$, medium-flow plan view of depth-averaged velocity magnitude and direction; $E$, high-flow cross-section velocity contour; and $F$, high-flow plan view of depth-averaged velocity magnitude and direction. (UTM, Universal Transverse Mercator) 

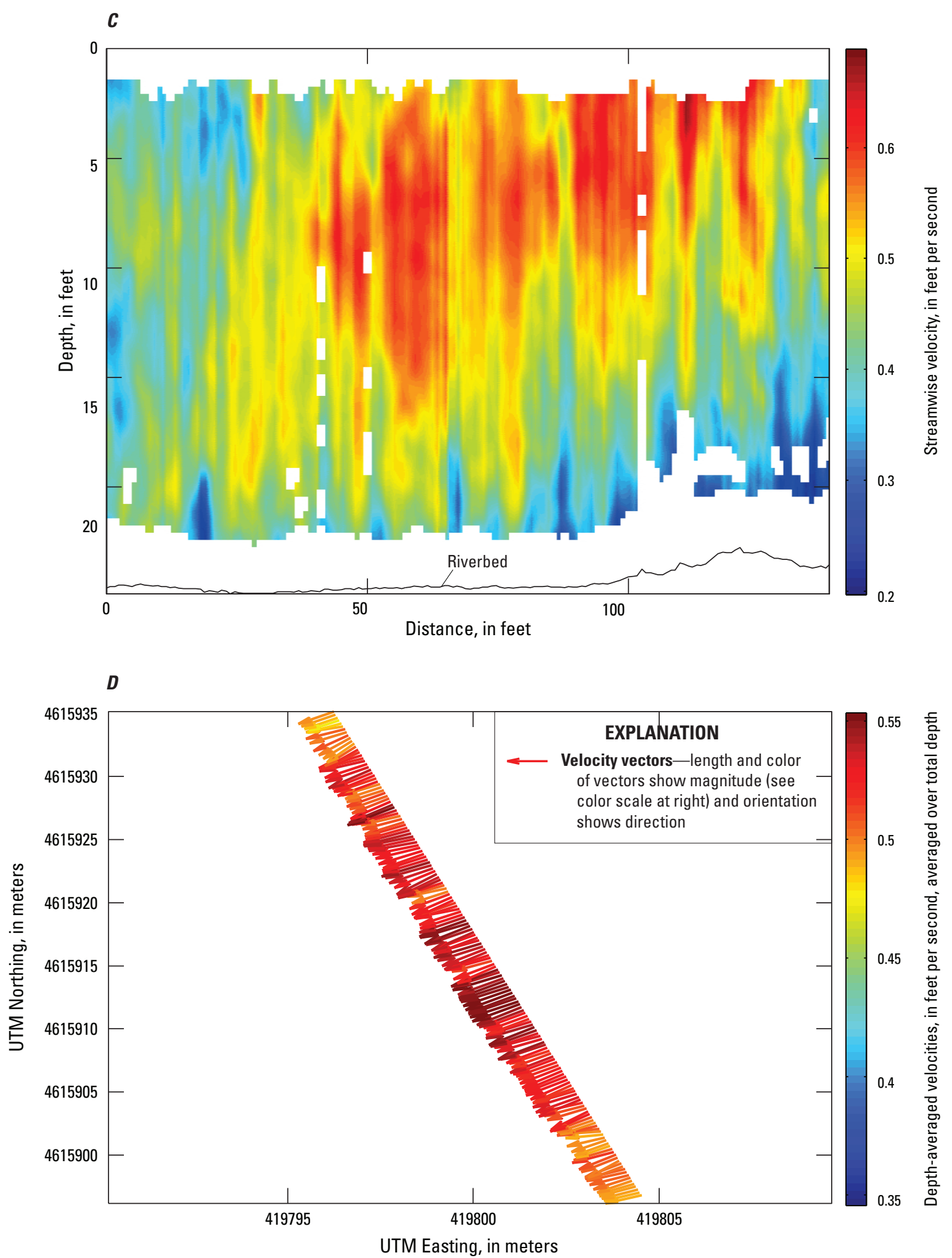

Figure 25. Data from low-, medium-, and high-flow acoustic Doppler current profiler measurements in the Chicago Sanitary and Ship Canal near Lemont, Illinois, showing: A, low-flow cross-section water velocity contour; B, low-flow plan view of depth-averaged velocity magnitude and direction; $C$, medium-flow cross-section velocity contour; $D$, medium-flow plan view of depth-averaged velocity magnitude and direction; $E$, high-flow cross-section velocity contour; and $F$, high-flow plan view of depth-averaged velocity magnitude and direction. - Continued (UTM, Universal Transverse Mercator) 

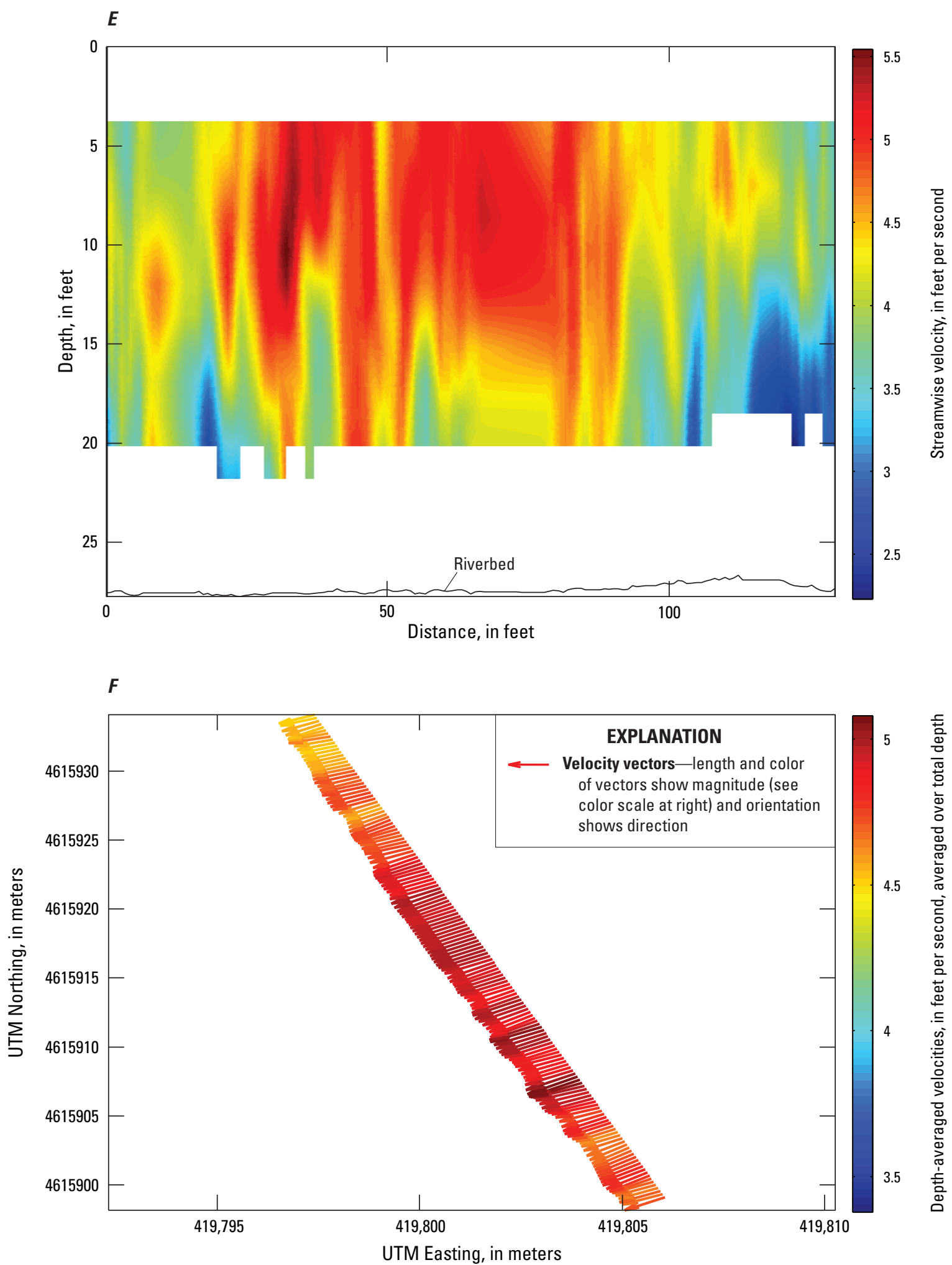

Figure 25. Data from low-, medium-, and high-flow acoustic Doppler current profiler measurements in the Chicago Sanitary and Ship Canal near Lemont, Illinois, showing: A, low-flow cross-section water velocity contour; B, low-flow plan view of depth-averaged velocity magnitude and direction; $C$, medium-flow cross-section velocity contour; $D$, medium-flow plan view of depth-averaged velocity magnitude and direction; $E$, high-flow cross-section velocity contour; and $F$, high-flow plan view of depth-averaged velocity magnitude and direction.-Continued (UTM, Universal Transverse Mercator) 


\section{Summit Conduit}

The Summit Conduit is a manmade concrete-lined tunnel structure that routes the flows from a drainage ditch on the northwest side (right bank) of the Des Plaines River underneath the Des Plaines River and discharges the flow into the CSSC (fig. 21). At the time of construction, the drainage area consisted primarily of a low-lying portion of the Des Plaines River floodplain. The ditch was excavated to permit the floodplain to be farmed. The Summit Conduit structure enables the flow within the ditch to be discharged directly into the CSSC. As the immediate area developed, the farmland disappeared and the drainage area consists of a large quarry operation and light industry. A USGS streamflow-gaging station was established at the entrance to the Summit Conduit in 2010 (fig. 26). Analysis of discharge data from the streamflow-gaging station confirms the regulation of flows within the ditch (fig 27). A relatively high sustained base flow and the occasional sudden increase or decrease of water levels are likely related to a nearby quarry operation. The limestone quarries in the area periodically utilize pumps to dewater sections of the quarries as part of routine quarry operations. The pumping is permitted through the Illinois Environmental Protection Agency.

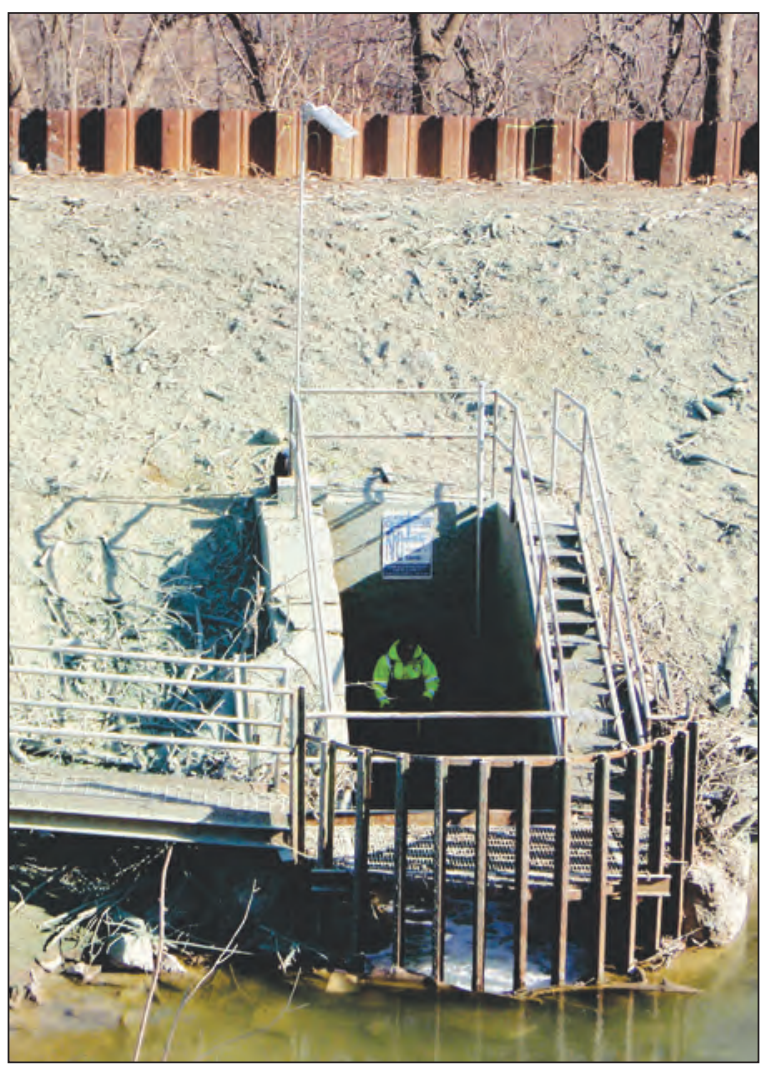

Figure 26. The entrance to the Summit Conduit and the location of the streamflow-gaging station.

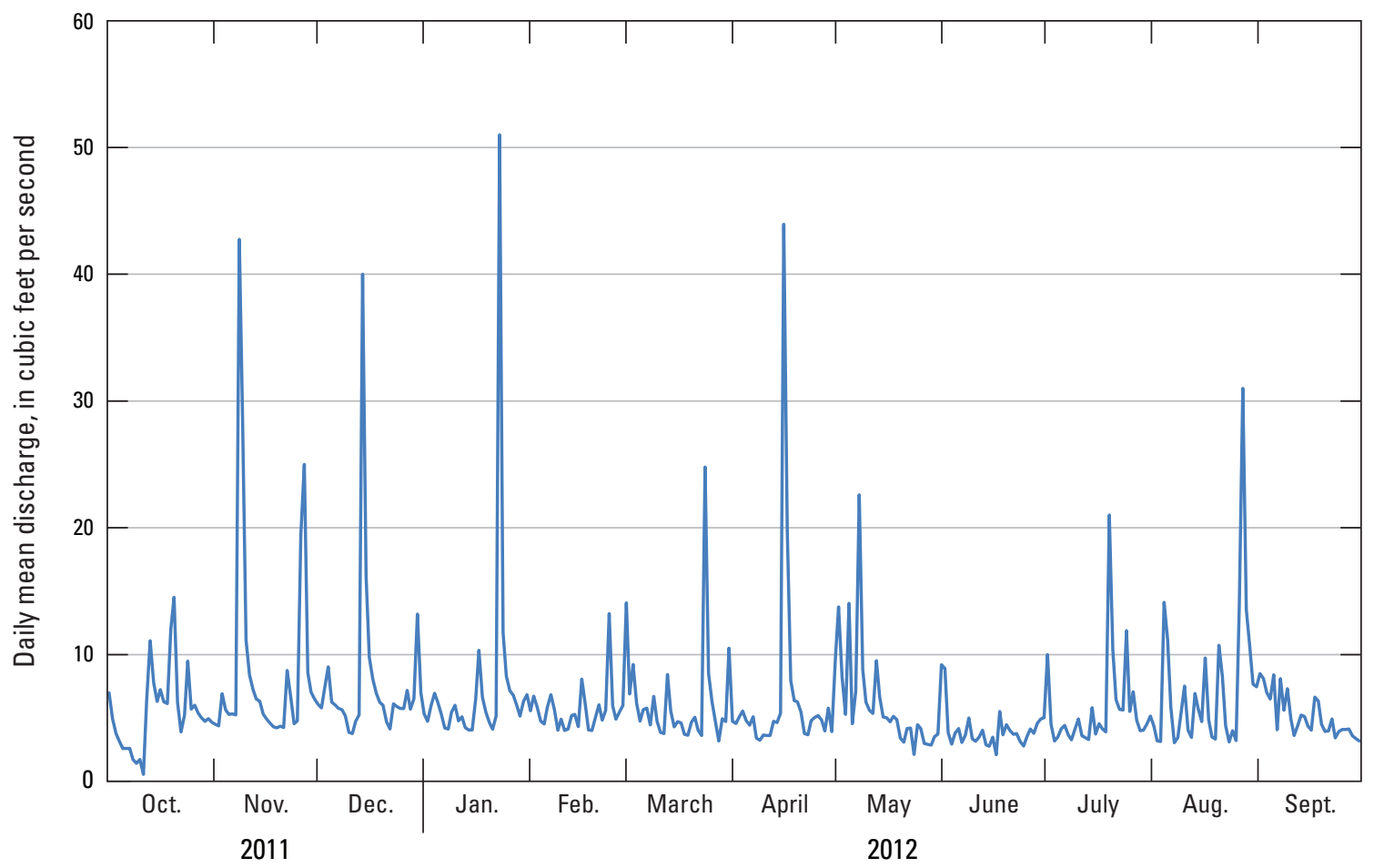

Figure 27. Daily mean discharge for the Summit Conduit at Summit, Illinois, for the 2012 water year. 


\section{Calumet Sag Channel}

The Calumet-Sag Channel consists of approximately 16 mi of manmade canal connecting the Little Calumet River to the CSSC (fig. 28). It was completed in 1922 and widened in 1960. The channel is approximately $220-270 \mathrm{ft}$ wide and 12-16 ft deep at normal pool elevation. The Calumet-Sag Channel captures flows from the Little Calumet River, Grand Calumet River, and several small tributary streams, including
Mill Creek, Stoney Creek, and Tinley Creek; the channel drains flow away from the natural outlet into Lake Michigan. The USACE Thomas J. O'Brien Lock and Dam, constructed in 1965, separates the Little Calumet River from Lake Michigan at a point approximately $6.8 \mathrm{mi}$ inland from the lake.

Flows within the Calumet-Sag Channel (fig. 29) are highly regulated. Water levels within the Calumet-Sag Channel and the lower part of the Little Calumet River up to O’Brien Lock and Dam are regulated by downstream control

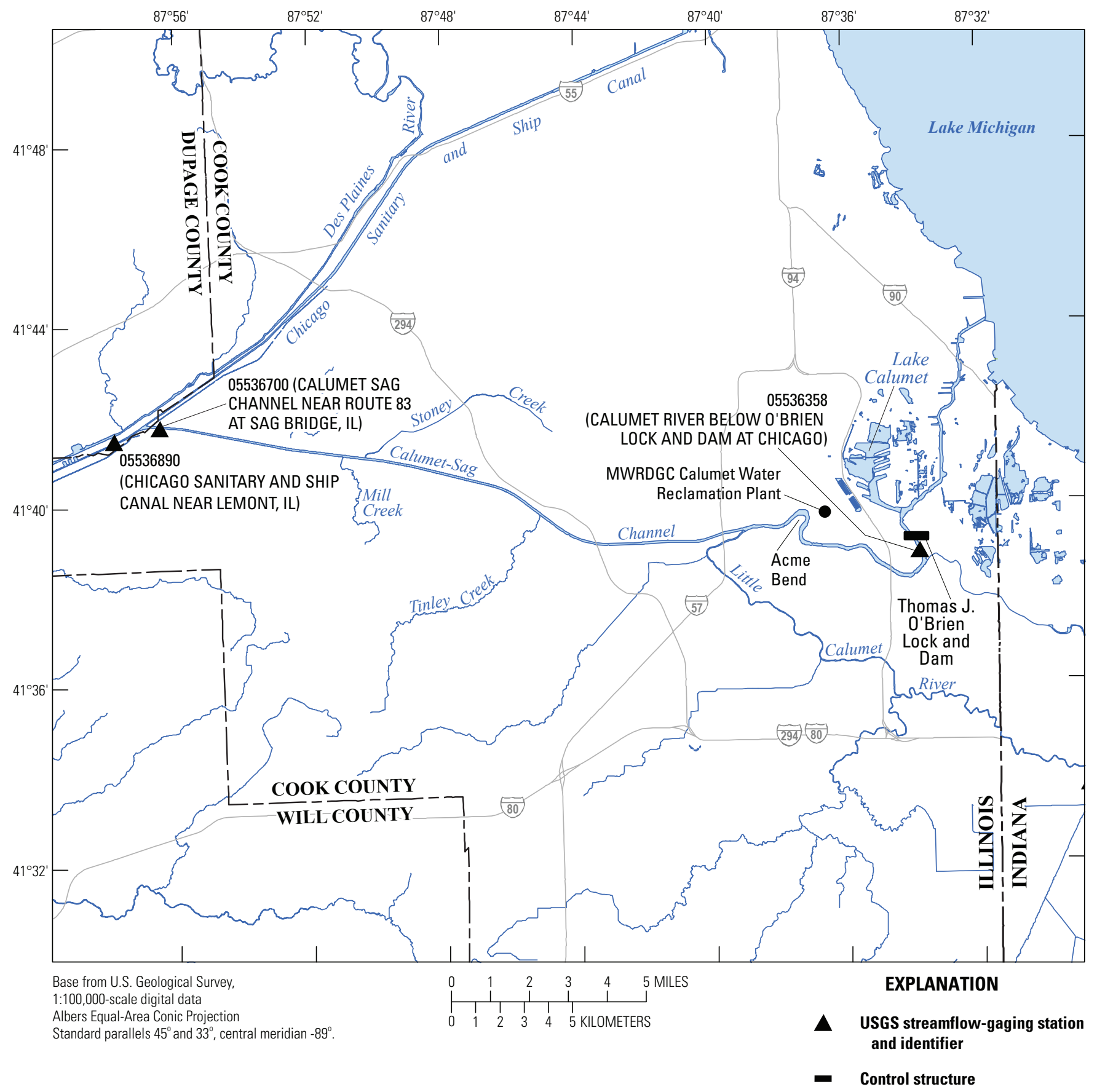

Figure 28. The Chicago Area Waterway System including the Calumet-Sag Channel, Chicago, Illinois, and vicinity. (USGS, U.S. Geological Survey) 
structures at Lockport (Lockport Lock and Dam, MWRDGC Lockport Powerhouse, and Lockport Controlling Works). The O'Brien Lock and Dam diverts Lake Michigan water into the Little Calumet River during lock operations and direct diversion through sluice gates.

The range in stage measured at the Calumet River downstream from O'Brien Lock and Dam streamflow-gaging station during the period of data collection (1997-2003 water years) was from -3.01 to $3.64 \mathrm{ft} \mathrm{CCD}$. The range in daily mean discharge during this same period was estimated to be from 844 to $1,069 \mathrm{ft}^{3} / \mathrm{s}$. Velocity data and ADCP discharge measurements downstream from the O'Brien Lock and Dam define a complex hydraulic setting (fig. 30). Discharge measurements made during the April 2013 backflow event were negative (going out to the lake), $-7,409 \mathrm{ft}^{3} / \mathrm{s}$ through the lock chamber and $-5,573 \mathrm{ft}^{3} / \mathrm{s}$ through the sluice gates for a total of $-12,982 \mathrm{ft}^{3} / \mathrm{s}$. These measurements document the conveyance of the channel, and lock and dam structure, during one of the relatively rare backflow events.

The USGS installed a short-term streamflow-gaging station on the Calumet-Sag Channel near Route 83 (fig. 21) in 2011 to characterize the flow contribution of the Calumet-Sag Channel to the CSSC (fig. 30). The data at this location were collected primarily for a modeling study related to the monitoring of flows for the Lake Michigan Diversion Accounting Program.

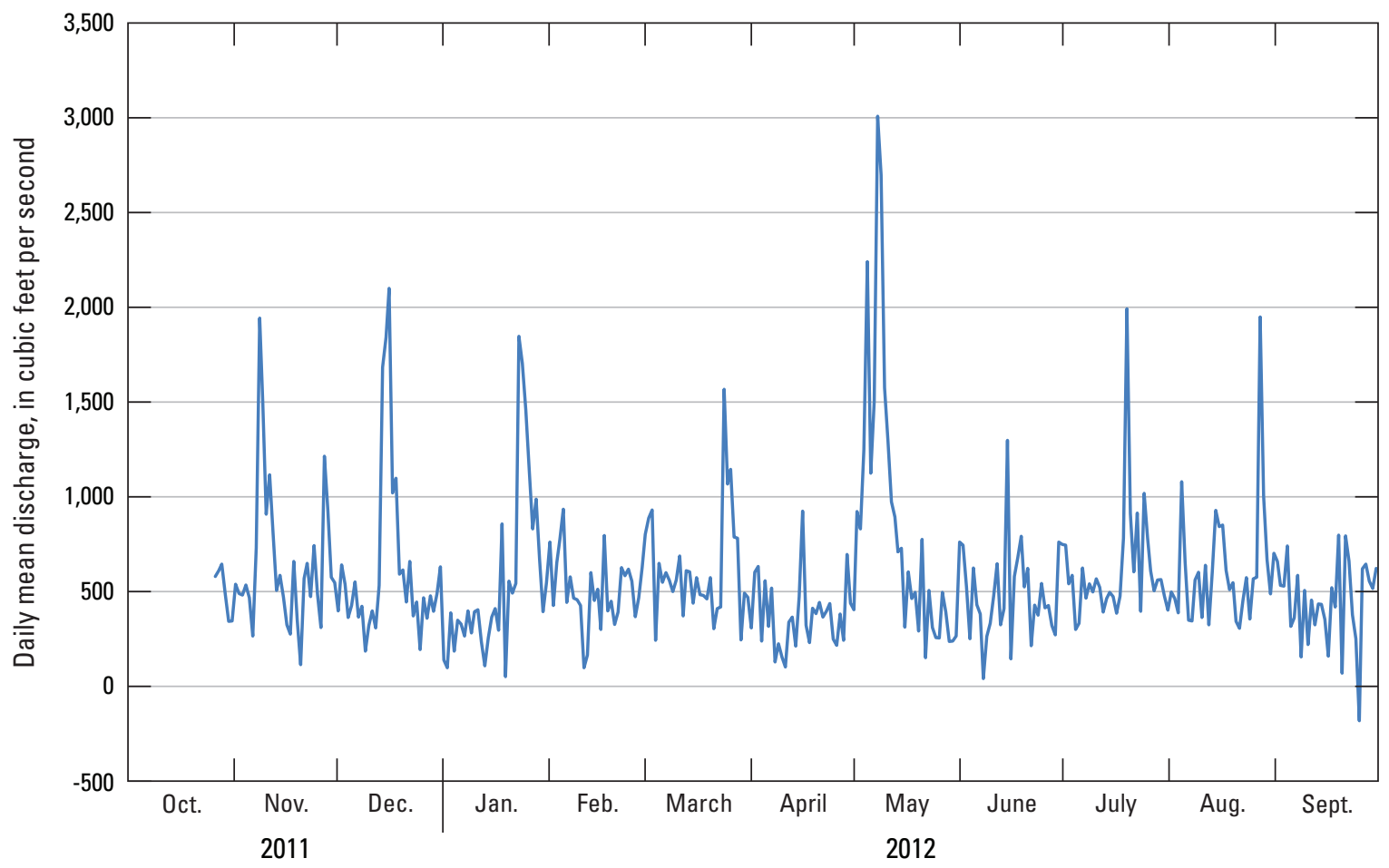

Figure 29. Daily mean discharge at the U.S. Geological streamflow-gaging station on the Calumet Sag Channel near Route 83 at Sag Bridge, Illinois, for the 2012 water year. 

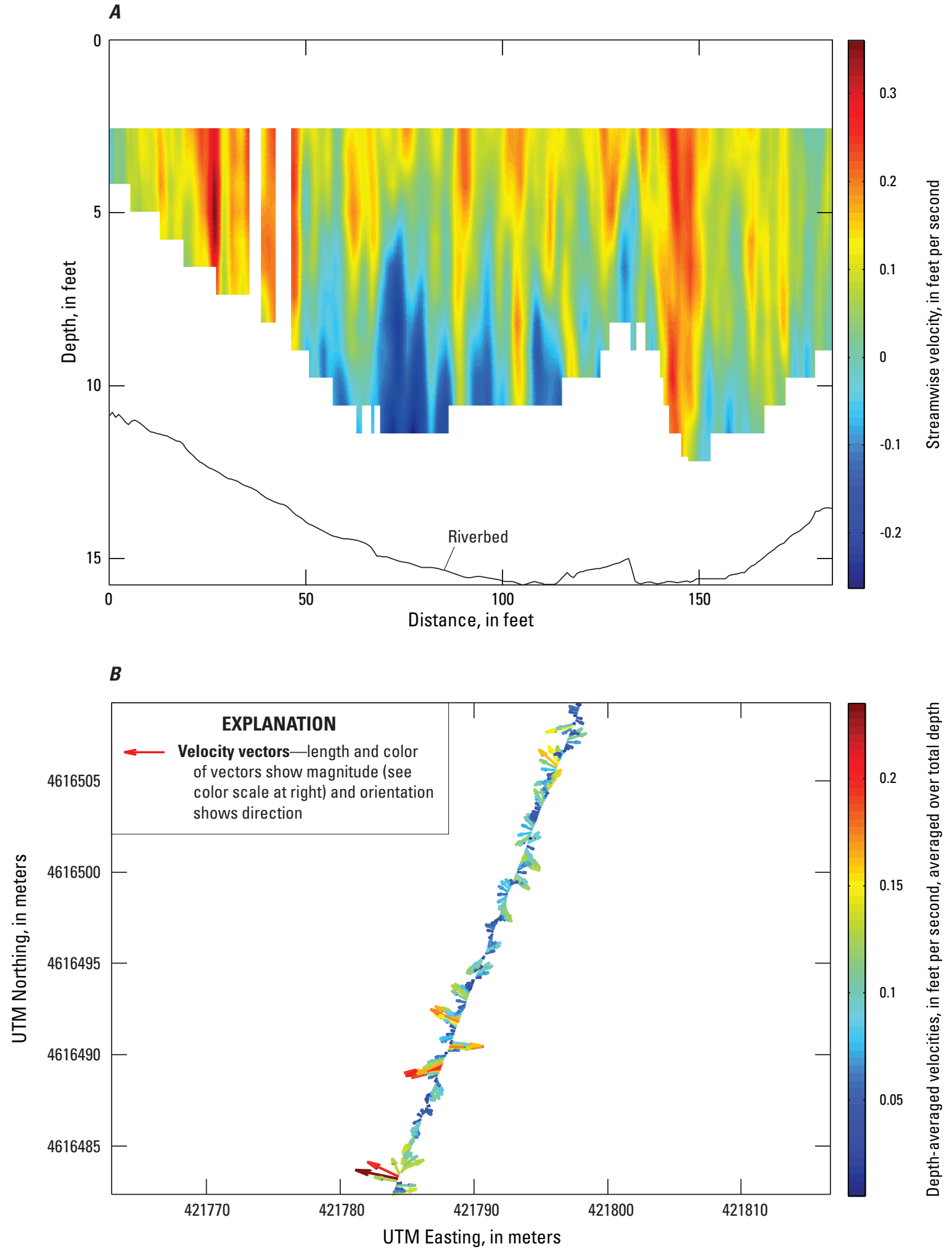

Figure 30. Data from low- and high-flow acoustic Doppler current profiler measurements in the Calumet Sag Channel near Route 83 at Sag Bridge, Illinois, showing, $A$, low-flow cross-section water velocity contour, $B$, low-flow plan view of depth-averaged velocity magnitude and direction, $C$, high-flow cross-section velocity contour; and $D$, high-flow plan view of depth-averaged velocity magnitude and direction. (UTM, Universal Transverse Mercator) 

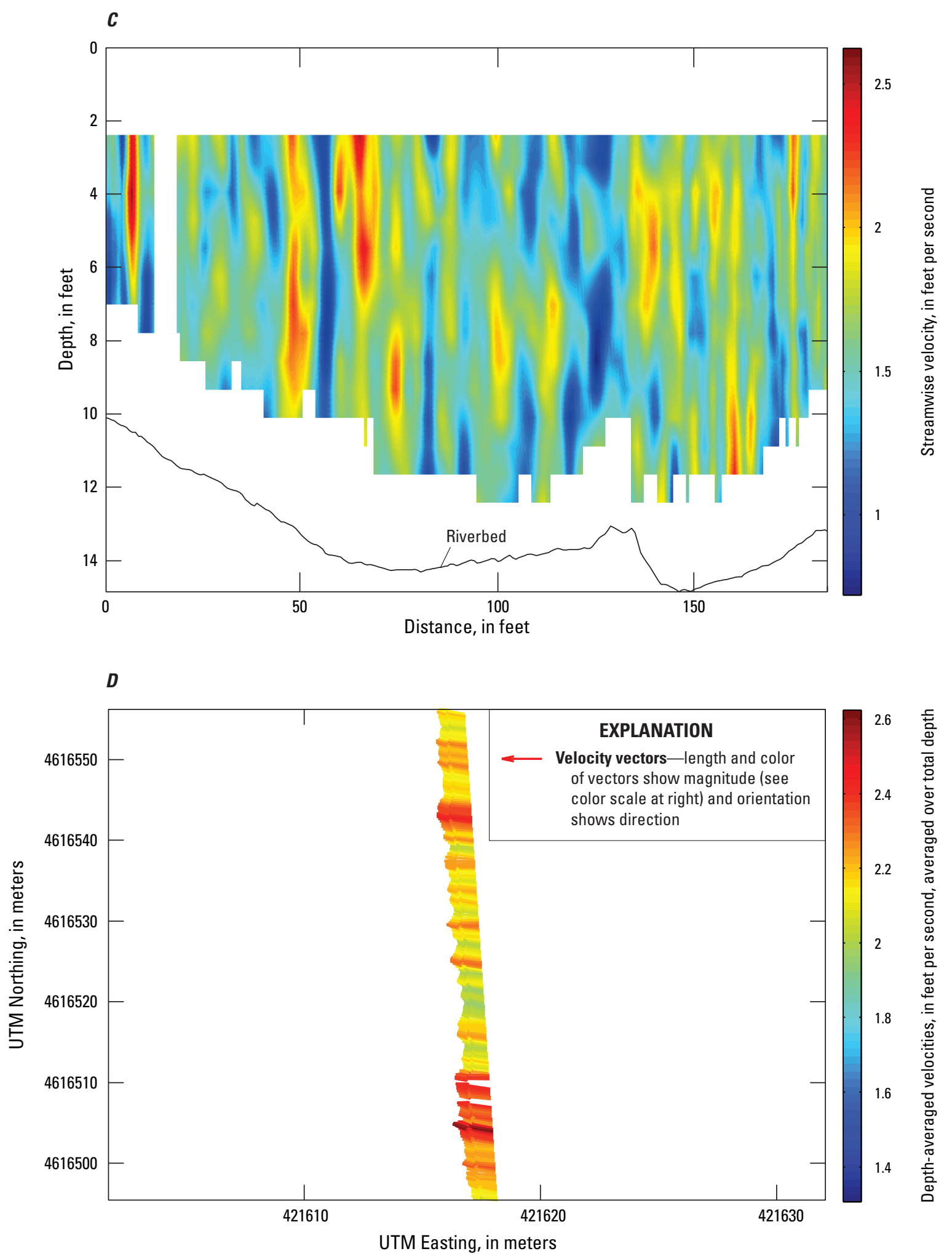

Figure 30. Data from low- and high-flow acoustic Doppler current profiler measurements in the Calumet Sag Channel near Route 83 at Sag Bridge, Illinois showing: $A$, low-flow cross-section water velocity contour, $B$, low-flow plan view of depth-averaged velocity magnitude and direction, $C$, high-flow cross-section velocity contour, and $D$, high-flow plan view of depth-averaged velocity magnitude and direction. (UTM, Universal Tranverse Mercator)—Continued 
The flow in the Calumet-Sag Channel is characteristic of the unsteady conditions in the CAWS. This reach of the Calumet-Sag Channel is also affected by the complex hydraulic setting just downstream at Sag Junction, the confluence of the Calumet-Sag Channel and the CSSC. During storms, flow at the complex hydraulic setting at the confluence of the Calumet-Sag Channel and CSSC forms eddies that collect a lot of floating debris, and at times, visible contrasts in sediment loads were observed. A USGS multibeam echosounder survey in this reach mapped the change in streambed elevations between the Calumet-Sag Channel (shallower) and the CSSC. Discharge measurements made with an ADCP were used in this reach to document complex velocity and flow direction related to density contrasts between the Calumet-Sag Channel and the CSSC.

The discharge hydrograph for the 2012 water year at the MWRDGC Calumet Water Reclamation Plant (WRP) is shown in figure 31 . The bending channel and variable outflow of wastewater effluent produce a complex hydraulic setting in the reach near Acme Bend. During winter months, the Calumet-Sag Channel (fig. 21) can be ice covered over much of its length. Barge traffic during winter months breaks the ice cover in the navigation channel.

The regulation of flows, control structures, low water slope, and channel characteristics all combine to produce a very complex hydraulic setting. The USGS operated and maintained an AVM streamflow-gaging station on the river side of O'Brien Lock and Dam from 1997 to 2003 as part of the Lake Michigan Diversion Accounting program. The AVM streamflow-gaging station was located at the end of the lock guidewall approximately $1,000 \mathrm{ft}$ from the lock and dam on the river side. Flow data from the AVM streamflow-gaging station and ADCP discharge measurements made in the channel reach near the lock and dam document the complex hydraulic setting (fig. $32 A$ ). A series of ADCP discharge measurements in the channel reach near the I-94 bridge (fig. 28) were made in May 2010 prior to a rapid-response effort for Asian carp control (Asian Carp Regional Coordinating Committee, May 2010). These measurements document the variability of water velocity and flow direction in this reach and further document the complex hydraulic setting (Jackson and Lageman, 2014; fig. $32 B-C$ ).

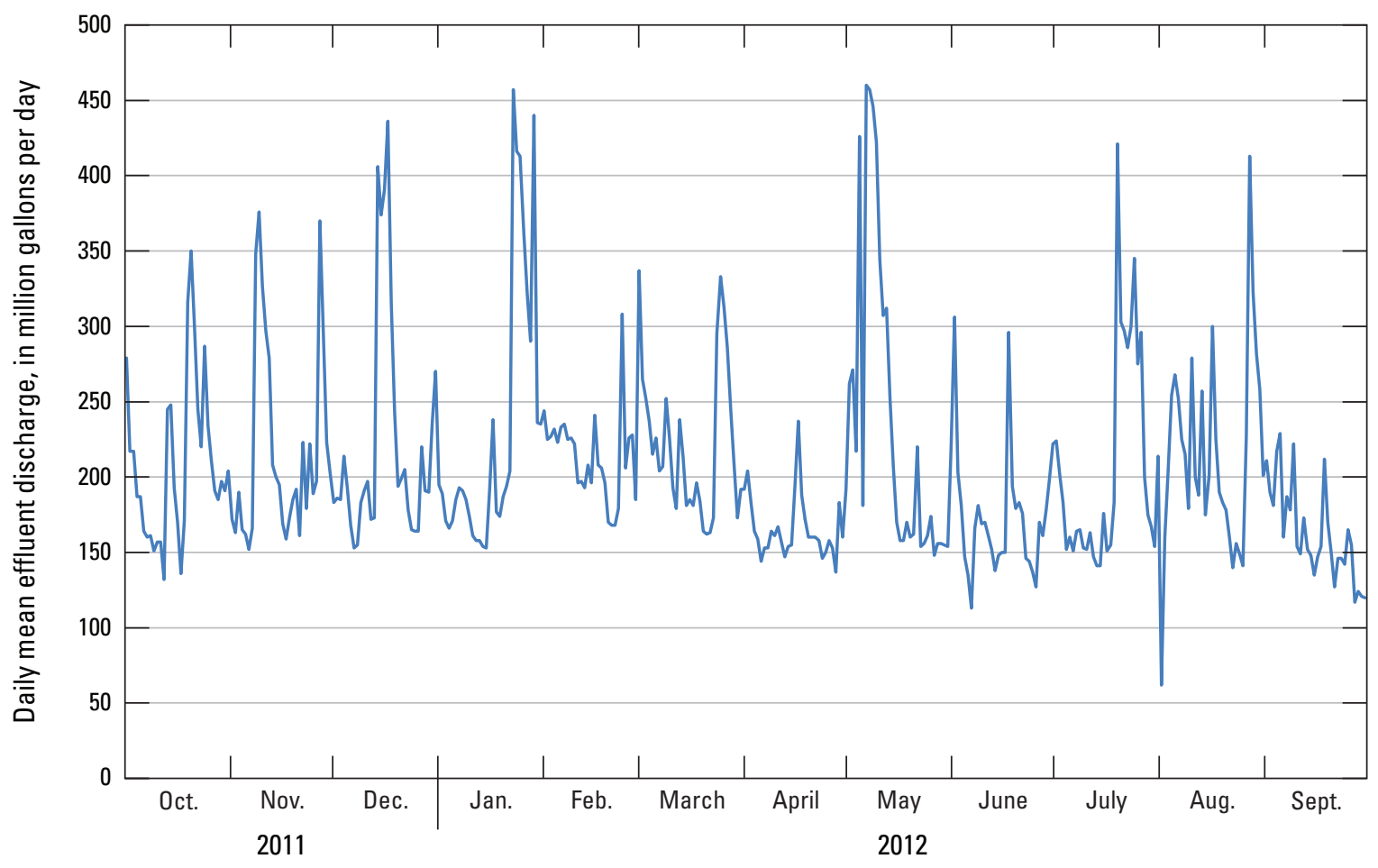

Figure 31. Daily mean effluent discharge for the Metropolitan Water Reclamation District of Greater Chicago Calumet Water Reclamation Plant in Illinois for the 2012 water year. 
A

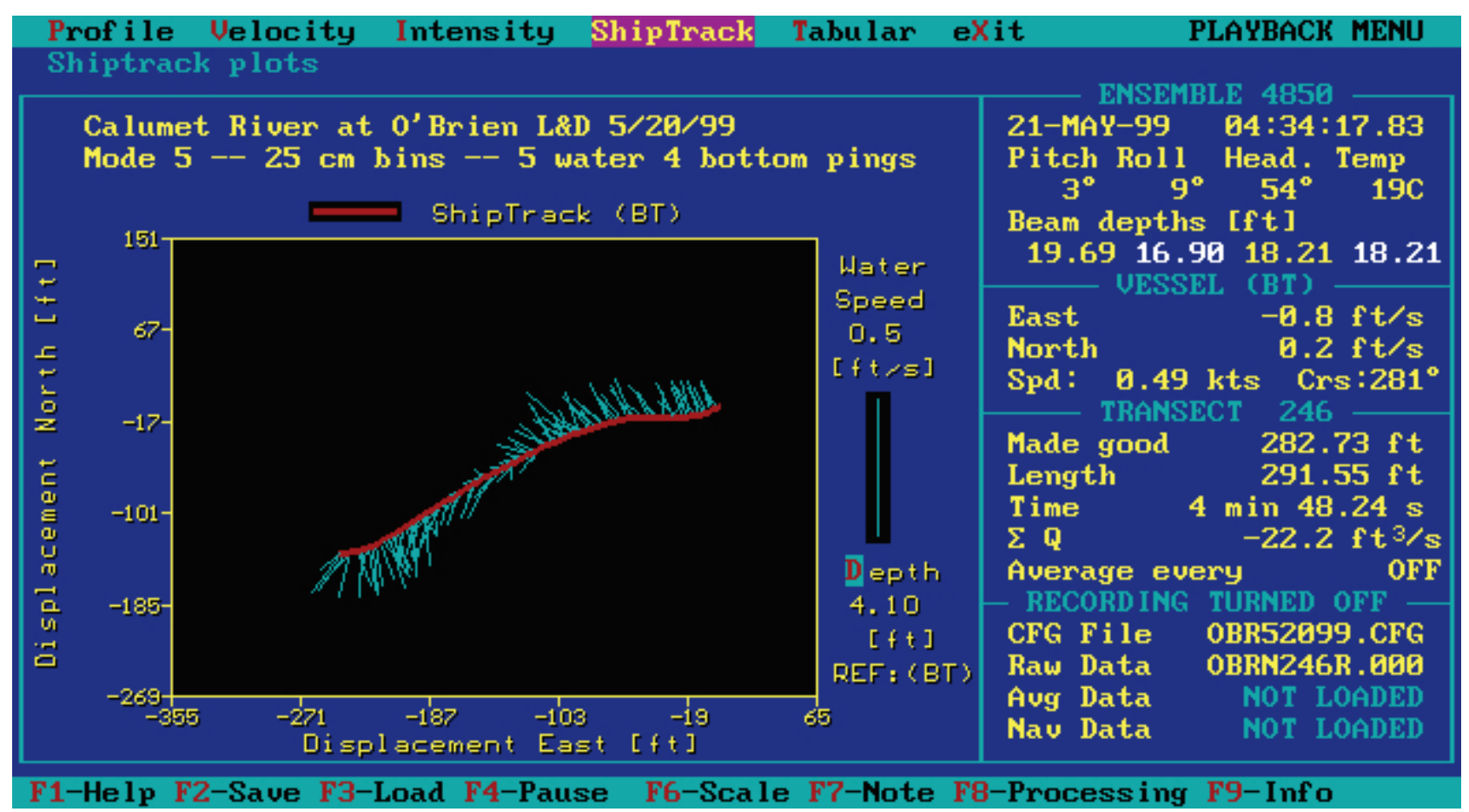

Figure 32. Data from acoustic Doppler current profiler measurements in the Calumet River near the Thomas J. O'Brien Lock and Dam, Chicago, Illinois, showing: $A$, complex water velocity patterns adjacent to the lock and dam, $B$, circulation patterns in the Calumet River below the lock and dam, and $C$, the complex velocity patterns near the Calumet Water Reclamation Plant outfall. (WRP, water reclamation plant; from Jackson and Lageman, 2014) 
B Sluice gates

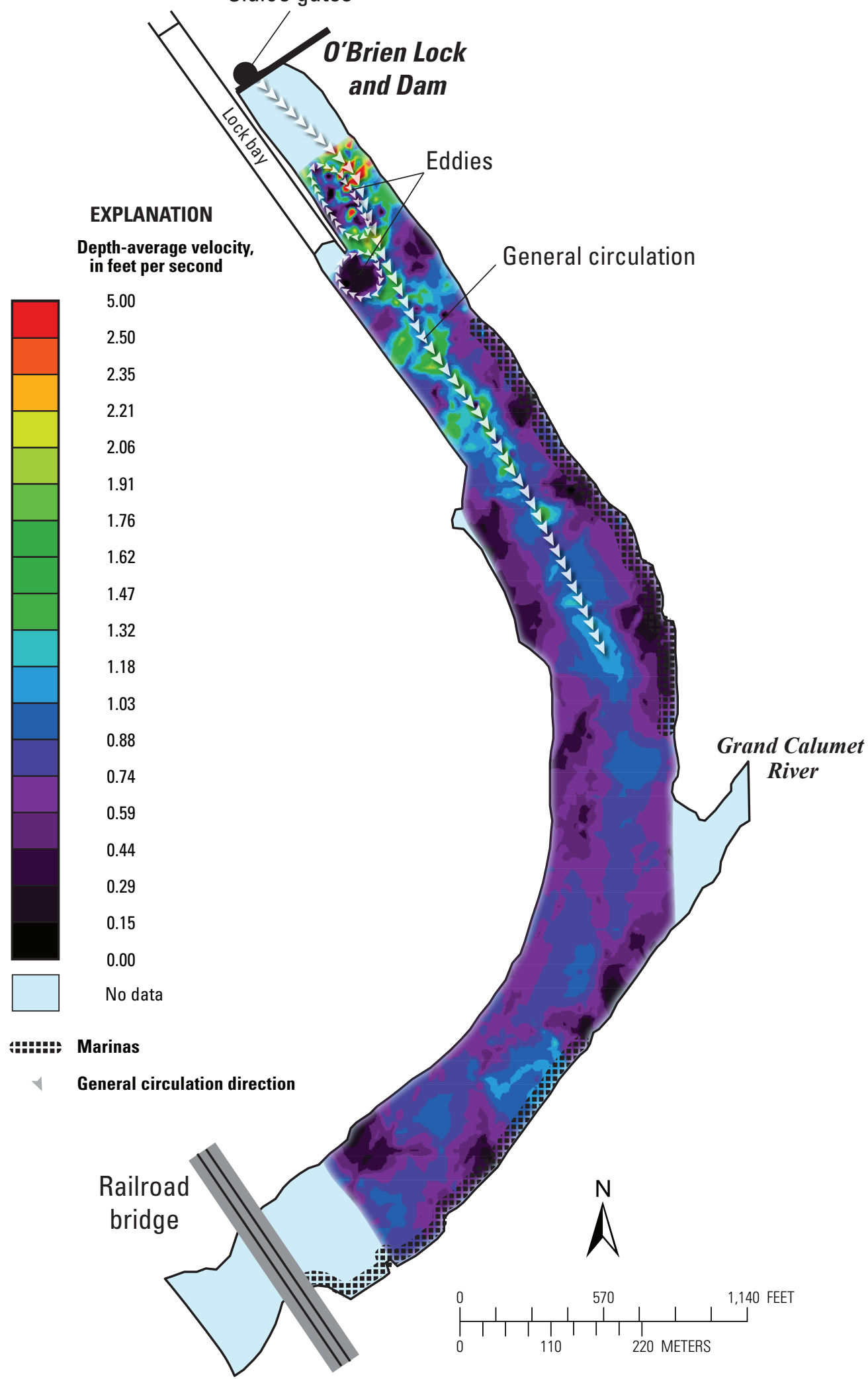

Figure 32. Data from acoustic Doppler current profiler measurements in the Calumet River near the Thomas J. O'Brien Lock and Dam, Chicago, Illinois showing: $A$, complex water velocity patterns adjacent to the lock and dam, $B$, circulation patterns in the Calumet River below the lock and dam, and $C$, the complex velocity patterns near the Calumet Water Reclamation Plant outfall. (WRP, water reclamation plant; from Jackson and Lageman, 2014)—Continued 
C
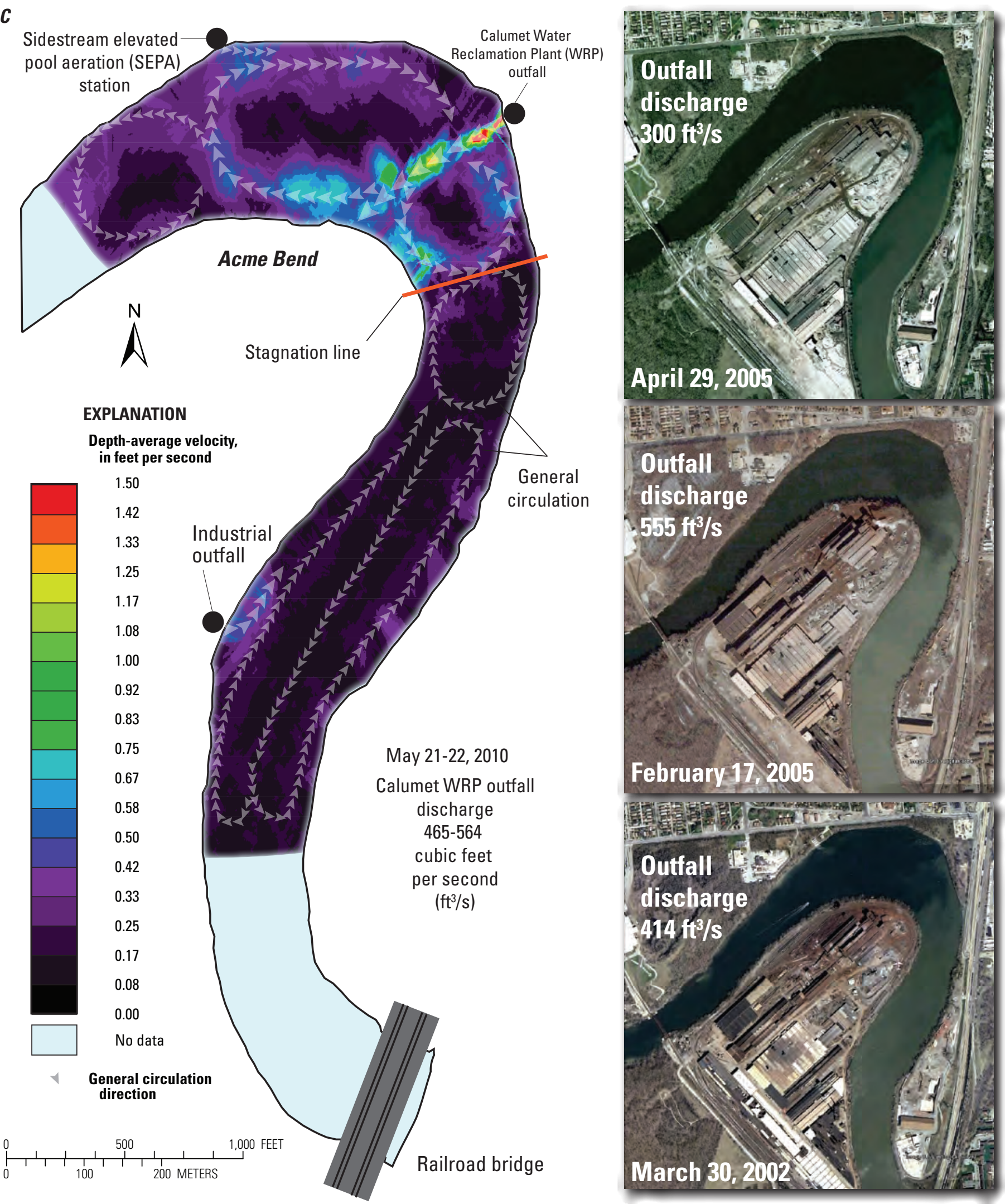

Figure 32. Data from acoustic Doppler current profiler measurements in the Calumet River near the Thomas J. O'Brien Lock and Dam, Chicago, Illinois showing: $A$, complex water velocity patterns adjacent to the lock and dam, $B$, circulation patterns in the Calumet River below the lock and dam, and $C$, the complex velocity patterns near the Calumet Water Reclamation Plant outfall. (WRP, water reclamation plant; from Jackson and Lageman, 2014)—Continued 


\section{Little Calumet River}

The Little Calumet River watershed upstream from the confluence with the Calumet-Sag Channel drains to the Calumet-Sag Channel. After completion, the Calumet-Sag Channel intercepted the flow from the Little Calumet River and diverted the flow away from Lake Michigan.

During dry weather, the flows are affected by wastewatereffluent discharge from the Thorn Creek Sanitary District treatment plant (not shown) along the tributary Thorn Creek. The Little Calumet River receives stormwater runoff from the heavily urbanized parts of the watershed and combined sewer overflows during wet weather. During winter months, the Little Calumet River is often completely ice covered. The southwest-northeast orientation of the channel of the Little Calumet River at the confluence with the Calumet-Sag Channel contributes to the complex hydraulic setting in this reach.

The USACE constructed several flood control projects in the Little Calumet River drainage basin. A control structure near the mouth of Hart Ditch (not shown) regulates the flows and restricts westward flow during large storms. A natural drainage divide in the area around the mouth of Hart Ditch produced variable flow directions in this reach of the channel prior to the flood control projects. The Little Calumet River is gaged at four locations along the main channel and at multiple streams tributary to the Little Calumet River. The main channel streamflow-gaging stations are located at South Holland, Ill., and at Hammond, Highland, and Munster, Indiana. Several small tributary streams flow into the CalumetSag Channel, including Tinley Creek, Stoney Creek, and Mill Creek. During dry weather the combined flows of these tributaries represent a relatively small fraction of the flow within the Calumet-Sag Channel. Daily mean discharge for Tinley Creek is shown in figure 33.

\section{Current Monitoring Issues for the Chicago Area Waterway System}

The CAWS is presently a focal point for several important issues that require an understanding of the complex waterway, such as

- Lake Michigan Diversion accounting,

- long-term regional water supply,

- invasive species,

- waterway separation,

- regional waterway transportation, and

- local and regional flood control issues.

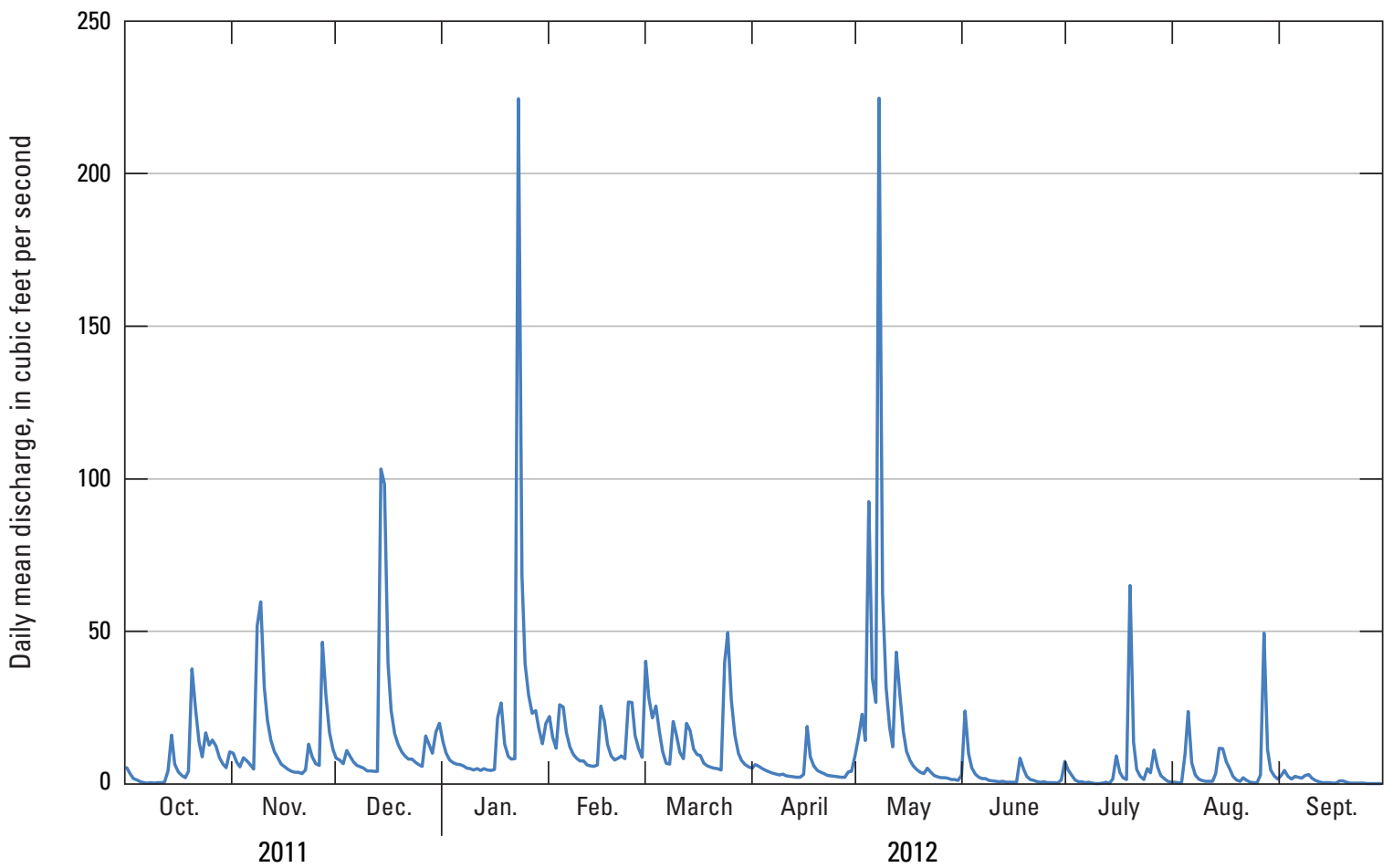

Figure 33. Daily mean discharge for Tinley Creek near Palos Park, Illinois, for the 2012 water year. 
As of 2014, the purpose of CAWS monitoring has expanded to address many issues beyond the monitoring needs of 1900. The demands on the CAWS have increased over time. Navigation and wastewater discharge regulations have become increasingly stringent and require more detailed monitoring to effectively meet the regulatory needs. Waterway operations must balance increasing demands for water quality, commercial and recreational navigation, regional flood control, and newer issues such as wastewater disinfection and the threat from aquatic invasive species. Overall there continues to be a regional recognition of Lake Michigan water as a valuable resource. These needs emphasize that, more than ever before, there is an increased need for CAWS monitoring.

There are several issues pertinent to the CAWS that are dependent upon or directly benefit from accurate waterway monitoring data. A primary reason for monitoring flows within the CAWS is to maintain compliance with the U.S. Supreme Court decree on Lake Michigan Diversion accounting. Monitoring water levels at various points within the CAWS insures appropriate depths for navigation within the waterway. The waterway is also a critical component of a regional floodcontrol program, which is dependent on waterway monitoring. The monitoring of flow within the waterway is a critical component to maintaining compliance with State and Federal water-quality standards. Flow monitoring provides critical information for several power plants and industries located along the CAWS that use the CAWS for cooling water.

\section{Lake Michigan Diversion Accounting}

The USGS streamflow-gaging station (05536890) on the CSSC near Lemont, Ill., functions as the primary measurement point for Lake Michigan diversion accounting. Long-term monitoring of the CAWS at this location meets the requirements of the 1980 U.S. Supreme Court decree (Consent Decree 388 U.S. 426 [1967] Modified 449 U.S. 48 [1980]) and provides a long-term continuous record of discharge for the CAWS. The value of the long-term streamflow-gaging station is that it allows engineers and scientists to analyze the flow records for trends. Implementation of water-conservation measures and repairs made to the critical infrastructure in the Chicago area can be detected in the flow records when they are evaluated over an extended period. The single streamflowgaging station at the lower end of the CAWS (fig. 1; Romeoville 1984-2006, then Lemont 2006-present) records the cumulative effects of changes within the hydrology of the entire Chicago area.

The 1980 U.S. Supreme Court decree mandates that the USACE Lake Michigan Diversion Accounting Program be reviewed by an independent technical review committee every 5 years. The technical review committees recognized that data from the single streamflow-gaging station at Romeoville/ Lemont were not adequate to address questions regarding the distribution of flows near the lakefront structures and leakage through the lakefront control structures. The committee was also interested in a simpler approach to diversion accounting that did not rely on complex modeling to complete the annual computations. An alternative monitoring network to the Romeoville streamflow-gaging station was proposed by the Third Technical Review Committee on Lake Michigan Diversion (Espey and others, 1994). These recommendations resulted in the installation of three additional AVM streamflow-gaging stations in close proximity to the lakefront control structures. These streamflow-gaging stations (fig. 1) are located at (1) North Shore Channel at Wilmette, Ill., (2) Chicago River at Columbus Drive at Chicago, Ill., and (3) Calumet River below O'Brien Lock and Dam at Chicago, Ill. Streamflow data collected at these three gaging stations helped define the distribution of direct diversion flow within the CAWS, seasonal timing of direct diversion into the CAWS, and detailed timing and flow of storm-related backflow events. Although the USACE Lake Michigan diversion accounting program has ended the alternative monitoring network concept, the data collected from the three streamflow-gaging stations has contributed to a better understanding of the CAWS.

\section{Regional Flooding}

As the primary outlet for stormwater in the region, flow within the CAWS is managed by the MWRDGC to prevent flooding during storms. The CAWS is an important component of MWRDGC's regional flood control program. As storms approach the region, the MWRDGC actively manages water levels within the CAWS to provide for more channel storage of stormwater within the channel. The MWRDGC TARP system of sewers, tunnels, and reservoirs works together to capture stormwater and combined sewer flows. During large or intense storms, the capacity of the system is exceeded and the excess flow is diverted directly to the CAWS. Control structures at Lockport, the Wilmette Pumping Station, the CRCW, and the T.J. O'Brien Lock and Dam are used to prevent flooding. As new TARP reservoirs are completed, the hydrology of the CAWS is likely to change to reflect the additional storage and delayed release of reservoir water to the CAWS. The near real-time data from the AVM streamflow-gaging stations on the CAWS is used to monitor the water levels within the system and evaluate the routing of flood hydrographs. Operators at the control structures use the data during floods for operation of water-level control. The USGS has worked closely with the USACE and the MWRDGC to provide near real-time data for waterway operations.

Discharge data are also critical for the calibration of hydraulic models that engineers use in regional flood control projects. The USACE has recently completed (2011) the flood protection features for a major flood control project along the Little Calumet River. The levees, floodwalls, pump stations and flow control structures will provide 200-year level of flood protection to more than 9,500 homes and businesses in the Little Calumet River watershed and prevent nearly $\$ 11$ million in average flood damage. Flood control projects like the USACE Little Calumet River Project rely on accurate waterway gage data for the design of flood control measures. 


\section{Power Plant Thermal Load Modeling}

Several major coal-fired power plants (Midwest Generation Plants-Will County, Fisk, and Crawford) are located along the CAWS and rely directly on the volume of flow in the CAWS for cooling water (fig. 34). Two of the three power plants (Fisk and Crawford) have recently closed or are in the processing of closing operations (as of 2014). Each of these plants operate or operated as "once-through" cooling systems where water is withdrawn directly from the waterway, absorbs heat from cooling coils, and is returned to the waterway. The water withdrawals of these plants directly impact the local flows within the CAWS. The USGS studied this reach in detail in 2010 (Jackson and Lageman, 2014) using Rhodamine dye as a tracer. The dye data defined a low-velocity stagnant zone of water between power plant intake and return channel. The thermal loading from these withdrawals also impacts the water-quality conditions throughout the CAWS. A sharp increase in water temperature is observed at the warm water power plant discharge location (fig. 35), and elevated water temperatures are observed downstream from the power plants. Power plant operators currently rely on the real-time flow data from the USGS AVM gaging station on the CSSC near Lemont gaging station to meet waterway thermal regulations.

\section{Infrastructure Design}

Flow data are routinely used by engineers to design infrastructure components along waterways. Bridge piers, loading terminals, outfalls, and other structures that extend into the water require water level and flow data for proper design. Increased demands for recreational use of the CAWS brings more people in close contact with the waterway, from new river-walk paths and facilities to new boathouses for humanpowered craft; the associated facilities and structures that are built along the waterways are designed and constructed using water level and flow data (fig. 36).

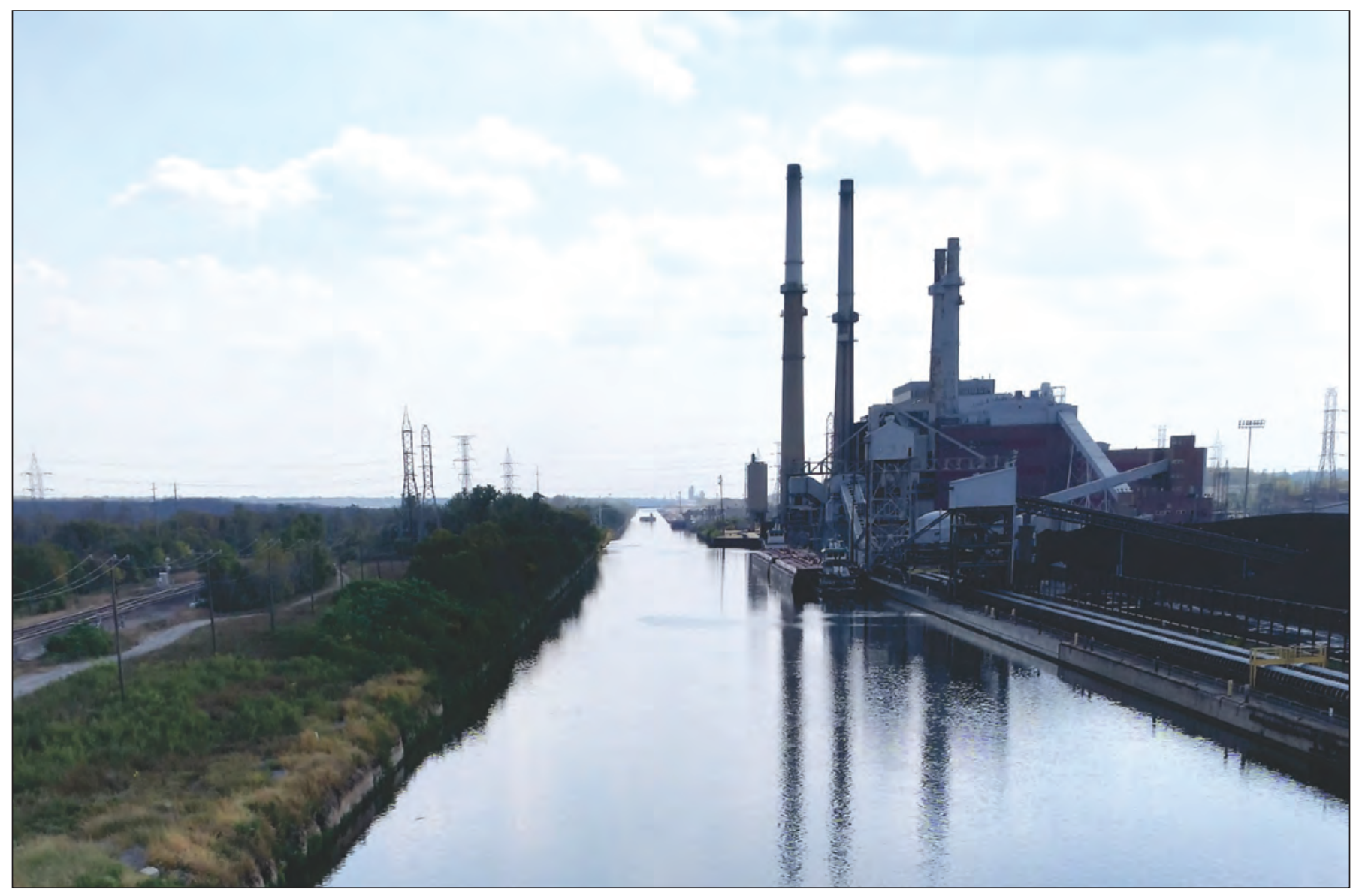

Figure 34. The coal-fired power plant at Romeo Rd (135th Street) along the Chicago Sanitary and Ship Canal near Romeoville, Illinois. 


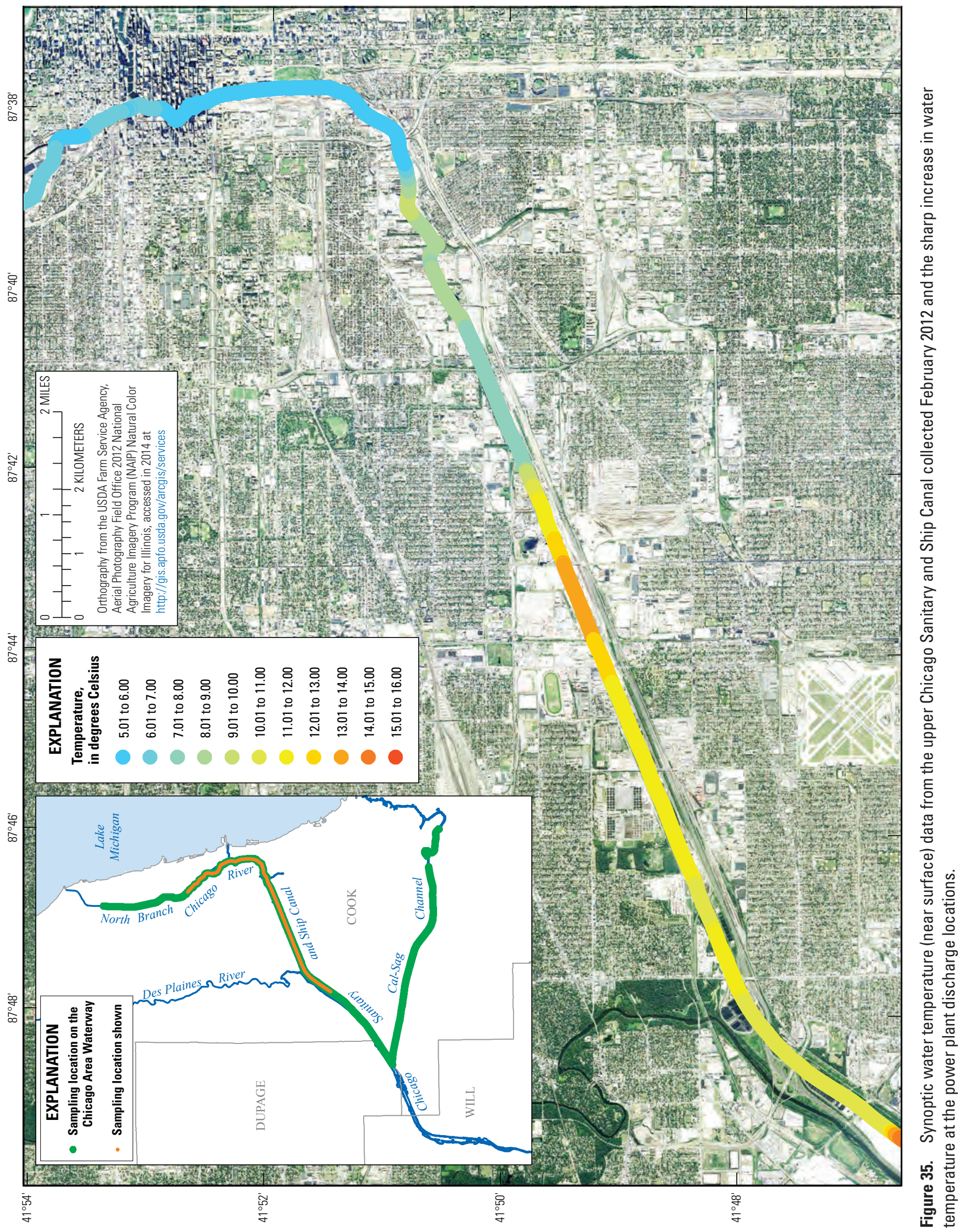




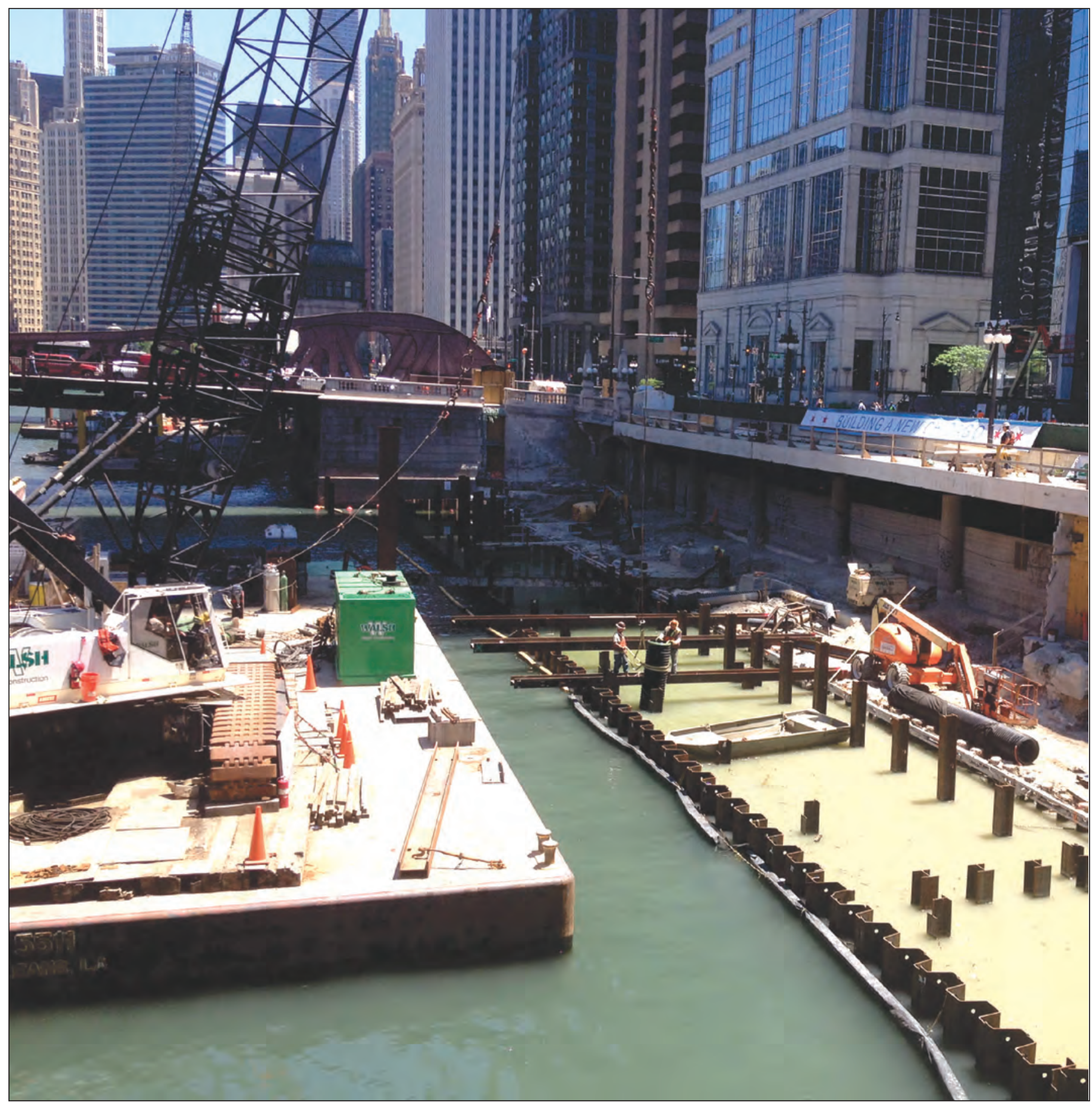

Figure 36. Construction of the river walk along the mainstem of the Chicago River. 


\section{Waterway Separation}

Construction of the CAWS provided an important waterway link between the Lake Michigan Basin and the Illinois River/Mississippi River Basin. While this link is important to transportation of bulk goods in and out of the region and the reduction of wastewater discharge to Lake Michigan, it also is an open pathway for the movement of aquatic invasive species. In 2002, the USACE constructed an electric fish barrier in the lower reaches of the CAWS to prevent the movement of invasive species through the waterway. Recent movement of several species of Asian carps up the Illinois River (not shown) towards the CAWS spurred discussions on a complete waterway separation of the CAWS to permanently sever the waterway link between Lake Michigan and the Illinois River/ Mississippi River Basins. A major concern for separating the waterways is the threat that invasive Asian carps may pose to the sport fishing industry in the Great Lakes. Concurrent studies by the Great Lakes Commission (Great Lakes Commission, 2012) and the USACE (U.S. Army Corps of Engineers, 2014) are evaluating the feasibility and technical issues of waterway separation. Several separation scenarios and separation locations have been evaluated (fig. 37). The physical placement of a barrier or multiple barriers in the waterway represents a radical change in the hydraulics and hydrology of the CAWS. Each scenario and location has positive and negative aspects with regards to transportation, flooding, water quality, and costs. The effects of the barriers at different scenario locations will be addressed through engineering studies using hydraulic model simulation. Addressing the data requirements for proper calibration of the hydraulic models is just one type of shortterm use of waterway data.

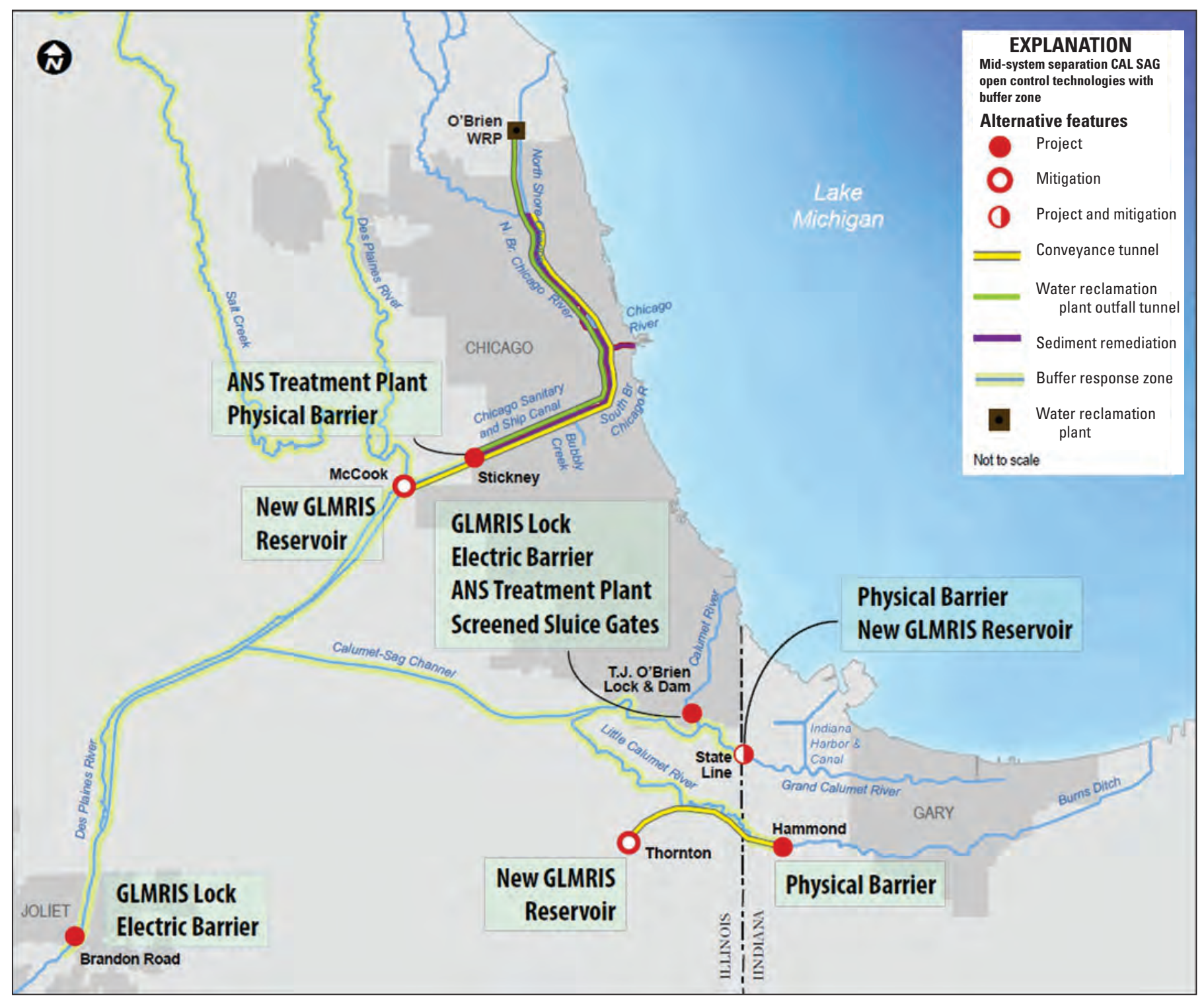

Figure 37. One of the waterway separation scenarios proposed by the U.S. Army Corps of Engineers Great Lakes and Mississippi River Interbasin Study. (From U.S. Army Corps of Engineers, 2014; GLMRIS, Great Lakes and Mississippi River Interbasin Study; ANS, aquatic nuisance species; CAL SAG, Calumet Sag Channel; WRP, water reclamation plant) 


\section{Summary}

The hydrology of the Chicago Area Waterway System (CAWS) can be characterized as a low-slope natural drainage system that has been highly modified to facilitate the drainage of a large metropolitan area. The construction of manmade canals, water-control structures, tunnels, and reservoirs to interrupt the natural drainage patterns and convey water away from Lake Michigan has produced a complex regulated hydraulic setting. This report describes the hydraulic characteristics of the different reaches of the CAWS and presents examples of the flow measurement data over a wide range of flow conditions. Examples of flow measurement data through a range of flow conditions including low, medium, high, and in some locations, reverse flow are presented. The unsteady flow characteristics found throughout the CAWS are evident in the data and presented graphically. The detailed hydraulic data collected by the U.S. Geological Survey at streamflow-gaging stations throughout the CAWS provide engineers and scientists with an understanding of how this complex waterway system operates and contribute to a more efficient operation of the CAWS. The use of hydroacoustic flow measurement instruments like acoustic velocity meters and acoustic Doppler current profilers has advanced the understanding of the complex hydraulic setting characteristic of many reaches of the CAWS. The implementation of near real-time telemetry to streamflow-gaging stations on the CAWS helps to reduce the amount of missing record in the operation and maintenance of the streamflow-gaging stations. The many issues affecting the CAWS reinforce the need for detailed hydraulic data to understand the complex hydraulic setting.

Since its construction in 1900, the CAWS has served several important functions for the Chicago region, including a long-term regional water supply/wastewater diversion function that provides municipal water supply for approximately 9 million people and helps maintain water quality in Lake Michigan, a regional waterway for transportation, and local and regional flood control. Recently, the CAWS has become the focal point for several important regional issues. Proposed changes to the State of Illinois' diversion of Lake Michigan water, water supply needs for projected growth in the population of the Chicago metropolitan area, protection from and control of invasive species that threaten the ecology of both the Great Lakes and Illinois River, regional flood control functions, infrastructure design, and cooling water demands for power plants are just some of the issues that currently or will potentially impact the CAWS in the near future. Increased levels of waterway monitoring can provide scientists and engineers a better understanding of CAWS hydrology and the data to address current and future uses for the CAWS. 


\section{References Cited}

Burch, S. L., 2008, A comparison of potentiometric surfaces for the Cambrian-Ordovician aquifers of northeastern Illinois, 2000 and 2007: Illinois State Water Survey, 41 p.

Changnon, S.A., Angel, J.R., Kunkel, K.E., and Lehmann, M.B., 2004, Climate atlas of Illinois: Illinois State Water Survey, $309 \mathrm{p}$.

Copeland, C., 2010, Clean Water Act: A summary of the law: Washington, D.C., Congressional Research Service, Report No. RL30030, 11 p.

Espey, W.H., Lara, O.G., and Barkau, R.L., 1994, Findings of the Third Technical Committee for Review of Diversion Flow Measurements and Accounting Procedures, in U.S. Army Corps of Engineers, 1994, Lake Michigan Diversion Accounting Water Year 1993, Annual Report, 125 p. and 8 appendixes.

Great Lakes Commission, 2012, Evaluation of physical separation alternatives for the Great Lakes and Mississippi River Basins in the Chicago Area Waterway System: Technical Report to the Great Lakes Commission and the Great Lakes and St. Lawrence Cities Initiative, $210 \mathrm{p}$.

Hill, C.S., 1896, The Chicago main drainage channel: A description of the machinery used and methods of work adopted in excavating the 28-mile drainage canal from Chicago to Lockport, III.: New York, The Engineering News Publishing Co., 129 p.

Hill, L., 2000, The Chicago River: A natural and unnatural history: Chicago, Lake Claremont Press, 302 p.

Hines, N.W., 2012, History of the 1972 Clean Water Act: The story behind how the 1972 Act became the capstone on a decade of extraordinary environmental reform: University of Iowa, Legal Studies research paper no. 12-12, 56 p.

Jackson, P.R., Garcia, C.M., Oberg, K.O., Johnson, K.K., and Garcia, M.H., 2008, Density currents in the Chicago River - Characterization, effects on water quality, and potential sources: Science of the Total Environment, v. 401, p. 130-143.

Jackson, P.R., Johnson, K.K., and Duncker, J.J., 2011, Comparison of index velocity measurements made with a horizontal acoustic Doppler current profiler and a three-path acoustic velocity meter for computation of discharge in the Chicago Sanitary and Ship Canal near Lemont, Illinois: U.S. Geological Survey Scientific Investigations Report 2011-5205, 42 p.
Jackson, P.R., and Lageman, J.D., 2014, Real-time piscicide tracking using Rhodamine WT dye for support of application, transport, and deactivation strategies in riverine environments: U.S. Geological Survey Scientific Investigations Report 2013-5211, 43 p.

Kolata, D.R., and Nimz, C.K., 2010, Geology of Illinois: Illinois State Geological Survey, 530 p.

Metropolitan Water Reclamation District of Greater Chicago, Reversals to Lake Michigan, 1985-present, accessed February 19, 2014, at https://www.mwrd.org/irj/go/km/docs/ documents/MWRD/internet/protecting_the_environment/ Combined_Sewer_Overflows/pdfs/Reversals.pdf.

Metropolitan Water Reclamation District of Greater Chicago, Stickney WRP, accessed September 2, 2014, at https://www. mwrd.org/irj/portal/anonymous/stickney.

Piskin, K., and Bergstrom, R.E., 1975, Glacial drift in Illinois: Thickness and character: Illinois State Geological Survey Circular 490, $73 \mathrm{p}$.

Solzman, D.M., 1998, The Chicago River: An illustrated history and guide to the river and its waterways: Chicago, The University of Chicago Press, 289 p.

U.S. Army Corps of Engineers (USACE), Chicago District, [n.d.], Lake Michigan diversion accounting water year 2001 annual report, v. 1, 11 p. plus appendixes.

U.S. Army Corps of Engineers (USACE), 2014, Summary of the Great Lakes and Mississippi River Interbasin Study, $25 \mathrm{p}$.

U.S. Geological Survey, 1998, A new evaluation of the USGS streamgaging network: A Report to Congress, November 30, 1998: U.S. Geological Survey, 21 p.

U.S. Geological Survey, 2014, The water cycle: U.S. Geological Survey, The Water Cycle-USGS Water Science School Web page, accessed July 27, 2015, at http://water.usgs.gov/ edu/watercycle.html.

Westcott, N. E., 2013, Continued operation of a 25-raingage network for collection, reduction, and analyses of precipitation data for Lake Michigan Diversion Accounting: Water year 2012: Champaign, Ill., University of Illinois, Contract Report 2012-02. 

